\title{
Arm Movements and Dynamic Postural Stability: Accelerometer-based Balance Tests
}

by

Matija Milosevic, B.Eng (Ryerson University, 2009)

\author{
A project \\ presented to Ryerson University \\ in partial fulfillment of the \\ requirements for the degree of \\ Master of Engineering \\ in the Program of \\ Electrical and Computer Engineering
}

Toronto, Ontario, Canada, 2009

(C) Matija Milosevic 2009 

I hereby declare that I am the sole author of this project.

I authorize Ryerson University to lend this thesis to other institutions or individuals for the purpose of scholarly research.

Matija Milosevic

Date

I further authorize Ryerson University to reproduce this project by photocopying or by other means, in total or in part, at the request of other institutions or individuals for the purpose of scholarly research.

Matija Milosevic

Date 


\begin{abstract}
Background: Epidemiological studies show a high incidence of falls and demonstrate that they cause serious consequences to individual health and quality of life, as well as significant social and healthcare impacts. The literature shows that poor balance is a major cause of falls, and emphasizes the need for valid and effective balance diagnostics and risk assessment of falls and balance impairments. The literature review also indicates that arm movements have a potentially significant effect on balance.
\end{abstract}

Objectives: Since existing balance diagnostics usually require complex measurement and specialized labs, this study proposes a set of accelerometer-based tests of dynamic postural balance. The first objective of this study is to develop and evaluate novel accelerometer-based methods for balance and arm movement diagnostics. The second objective is to explore the impact of arm movements on the maintenance balance, and investigate the functions of the dominant and non-dominant arms during dynamic balance.

Methods: The study applies a set of new, instrumented, accelerometer-based balance tests to measure postural balance, trunk (center of mass - CoM), and arm movements during dynamic balancing tasks. The balance evaluation consists of a set of standard balance tests and new instrumented balance board tests. This study explores the impact of arm movements on postural balance and CoM dynamics, as well as the specific arm movement strategies during the balancing tasks.

Results: The findings suggest that arms play an important role in the improvement of balance. The results provide evidence that arm use during the performance of balance tests significantly alters the trunk dynamics (CoM). Arm movements are associated with the increased magnitude of trunk movements that are required for adjusting the centre of mass to the base of support. Overall, the arm movements improve mobility, lateral balance, and contribute to prevention of falls. The results support the model of dynamic arm dominance, suggesting the specific role of the dominant and non-dominant arms. In summary, the most prevalent arm strategy, contributing to better balance performance was shown to be the active, counterbalancing and coordinated arm movements strategy.

Conclusions: This study shows that the proposed accelerometer-based tests provide useful diagnostic information for postural balance and arm movements evaluation. These devices provide valuable diagnostics information, data for progress monitoring during balance training, and consequently enhance risk assessment and falls prevention. Finally, the study shows the important impact of arm movements on dynamic balance and provides an insight into dynamics of the arm movements and balance maintenance. 



\section{ACKNOWLEDGEMENTS}

I would like to express my sincere appreciation to my supervisor, Prof. Dr. Kristiina M. Valter McConville for her help, support, knowledgeable and professional guidance throughout my entire studies.

I would also like to express my gratefulness to Prof. Dr. B. Todorow who provided invaluable help in understanding statistics and methodology of biomedical engineering. I am grateful to Prof. Dr. J. Smith for his detailed and constructive comments and support.

I feel fortunate to have been in the SPIRALL Laboratory and I appreciate my colleagues from this lab who provided helpful comments and suggestions during the initial parts of my study. I would like to express many thanks to all of the volunteer participants who participated in my study. This study was supported by the Discovery Grant from the Natural Sciences and Engineering Research Council of Canada (NSERC) administered by Dr. K. V. M. McConville.

I am also indebted to Dr. K. Masani and Dr. D. Sayenko from Toronto Rehabilitation Institute, REL Laboratory of the University of Toronto who provided valuable comments related to my studies. Particular appreciation, I owe to my co-supervisor Prof. Dr. M. R. Popovic who provided valuable ideas and opportunities to expend my research work and support.

I owe the greatest appreciation to my family, brother Luka, mother Vesna and father Misko for their enduring and endless support.

\section{Matija Milosevic}

May, 2009 

Abstract

1 Introduction

1.1 Literature Review

Page 6

1.2 Arm Movements in Posture and Balance

1.3 Handedness in Balance

1.4 Clinical Balance Tests for Risk Assessment

1.5 Summary of the Literature Review

1.6 Objectives

2 Methods

Page 18

2.1 Subjects

2.2 Protocol

2.3 Balance Board

2.4 Data Acquisition

2.5 Signal Analysis

2.6 Statistical Analysis

3 Results

Page 32

3.1 Classic Balance Tests and Arm Movements

3.2 Classic Balance Tests and Trunk Movements

3.3 Balance Board Tests and Arms Movements Tests

4 Discussions

Page 79

5 Conclusions

Page 87

References

Page 89

Appendix

Page 98

Appendix A: Canadian Community Health Survey 



\section{Arm Movements and Dymamic Postural Stability: Accelerometer-based Balance Tests}

\section{Introduction}

In this study, I evaluate a set of accelerometer-based tests of dynamic postural balance, and examine the roles of arm movements for its maintenance during balancing tasks. The first chapter consists of a literature review that details the incidence, consequences and causes of falls. The objectives of the study are defined to explore the apparent knowledge gaps related to arm movements and the roles of dominant and non-dominant arms in posture and balance. The second chapter explains the methodology for the design and development of the instrumented balance assessment for the classic and novel balance tests used in my study. This chapter describes the study's instruments, data acquisition, signal procession and statistical data analysis.

The results obtained through this study are presented in Chapter Three in the following sections. The first section includes the results on the classic balance tests and compares the performance obtained with restricted and free arm movements. The second section presents the association between results on classic and accelerometer-based tests obtained with limited and free arm movements by evaluating the magnitude of accelerations of the centre of mass (CoM) during balancing tasks, then comparing them to the standard outcome measures. The last section includes an analysis of arm movements during maintenance of postural balance. Arm movements are analyzed during stable and balance recovery tasks. This chapter also examines handedness, and the role that dominant and non-dominant arms play in balance maintenance.

A discussion of the results and the relevance of this study for balance diagnostics and assessment is presented in Chapter Four. The fifth chapter contains an explanation of the study's limitations, as well as suggestions for future studies in this domain. 


\subsection{Literature Review}

A review of the literature reveals a significant number of studies that provide evidence of the high incidence and serious consequences of falls. Many epidemiological studies (e.g. Rubenstein, 2006; Maki, 2003) suggest that falls are the most frequent cause of injuries in the general population. It has been documented that in the United States, falls result in some 300,000 hip fractures per year, with associated healthcare costs of US\$10 billion; this is expected to increase four times over the next 40 years (Maki, 2003; Hayes et al., 1996). Fear of falling has been linked with social withdrawal, inactivity, and decreased mobility in seniors and is the cause of about $40 \%$ of nursing home admissions (Maki, 2003; Tinetti \& Williams, 1997).

The main issue in falls prevention is the high frequency and severity of falls among the elderly. Particularly among the ageing baby-boomer population, the effects of falls represent a significant financial burden on the healthcare system, and, as such, require extensive research. Numerous epidemiological studies have provided evidence of the high incidence and significant consequences of falls on health-related quality of life, and on their social impacts (Maki, et al. 2003; Rubenstein, 2006; Rubenstein \& Josephson, 2006; Hayes et al., 1997; Tinetti \& Williams, 1997).

Analysis of comparable data from the Canadian Community Health Survey (CCHS) indicates similar tendencies. Our analysis of the 2005 CCHS (see tables in Appendix A), based on a large national sample $(\mathrm{N}=132,221)$, indicates similar trends to those in the US (Milosevic \& McConville 2007). It has been shown that among Canadians, falls cause the most serious injuries, most frequently in adults over the age of 65 . In addition, slips, trips and stumbles as a cause for serious injury seem to have greater prevalence among the elderly (Appendix A, Figure 4). Hospitalization and emergency room visits are also much higher among this group (Appendix A, 
Figures 5 and 6), which is associated not only with falls-related hip fractures but with other results of falls such as fear of falling and isolation from society (Tinetti \& Williams, 1997).

Considering the fact that some $95 \%$ of hip fractures are caused by falls, Stevens \& Olson (2003) advocate the development of new approaches to primary and secondary falls prevention, based on multifaceted strategies including changes to behavior and environment, with an emphasis on education and skills related to risk factors.

According to data from the US National Center for Injury Prevention and Control, fallrelated injuries constitute a significant risk for the entire society, and for the elderly population in particular, since they represent a major cause of injury-related deaths and disabilities for this age group. The most serious falls-related injury is the hip fracture, which in the US causes more than a third of a million $(340,000)$ hospitalizations per year (Stevens \& Olson, 2003).

A more recent epidemiological study (Stalenhoef et al., 1999) found that the prevalence of falls among persons of 55 to 64 years was $25 \%$ and that among persons of 65 years and over it was $31 \%$. The same study found that falls cause some $9 \%$ of serious injury, including $4 \%$ of bone fractures. Lord et al. (1994) found a similar rate of falls among persons over 60 years, who reported approximately $28 \%$ of falls during the past year. Examining falls prevalence, the Baltimore Longitudinal Study on Aging (Talbot et al., 2005) has found that among those who fell, $70.5 \%$ sustained injuries, and women reported a higher incidence of falls than men.

Based on recent systematic reviews of evidence on falls and falls prevention, Rubenstein (2006) and Rubenstein and Josephson (2006) document the strong impact of falls on increased morbidity and mortality among the elderly, and their social consequences, including an increased use of healthcare and nursing home services. 
Rubenstein and Josephson (2006) demonstrate the multiple causes of falls and provide evidence that many of them can be eliminated through preventative interventions. According to these reviews, the most important factor is the availability of feasible and cost-effective comprehensive risk assessment tools for falls prevention, as well as the appropriate training programs.

In addition to hip fractures, falls are the second leading cause of traumatic brain injury (TBI), which is a major contributor to morbidity and mortality in the United States (Centers for Disease Control and Prevention, 2003).

Falls and other related balance impairments represent a serious risk for people who suffer from different neurological disorders (Stolze et al., 2004), as well as for able-bodied subjects (Popovic, 2000; Masani, Vette, \& Popovic, 2006). Balance impairments are frequent and particularly high among people who suffer from stroke, TBI, incomplete spinal cord injuries, Parkinson's disease, multiple sclerosis and diabetic peripheral neuropathy, as well as among the populations previously discussed. For all of these groups, balance disorders have major social and quality of life implications, which require attention and exploration of effective ways to assess risk and develop training/rehabilitation programs that prevent falls.

Risk assessment has a significant role for falls prevention, but the literature review (Boulgarides, et al., 2003) shows the low predictive power of classic clinical balance tests. In addition, the existing techniques for balance evaluation rely on either subjective or timeconsuming and expensive diagnostic methods. Also, the motion capture systems currently used for precise quantitative balance evaluation rely on expensive permanent research laboratory setups and thus are not feasible for clinical application. 
Epidemiological studies show a high incidence of falls and their serious consequences for individuals with a history of falling, as well as for the healthcare system and society at large. Based on the suggestions from the literature related to balance and falls prevention and on the results from previous studies, my study focuses on specific aspects of arm movements, with particular attention on the impact of the dominant and non-dominant arms on balance, which is often the cause of serious injuries.

\subsection{Arm Movements in Posture and Balance}

Numerous studies provide evidence of the important role of arm movements for balance maintenance and recovery, and of the increased risks of falling among the elderly because of deteriorating sensorimotor functions and less effective arm use (e.g. Allum, 2002). Specific age-dependent patterns of falls (e.g. Maki, Mcllroy \& Fernie, 2003) show that older adults suffer head and knee injuries more frequently than younger adults (Talbot et al., 2005).

A significant number of studies suggest that efficient arm movements strategies can significantly mitigate the consequences of falls (Kim \& Ashton-Miller, 2003; Maki et al., 2007; Kim \& Ashton-Miller, 2009). These studies provide support for the hypothesis that free arm movements, increased awareness and readiness to regain balance can contribute to efficient balance strategy.

Similarly, Woollacott, Inglin and Manchester (1988), who explored the linkage between arm movements and postural muscles, found a deterioration of the speed of activation in the control of postural balance. In addition, a study that explored the biomechanics of fall arrests and the use of the upper extremities (Kim \& Ashton-Miller, 2003) emphasizes knowledge gaps 
concerning their role during the fall impact. Examining the risk of future falling, Maki et al. (1994a) found that control of lateral stability may be essential in falls preventative interventions.

Based on a synthesis of studies related to change-in-support reactions, Maki, Mcllroy \& Fernie (2003) documented the important role of grasping reactions and the design of assistive devices for balance recovery. According to this research, compensatory stepping and grasping arm movements have a critical role in falls prevention. In a more recent study, Maki and Mcllroy (2006) presented an overview of new findings on stepping and reaching movements and their relevance for falls prevention, and demonstrated the crucial impact of rapid limb movements on both this and balance recovery. The authors underline the role of lateral balance control, a factor which may prevent the lateral falls that often cause hip fractures.

Despite the evident deterioration of the neural, sensory and/or musculoskeletal functions among older people, Maki and Mcllroy indicate the possibility of remodeling these functions, and advocate the more effective use of stepping and reaching reactions. Another study that investigated the impact of ageing on the directional sensitivity of balance corrections and the role of arm movements (Allum et al., 2002) also found that arm movements have a protective function but deteriorate with age. This study indicates that new strategies of balance training should include arm movements as a significant factor for regaining balance control.

A similar conclusion is also presented in a recent study that employed a wide variety of biomechanical and electromyographic (EMG) measures, video recording, and accelerometeric and force-plate measurements (Yamazaki et al., 2005) to demonstrate that rapid arm movements together with hip joint muscles contribute to the maintenance of standing posture. According to the results in this study, rapid arm movements cause trunk muscle contractions that contribute to the stabilization of hip joints. 
Concerning the possibility of arm movement changes, Borello-France et al. (2002) demonstrate that people suffering from vestibular loss were able to alter their voluntary arm movements. A recent study (Bugnariu \& Fung, 2007) also demonstrates the possibility of adapting sensory integration in older adults and improving balance capability through balance exercise, based on an innovative training program in a virtual environment. Another study of balance related to the virtual environments (VE) and vestibular rehabilitation conducted in the SPIRALL laboratory provides indications of possibilities for improvement of balance through virtual reality based training (McConville, Virk \& Milosevic, 2007). Mansfield et.al. (2007) indicate promising results through therapeutic approaches to balance rectification using a complex exercise program that provides a safe and effective environment for change-in-support balance reactions.

Table 1.1: Summary of Major Postural Stability Strategies Classified in the Literature.

\begin{tabular}{|l|l|l|}
\hline \multirow{3}{*}{$\begin{array}{c}\text { Leg \& Trunk } \\
\text { strategies }\end{array}$} & -Hip strategy / CoM & Horak, 2006, Horak \& Mcphason, 1997 \\
\cline { 2 - 3 } & - Ankle strategy & Horak, 2006, Horak \& Mcphason, 1997 \\
\cline { 2 - 3 } & - Change-of-support (stepping) & Maki \& Mcllroy, 2006 \\
\hline \multirow{3}{*}{$\begin{array}{l}\text { Arm strategies } \\
\end{array}$} & - Reaching-grasping & Maki, Mcllroy \& Fernie, 2003 \\
\cline { 2 - 3 } & - Protective movements & Maki, Mcllroy \& Fernie, 2003 \\
\cline { 2 - 3 } & Counter-balancing & Milosevic \& McConville, 2007 \\
\hline
\end{tabular}

In summary, the major balance strategies addressed in the literature review are included in Table 1.1. They show the significant role of arm, leg and trunk movement strategies for falls prevention. Reaching and grasping movements are also regarded as prevention mechanisms. Many clinical studies indicate the important role of free arm movements for activities relevant to balance maintenance or recovery. Bateni et al., 2004 have shown that the central nervous system gives priority to a holding task suggesting the importance of arm movement reactions. 
Anticipatory postural adjustments (APA) of the body in response to voluntary arm movements have been studied and were found to be a significant factor in the ability to maintain postural balance (Horak \& Macpharson, 1997; Yamazaki et al., 2005). Individual responses related to APA are supported by the theories describing balance as a dynamic integration of interdependent systems (Horak, 2006). It is important to investigate the role of arm movements as they relate to balance, and the possibility of correcting dynamic posture through better overall balancing strategies. My study will investigate the effects of arm movement dynamics on the dynamics of the trunk, which has been regarded as one of the most important balancing strategies (Redyke et al, 1999; Horak, 2006).

\subsection{Handedness in Balance}

Postural control has been regarded as being dominated by the right hemisphere. In a study analyzing the effects of stroke lesion location and dimensions, Perennou et al. (1999) provided evidence of the existence of right hemispheric dominance for this function, showing lower postural performance in right brain-damaged patients than in left brain-damaged patients. Likewise, handedness has been thought of as a result of the control mechanism of the dominant hemisphere (Sainburg, 2007; Wang and Sainburg, 2007).

However, recent studies contradict the idea that motor lateralization reflects a global advantage of one dominant hemisphere or limb system (Wang and Sainburg, 2007). The dynamic dominance model shows that each hemisphere/limb system is specialized for controlling different features of performance (Zhang et al., 2006). In a study of ipsilesional motor deficits following a stroke, Schaefer et al. (2007) confirm motor lateralization theory supporting that the 
left and right hemispheres are specialized for controlling different features of movement. This study demonstrated that dominant and non-dominant arms have distinct control mechanisms.

Studies on handedness mainly examine the role of different arms for manual motor control tasks. According to Sainburg (2007), this field requires further research; consequently, my thesis intends to examine the role of dominant and non-dominant arm movements for maintenance of dynamic postural balance during balance board tests.

\subsection{Clinical Balance Tests for Risk Assessment}

Reviews of evidence on falls and falls prevention (Rubenstein, 2006; Rubenstein \& Josephson, 2006; Horak, 2006) indicate the existence of knowledge gaps related to interdisciplinary studies, diagnostic procedures, and feasible and cost-effective balance assessment and training programs.

Postural balance studies use a variety of methods, including biomechanical and EMG measures, video recording, accelerometeric and force-plate measurements. There are studies that report successful identification of people at risk of falling and fall-related injury (Lord et al., 1994; Toronto Rehabilitation Institute, 1998; Howe, 2006). However, several studies on musculoskeletal equilibrium and psychomotor performance (Fujiwara et al., 2001) indicate difficulties making complex and precise measurements and a lack of predictive validity for classic balance tests (Boulgarides et al., 2003).

Other reviews of literature on falls prevention (Rubenstein, 2006; Rubenstein and Josephson, 2006) recognize similar knowledge gaps and emphasize the significant role of new strategies for falls prevention. There is also a need for the development of new methods for 
diagnostics relevant for balance maintenance and balance recovery. My study intends to contribute to the body of knowledge and methodology of research on postural balance.

Rietdyk et al. (1999) noted that most postural control studies have been limited by the available measures (kinematics, surface forces, and EMG) used to examine postural control. According to this study, it is important to consider a wider array of balancing tasks and to examine often ignored balancing strategies to provide a more complete explanation of balance and falls-related risks.

A recent review of existing and possible applications of accelerometers to rehabilitation medicine (Culhane et al., 2005) anticipates useful results from these devices. Similarly, Chiar (2005) presents a prototype based on MEMS accelerometers that seems useful for balance rehabilitation and for diagnostics of standing balance. My study uses MEMS accelerometers to collect data from the external balance board, patient arms and CoM movements during balancing tasks.

\subsection{Summary of the Literature Review}

Considering the consequences of falls (head, knee and hip injuries) and the role of arm movements in balance recovery and falls avoidance, my study aims to provide evidence related to arm movements and their function in maintaining postural balance. My study also provides evaluation of diagnostic devices for the examination of postural balance, as well as evidence for the effectiveness of balance training programs. It is expected that the presented study will help to make a positive social impact through falls prevention, and through a reduction in the number of emergency medical interventions and hospital admissions.

As major studies in the domain of balance suggest (e.g. Horak, 2006), my project aims to 
explore arm movements as a component of the multiple interdependent processes of postural control. Based on the suggestions from the reviewed studies and the results from our preliminary research, my study investigates dynamic balancing tasks on the balance board and, more specifically, examines arm movement strategies during these tasks. Particular attention is also directed to examining lateral balance, which is the cause of most serious hip fractures.

The literature review also attests to significant gaps in knowledge related to specific aspects of reaching and grasping arm movements (Maki \& Mcllroy, 2006), to the role of the upper extremities during the fall impact (Kim \& Ashton-Miller, 2003), and to making precise and reliable measurements (Woollacott, Inglin \& Manchester, 1988).

Their ease of application, high sensitivity and low cost make accelerometer sensors appropriate for the development of diagnostic and training devices that are feasible, sustainable and cost effective, as Rubenstein (2006) recommends. Through the development of a new diagnostic tool, the following study can be expected to contribute to an interdisciplinary assessment and exploration of the factors that determine postural balance.

\subsection{Objectives}

The review of existing literature shows that arm movements have an important role in balance maintenance and recovery, and that they can contribute to falls prevention among the elderly, who suffer the most serious consequences from falls.

This study intends to explore the characteristics of arm movements and their relations to balance among the healthy middle aged. A particular intention of this study is to introduce more objective criteria for balance assessment based on an array of kinematic measures of arm and 
trunk movements. The presented study can also play a role in the explanation of processes that determine the dynamic postural balance.

Numerous studies demonstrate that the incidence and severity of falls increase with age. Because of the growing elderly population, it is expected that the number of falls will rise, and this is an emerging healthcare and societal issue (Maki, et al,, 2003; Rubenstein \& Josephson, 2006). According to the cited studies, research should be directed towards identifying determinants and risk factors, developing appropriate training programs and assistive devices, inventing new methods for balance assessment, evaluation and rehabilitation, and implementing them in clinical settings.

The first objective of my study is to demonstrate the application of new diagnostic instruments for balance and arm movements assessment, based on tri-axial accelerometers adapted to register the magnitude of movements during different balancing tasks. This is a novel method for balance assessment, using portable, cost-efficient and easy-to-implement accelerometer-based instrumentation.

My second objective is to determine the role that arm movements play in dynamic balance. The study aims to provide a more specific diagnostic and classification of arm movements and their roles for balance maintenance. In addition, it examines arm dominance during balancing tasks. The specific objectives of my study are:

- To examine the effect of arm movements on classic balance test outcomes.

- To examine the associations between the results of classic balance tests and trunk movements (CoM) during limited and free arm movements.

- To examine the specific impact of the dominant and non-dominant arms on dynamic postural balance during stable and recovery balance periods. 


\section{Methods}

\subsection{Subjects}

This study included ten healthy volunteer participants who were examined on the classic balance tests. Four of these were further examined on the quantitative balance board test. The mean age of all respondents was 56 , and all of them had a dominant right hand. All of the participants were healthy middle-aged adults. The participants had no background of neurological or other underlying disease, no history or fear of falls, and no vestibular and/or somatosensory, cognitive or musculoskeletal impairments that might have restricted them in participating. Recruitment was done through flyers, online postings and word of mouth. The participants were compensated with light refreshments.

\subsection{Protocol}

A cross-sectional study design with repeated measurements under different conditions was implemented. The testing included standard clinical classic tests and novel dynamic balance board tests. Each test was performed twice: for limited and free arm movements. In the first trial, the test was performed with the arms positioned against the body (limited arms), while in the second trial, it was performed with the arms being used freely (free arms).

All tests were first demonstrated to the participants. Afterwards, the participants were allowed to familiarize themselves with the apparatus and the tests for a total of approximately 15 minutes before data was collected. The familiarization period was implemented in order to provide experience with the testing protocol to all participants before the data collection (Boulgarides et al, 2003; Dite, \& Temple, 2002, Podsiadlo \& Richardson, 1991). The complete series of tests usually took approximately 30 minutes. 
The tests were performed without any support, but the investigator was always present to assist the participants to complete the tests safely. All participants were allowed to terminate the testing at any time if they felt uncomfortable with any of the tasks. However, all of them were able to complete the entire protocol successfully.

This study was designed in accordance with Ryerson University Research Ethics Board procedures. The protocol was implemented to represent a minimal safety risk, and ensured the participants' confidentiality. All of the participants consented by signing the participation agreement forms, and their confidentiality was ensured by coding any personal information and securely storing all data. This study was approved by the Ryerson University Research Ethics Board (REB 2009-042).

\section{Classic Balance Tests:}

The classic balance tests are commonly used clinical and research balance tests found in the literature (Isles, et al., 2004; Vaughan, Davis and O'Connor, 1992; Hausdorff and Alexander, 2005) and adapted for the purposes of examining the effects of arms. Each test was performed for the limited arms and free arms conditions. During the balancing tasks, the dynamics of the trunk (center of mass - CoM) were recorded. For each test, the standard performance outcomes were also measured and evaluated. The classic balance tests include evaluating the following tests of balance performance:

- Maximal Step Length Test (MSL): Beginning from a standing position, the participant is required to make the maximum step forward and return to the starting position, while keeping the other leg fixed. Performance is measured by the step length and the time taken to return to the initial position (Cho, et al., 2004; Lindemann, et al., 2008; Lindemann, et al., 2004; Schulz, et al., 2007). 
- Step Test (ST): The participant is required to stand on one leg, facing a wall, $5 \mathrm{~cm}$ from an $8.5 \mathrm{~cm}$ high block ( $41 \mathrm{~cm}$ wide by $72 \mathrm{~cm}$ wide) positioned against the wall, and to step on and off the block with both feet (one at a time) as many times as possible in 15 seconds. The total number of steps is counted (Dite, \& Temple, 2002; Hill et al., 1996; Isles et al., 2004 ; Nnodim et al., 2006).

- Timed Up and Go Test (TUG): Beginning from a sitting position, the participant is required to stand up, walk 10 feet forward, turn around, go back, and sit down on the chair. The time needed to execute the test is evaluated (Podsiadlo \& Richardson, 1991; Jaglal, Lakhani Schatzker, 2000).

- Walk along an Elliptical Line (WEL): Beginning from a standing position, the participant is required to walk along an elliptical path (major axis $=1.5 \mathrm{~m}$, minor axis $=3 \mathrm{~m}$ ) and return to the original position. The time needed to complete the task is evaluated (English, et al., 2007; Salbach, et al., 2001; Suzuki, et al., 1999; Wade, et al., 1987).

\section{Balance Board Tests:}

Additionally, participants were assessed on the novel dynamic balance tests. The balance board tests consist of maintaining balance on the modified clinical balance tool - a balance board (Mechling, 1986; Ferrell et al. 2004) that has been instrumented to monitor balancing performance. There are three variants of the balance board test that assess all directional balance, as well as lateral and anterior-posterior balance separately (see Balance Evaluation section). The tests consisted of maintaining balance on the balance board for one minute, and all the measurements were recorded for post-processing. During the experiment, there were no unexpected tasks or events. The investigators were always present during the experiment to assist in the completion of the tests if necessary. 
Each of the balancing tasks was evaluated under limited arms and free arms conditions. During these tasks, the dynamics of the arms as well as those of the balance board were recorded. Figure 2.1 shows the experimental setup during the balance board tests. The Balance Board tests require the following performance:

- The participants were asked to stand on the balance board and to maintain balance. This study uses three types of balance board. The first balance board moves in all directions (CBB), the second examines anterior-posterior (AP) balance only, and the third examines lateral (LAT) balance only.
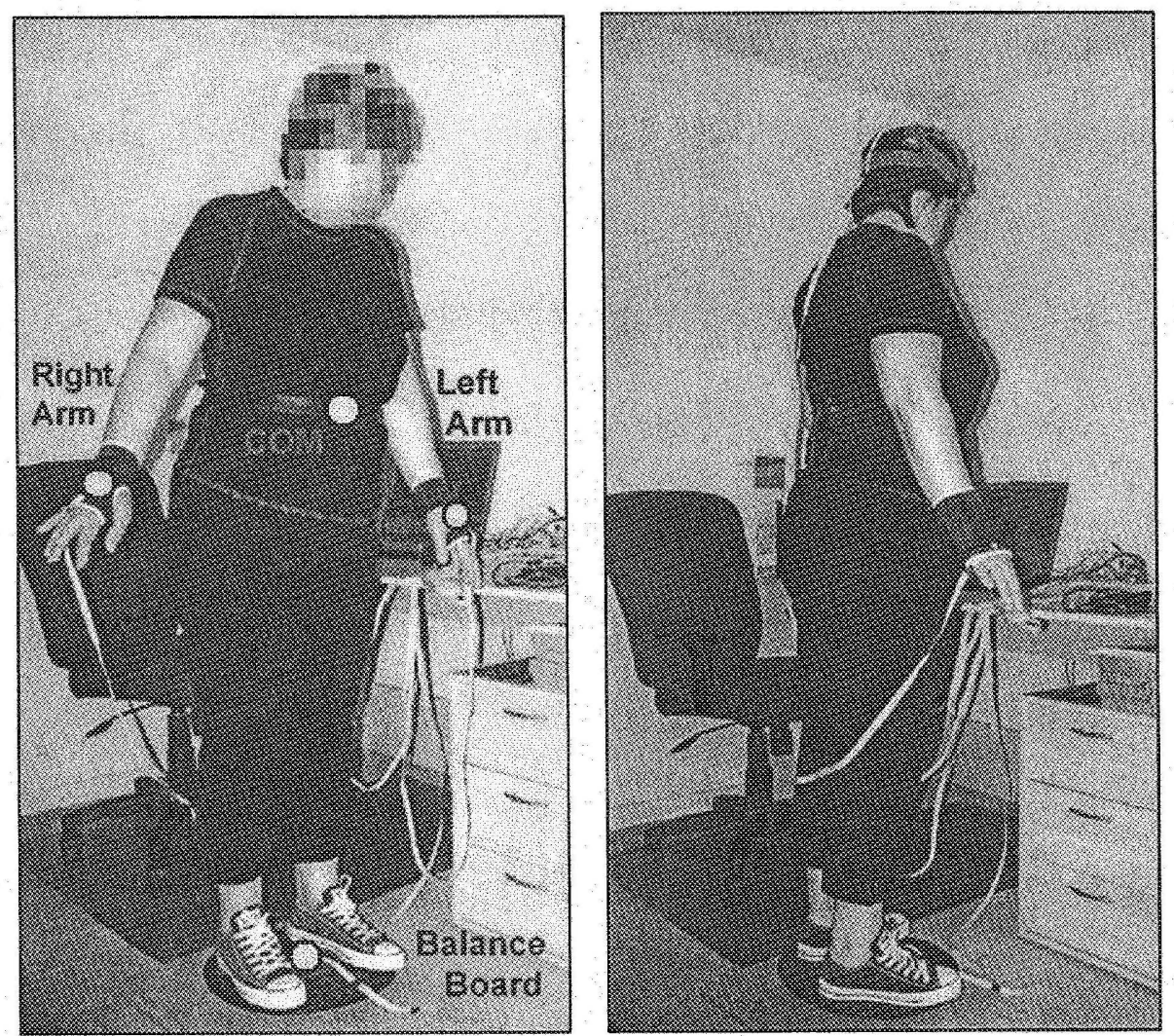

Figure 2.1: Experimental setup during the Balance Board tests

\subsection{Balance Board}

A commercially available, round balance board (PT Balance Board, PTfitness) was used ( $5.5 \mathrm{~cm}$ high, $36 \mathrm{~cm}$ diameter with 18 degrees of inclination). 

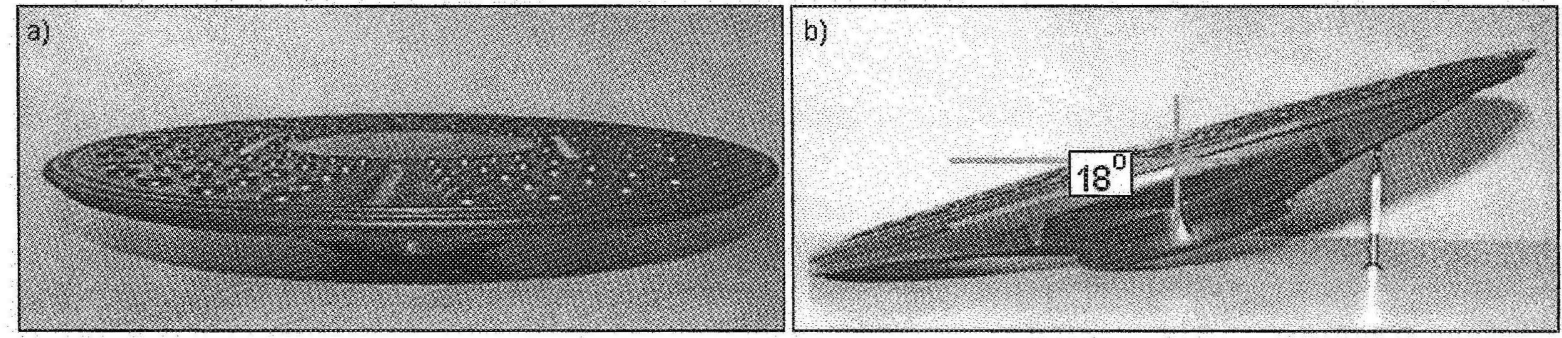

Figure 2.2: Shows the balance board used in the CBB balance board test. The balance board can move in all directions; a) $\mathrm{CBB}$ test balance board; b) $\mathrm{CBB}$ balance board maximal range of motion.
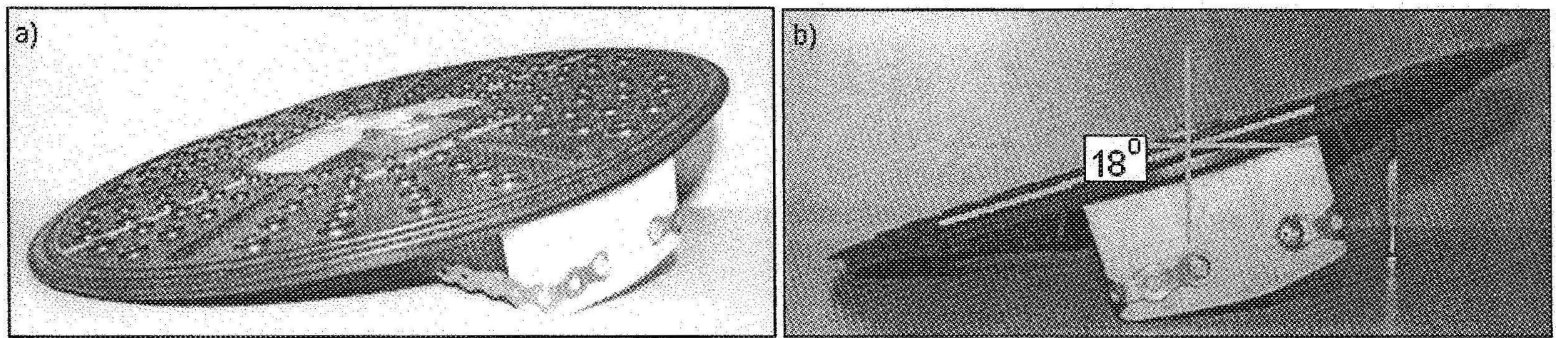

Figure 2.3: Shows the balance board used in the AP and LAT balance board tests. The balance board can move only in the selected direction and is constrained in other directions; a) AP and

LAT test balance board; b) AP and LAT balance board maximal range of motion.

The balance board is a standard wobble board used in clinical settings for physiotherapy.

Several studies (Mechling, 1986; Ferrell et al. 2004) show that they provide valuable information for postural balance diagnostics. In addition, it has been shown that exercise programs on balance boards can significantly improve patients' postural balance and muscle strength (Ferrell et al. 2004) and overall functional capacity (Diracoglu et al., 2005). Nordt at al. (1999) also demonstrate the usefulness of balance board-based training for the elderly. The existing evidence supports the use of balance boards as a relevant and meaningful tool for dynamic balance evaluation.

\subsection{Data Acquisition}

The experimental measurements were taken using MEMS differential capacitance accelerometers (Kionix Inc., USA, model KXM52-1050 and Analog Devices Inc., model MMA7260Q, 3-axial accelerometer with a range of $\pm 2.0 \mathrm{~g}$ ). 
For the classic balance tests, the CoM accelerometer was placed on the trunk to measure trunk dynamics. A digital stopwatch and measuring tape were also used during data acquisition for the classic balance tests to assess the performance using standard measures.

For the balance board tests, the accelerometers were placed on both arms and on the balance board. An additional accelerometer was placed at the CoM (on the trunk) to measure trunk movements, as shown in Figures 2.1 and Figure 2.4.

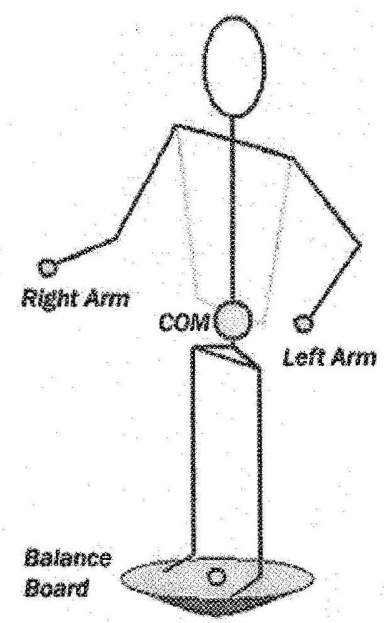

Figure 2.4: Sensor placement for the Balance Board test

\section{$\underline{\text { Sensors }}$}

The study data acquisition is based on the application of accelerometers with a $\pm 2.0 \mathrm{~g}$ force range, a sensitivity of $1 \mathrm{~V} / \mathrm{g}$ for the supply voltage $\mathrm{Vdd}=5 \mathrm{~V}$ and with the $0 \mathrm{~g}$ offset set at Vdd/2 for the KXM52-1050 accelerometer (Kionix Inc.). The signals were filtered to provide tilt and relative displacements appropriate to the diagnostics of human movements, including arm and trunk frequencies and balance board movement diagnostics. The packaged sensors were firmly fixed in the gloves on both arms and on the belt close to the trunk of each participant, as well as on the balance board. 


\section{Signal Acquisition and Processing}

Signals were acquired using a 12-bit data acquisition system (NI-USB 6008, National Instruments) and were further processed on a PC station (DELL XPS Laptop with an Inter Pentium $4 \mathrm{CPU} 3.40 \mathrm{GHz}, 1.00 \mathrm{~GB}$ RAM). Real-time acquisition and processing were performed using a LabVIEW 8.0 (National Instruments) custom-built application. The post-processing and filtering were performed using Matlab 7.0 (MathWorks, Inc.). Statistical analysis was performed using SPSS 16.0.1 (SPSS Inc.) and Statistica 6.0 (StatSoft, Inc.).

\subsection{Signal Analysis}

The analysis and preparation of kinematics data included filtering, segmenting and calculating the vector magnitudes of the tri-axial accelerometer readings. Signals were processed and analyzed according to the manufacturer's calibration specifications (Kionix Inc.). The evaluation of accelerometer vector magnitudes (which are a measurement of the magnitude of the accelerations being applied) (Kionix Inc.) is a physiologically meaningful manifestation of arm movements. The measurements of acceleration magnitudes and comparisons of magnitudes and variations over time provide physiologically interpretable results about arm movement dynamics (Jackson, 2003; Steele et al., 2000). However, the accelerometer data units are not biologically meaningful, since they do not calibrate against external measures of arm movements during balance. The unit calibration is not necessary for the purposes of my study, since my goal is to evaluate time trends and compare dynamics over time. The following analyses of the data were carried out:

- Band-pass filter: Since most human movements occur in the 0.3 to $3.5 \mathrm{~Hz}$ range (Steele et al., 2000 ), the signals were filtered to eliminate unnecessary frequencies above $10 \mathrm{~Hz}$. For the applications where only tilt was being observed, the signal was filtered to obtain the DC values. 
- Moving average filter: In order to reduce computational complexity and remove noise from the signal, a 10-point moving average filter was applied to the accelerometer data, according to Equation 1 (Rangayyan, 2002).

$$
y(n)=\frac{1}{10} \sum_{k=0}^{9} x[n-k]
$$

- Vector Magnitude Unit (VMU): Accelerometer outputs (acceleration) were measured in three spatial dimensions ( $\mathrm{X}, \mathrm{Y}$ and $\mathrm{Z}$ vectors), and combined to represent movements according to Equation 2 (Steele et al., 2000; Kionix Inc.).

$$
V M U=\sqrt{x^{2}+y^{2}+z^{2}}
$$

- Segmentation: Balancing tasks were segmented into two regions based on the accelerometer tilt dynamics measurements from the balance board during the balancing tasks. The stable (balance maintenance) regions were periods with below-average balance board activity and the unstable (balance recovery) regions were those with above-average balance board activity, where the subject is recovering from loss of balance (see Figure 2.5).

The algorithm for segmentation is based on finding the regions with a higher level and concentration of balance board movements and detecting the locations of these events independently of the number of their occurrence and duration throughout the testing period. After the segmentation, the analysis is performed synchronously for both arms (right and left arm dynamics) and analyzed in two different balance regions (stable and unstable balance regions).Data segmentation is performed by post-hoc analysis using a custom-made Matlab program. 


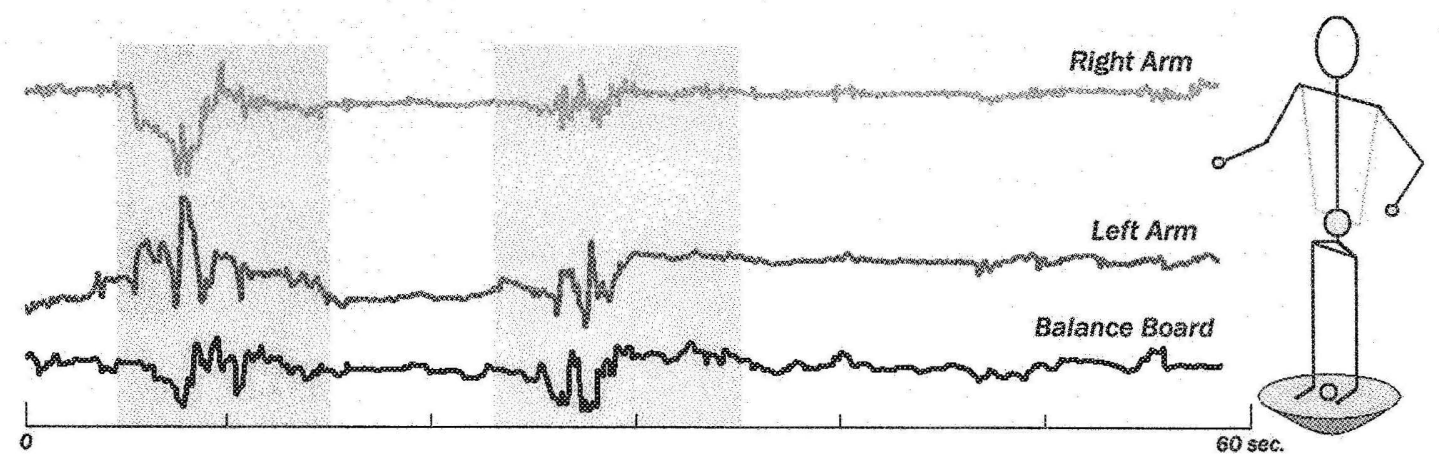

Figure 2.5: Segmentation of the data into Stable Regions (gray shaded area) and Recovery Regions (unshaded area) for the duration of one testing session for the LAT balance board test.

\section{Balance Regions Detection Algorithm}

The balance regions detection algorithm is based on analyzing signal slope, amplitude and width components (Rangayyan, 2002) of the balance board accelerometer signals. It is based on the adapted theory from the Pan and Tompkins (Tompkins, 1995; Pan and Tompkins, 1985) algorithm for ECG signal analysis. The block diagram implementation for the balance regions detection algorithm is shown in Figure 2.6.

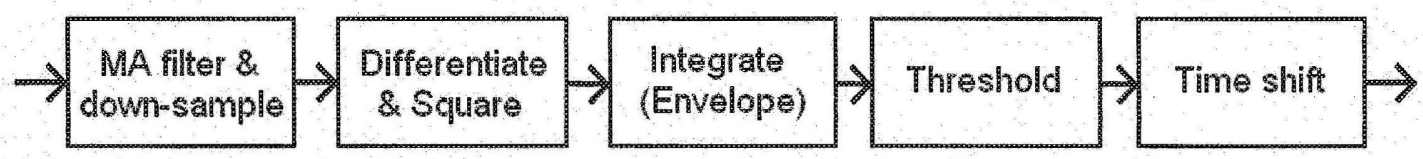

Figure 2.6: Block diagram implementation of the balance regions Segmentation Algorithm for detection of Stable and Recovery Regions.

The balance board accelerometer signal readings are pre-filtered by hardware using a low-pass filter $(\mathrm{fc}=0.16 \mathrm{~Hz}$ ). After acquisition, the algorithm is applied to segment the signal into the regions. The following is an explanation of the filtering process:

- Noise removal: The 10-point moving average filter (Equation 1) is applied to remove any interference noise from the signal, after which it is down-sampled. 
- Derivative \& Squaring Operations: The derivative operation highlights the high slopes of the signal attributed to the fast balance board movements, which are indicative of loss of balance, and suppresses the low-frequency components. The filter used in Equation 3 is ideal for processing signals up to $30 \mathrm{~Hz}$ (Rangayyan, 2002). The squaring operation further emphasizes the lower values, which are due to the loss of balance, and takes the absolute value of the signal.

$$
y(n)=\frac{1}{8}[2 x(n)+x(n-1)-n(n-3)-2 x(n-4)]
$$

- Integration Operation: The moving-window integration filter performs an enveloping operation, which helps to easily recognize the multiple regions of balance loss during the duration of recording. A window size of $\mathrm{N}=80$ was found to be ideal for precisely highlighting the regions of balance loss for this type of signal independently of their frequency of occurrence, duration and magnitude. The implementation of the filter can be seen in Equation 4 (Rangayyan, 2002).

$$
y(n)=\frac{1}{N}[x(n-(N-1))+x(n-(N-2))+\ldots+x(n)]
$$

- Thresholding: The thresholding procedure is used to define the regions of balance loss, based either on an experimentally determined threshold or a user definable input value. This allows the user to define the sensitivity of selection to reflect the individual subject's differences and their abilities to maintain balance on the balance board.

- Time-shift: It was determined that a time-shift of $\mathrm{N}=30$ was necessary to select the regions properly, due to the filtering offset. 


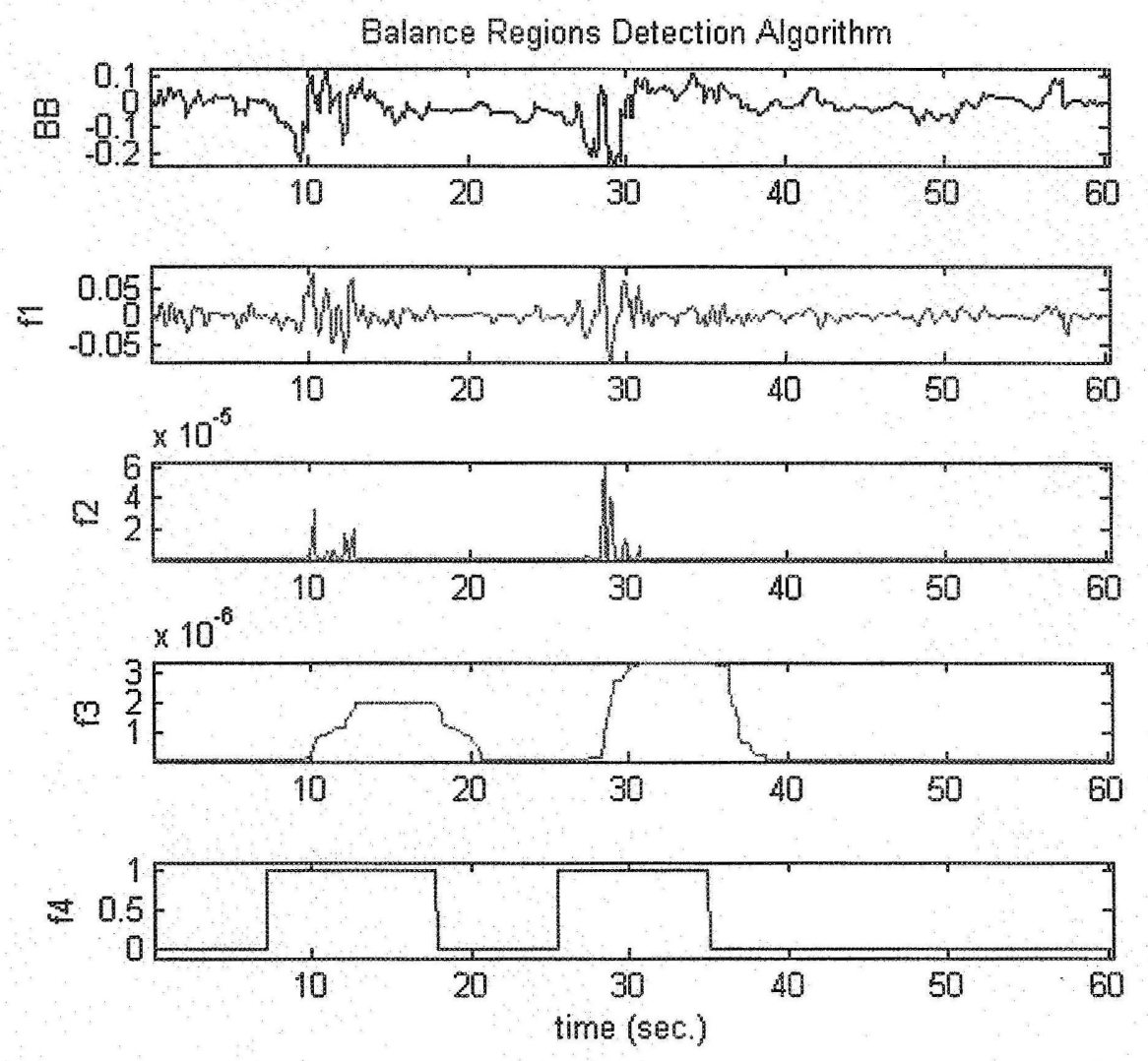

Figure 2.7: Results of the balance regions detection algorithm for detection on a sample LAT test of stable and recovery Regions. The diagram shows the segmentation process (from the top). BB: Recording of balance board tilt signal; fl: Differentiated balance board signal; $f$ : Squared differentiated signal; f3: Integration results of the squared signal; f4: Quantified signal after thresholding and time-shifting representing the balance regions $(1=$ recovery region; $0=$ stable region).

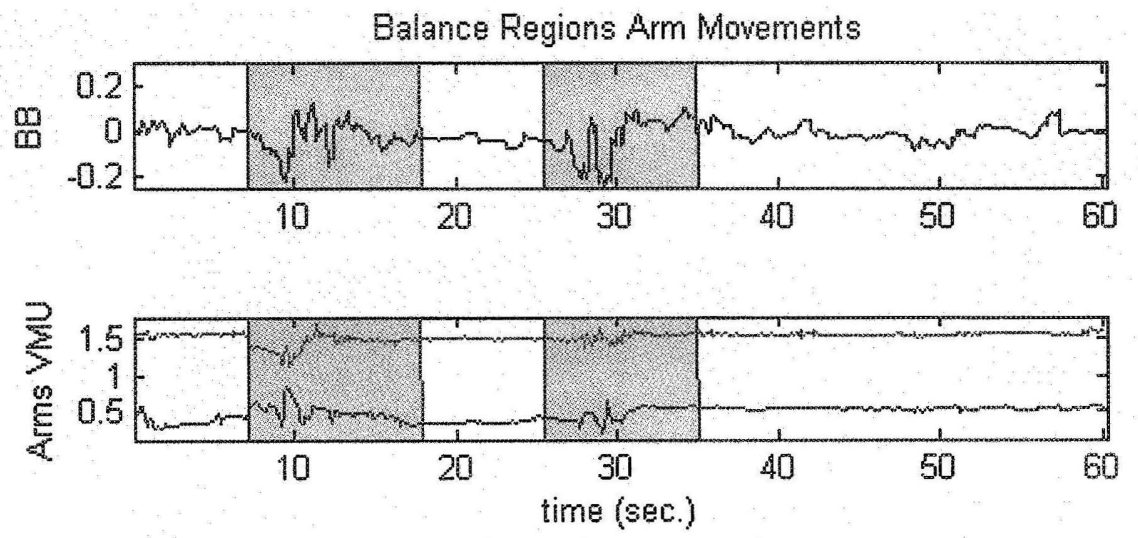

Figure 2.8: Stable regions (gray shaded) and recovery regions (unshaded) for the BB: Balance board tilt signals and Arms VMU: Right and left arm VMU measures. 

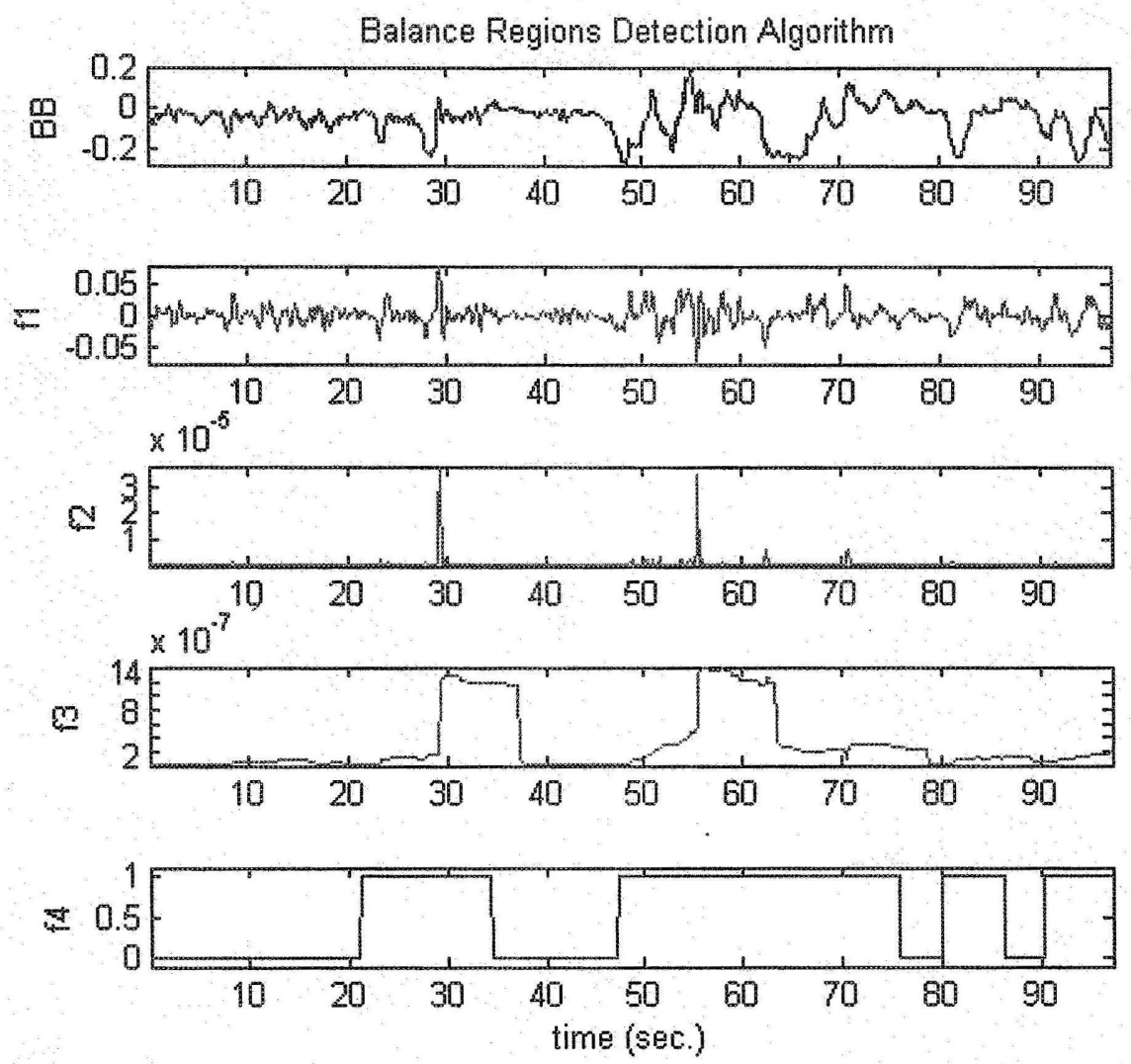

Figure 2.9: Results of the balance regions detection algorithm for detection on a sample AP test of stable and recovery regions. Demonstrates the time independence of the data collection.

Balance Regions Arm Movements
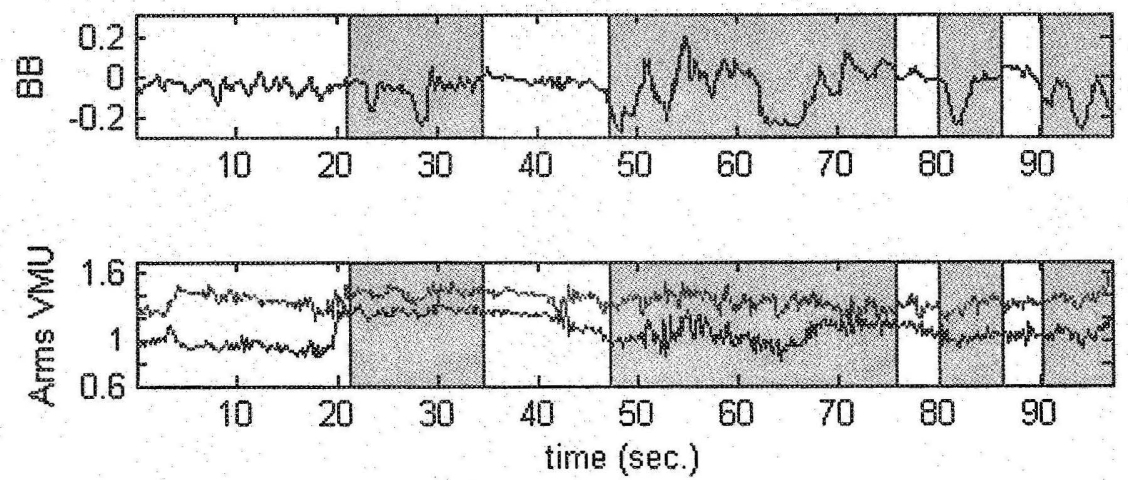

Figure 2.10: Stable regions (gray shaded) and recovery regions (unshaded) for the BB: Balance board tilt signals and Arms VMU: Right and left arm VMU measures. 
Balance Regions Detection Algorithm
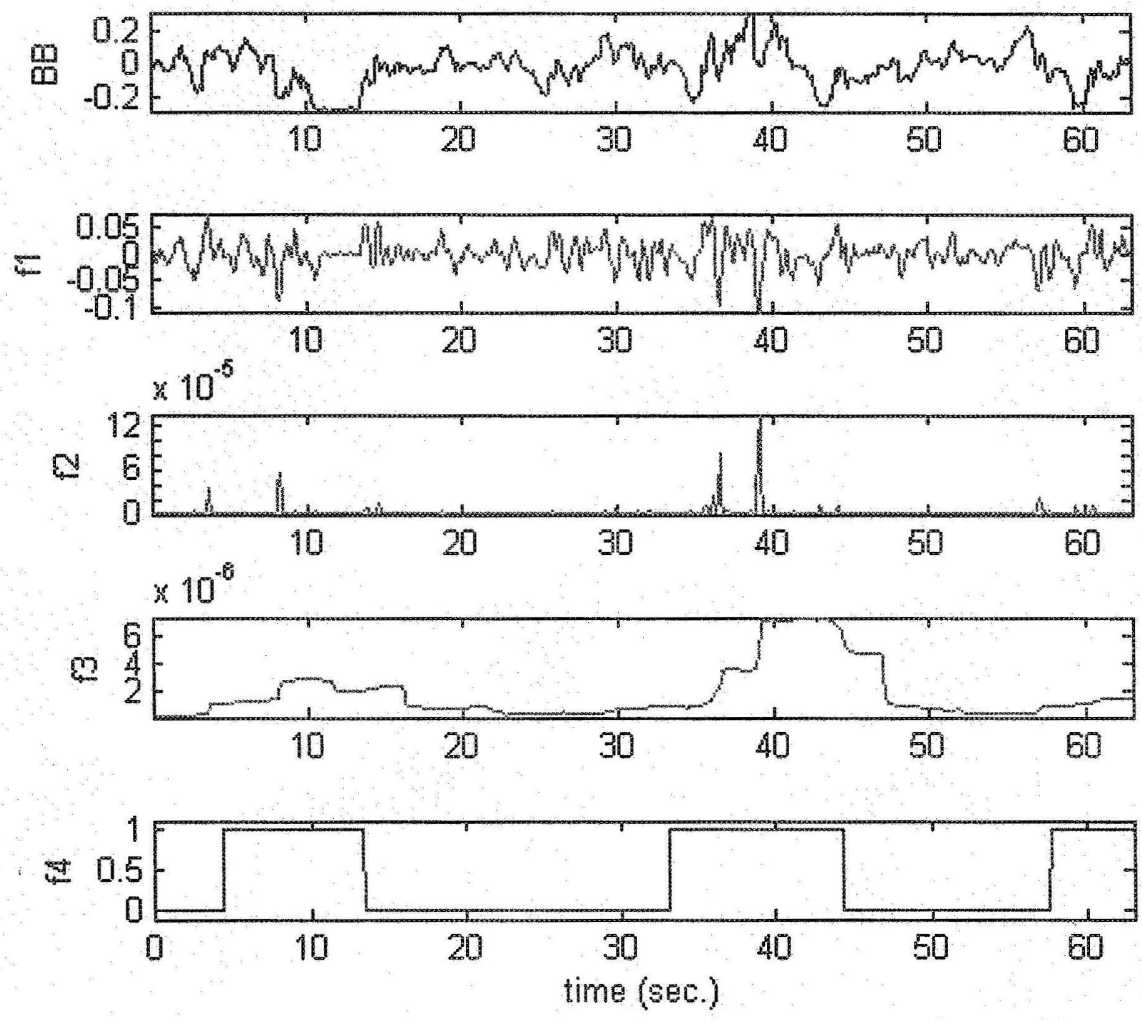

Figure 2.11: Results of the balance regions detection algorithm for detection on a sample CBB test of stable and recovery regions. This figure shows the "worst case" balance board (most unstable balance board for the most difficult balance board test) and a low sensitivity for the regions selection.

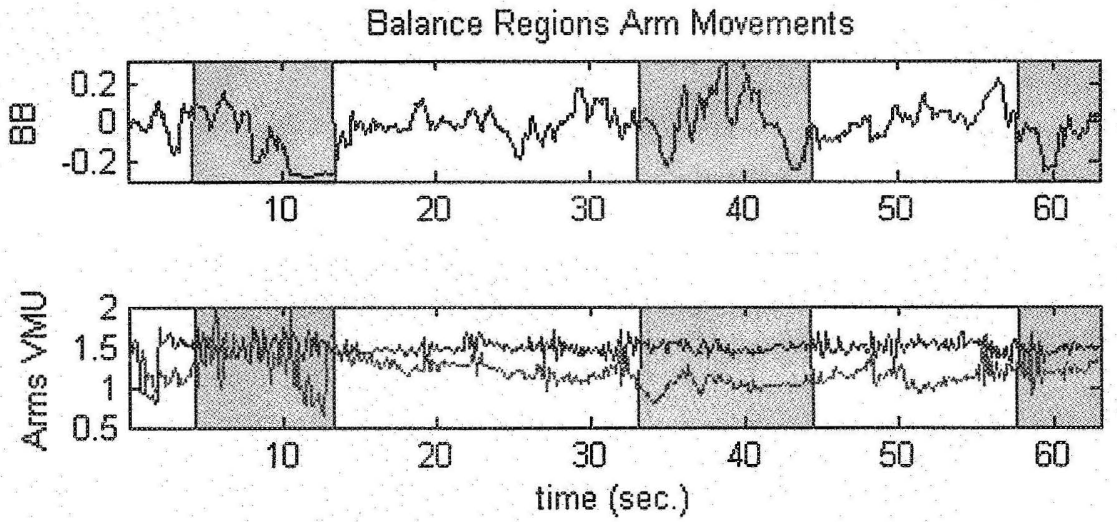

Figure 2.12: Stable regions (gray shaded) and recovery regions (unshaded) for the BB: balance board tilt signals and Arms VMU: Right and left arm VMU measures. 


\subsection{Statistical Analysis}

Statistical analyses include analyzing data using the outlined procedures. Below is an explanation of the tests and their applications.

- Exploratory data analysis (mean, variance, standard error, etc.).

- Paired-samples t-test procedures were applied to compare the means of the classic balance tests performed under different conditions (restricted and free arm movements).

- One-way analysis of variance (ANOVA) was used to determine the effects of arm movements on accelerometer-based Balance Board test performance.

- Two-way analysis of variance (ANOVA) was used to determine the impact of dominant and non-dominant arms during stable and recovery periods of balance maintenance during balance board tests.

- Differences in the variability of arm movements were analyzed using Levine's Test for Homogeneity of Variance, to compare dominant and non-dominant arms and to analyze balance recovery regions.

- The association between performance on the classic balance tests and trunk movements were analyzed using Spearman's correlation coefficient.

All statistical tests were two-tailed and the resulting significant statistics were flagged with asterisks. One asterisk ("**) denote statistics significant at the 0.05 level (two-tailed). Two asterisks ("***") signify statistics significant at the 0.01 level (two-tailed), and three asterisks (“****") represent statistics significant at the 0.001 level (two-tailed). 


\section{Results}

\subsection{Classic Balance Tests and Arm Movements}

This chapter compares the results that were achieved on the classic balance tests with limited arms and with free arms during the performance of the balance tests. The paired sample t-test analysis was used to compare the performance with limited and free arm movements on each classic balance tests. Significant improvements were shown with free arms use on five out of six classic balance test measures.

\section{Maximum Step Length (MSL) Test}

The Maximum Step Length (MSL) Test requires participants to make the maximum step forward with one leg and then return it back to the starting position, while the other leg remains in the original position. The performance was measured by evaluating the time to return to initial position and the length of the step. Also the speed of performance was computed and evaluated.

\section{Time on Maximum Step Length (tMSL) Test}

The results on the tMSL test show (Table 3.1.1) that the average time for completing MSL test decreased by 0.47 seconds $(16.4 \%)$ with the free arm use $(t=3.217, p<0.011)$.

Table 3.1.1: Mean Differences Between in the Average Time on Maximum Step Test (tMSL) obtained with Limited and Free Arm Movements

\begin{tabular}{|l|c|c|c|c|}
\hline tMSL & $\begin{array}{c}\text { Limited Arm } \\
\text { Movements }\end{array}$ & $\begin{array}{c}\text { Free Arm } \\
\text { Movements }\end{array}$ & t-test & $\begin{array}{c}\text { Sig. } \\
\text { (2-tailed) }\end{array}$ \\
\hline Mean Time (sec.) & 2.87 & 2.40 & 3.217 & .011 \\
\hline
\end{tabular}


Table 3.1.2: Time on Maximum Step Length (tMSL) Test: Descriptive Statistics

\begin{tabular}{|l|c|c|c|c|}
\hline \multirow{2}{*}{ Statistic (sec.) } & \multicolumn{3}{|c|}{ Limited Arm Movements } & \multicolumn{2}{c|}{ Free Arm Movements } \\
\cline { 2 - 5 } & Statistic & Std. Error & Statistic & Std. Error \\
\hline Mean & 2.8720 & .27160 & 2.4030 & .32560 \\
$95 \%$ C.I., Lower Bound & 2.2576 & & 1.6664 & \\
95\% C.I., Upper Bound & 3.4864 & & 3.1396 & \\
$5 \%$ Trimmed Mean & 2.8328 & & 2.3817 & \\
Median & 2.8550 & & 2.2250 & \\
Variance & .738 & & 1.060 & \\
Std. Deviation & .85889 & & 1.02965 & \\
Minimum & 1.75 & & 1.09 & \\
Maximum & 4.70 & & 4.10 & \\
Range & 2.95 & & 3.01 & \\
Interquartile Range & 1.14 & & 1.71 & \\
Skewness & .807 & .687 & .478 & .687 \\
Kurtosis & 1.317 & 1.334 & -.988 & 1.334 \\
\hline
\end{tabular}

Table 3.1.3: Distribution Normality for Time on Maximum Step (tMSL) Test

\begin{tabular}{|c|c|c|c|c|c|c|c|}
\hline & \multirow[t]{2}{*}{ Test type } & \multicolumn{3}{|c|}{ Kolmogorov-Smimov } & \multicolumn{3}{|c|}{ Shapiro-Wilk } \\
\hline & & Statistic & $d f$ & Sig. & Statistic & $\mathrm{df}$ & Sig. \\
\hline \multirow{2}{*}{ tMSL } & $\begin{array}{l}\text { Limited Arm } \\
\text { Movements }\end{array}$ & .143 & 10 & $.200^{*}$ & .942 & 10 & .575 \\
\hline & $\begin{array}{l}\text { Free Arm } \\
\text { Movements }\end{array}$ & .146 & 10 & $.200^{*}$ & .943 & 10 & .583 \\
\hline
\end{tabular}

Table 3.1.4: Test of Homogeneity of Variance for Time on Maximum Step (tMSL) Test

\begin{tabular}{|l|c|c|c|c|}
\hline TMSL & Levene Statistic & dfl & df2 & Sig. \\
\hline Based on Mean & .841 & 1 & 18 & .371 \\
Based on Median & .750 & 1 & 18 & .398 \\
Based on Median and with adjusted df & .750 & 1 & 17.998 & .398 \\
Based on trimmed mean & .795 & 1 & 18 & .384 \\
\hline
\end{tabular}

The Kolmogorov-Smirnov and Shapiro-Wilk tests (Table 3.1.3) both indicate that the results on the AMT test follow the normal distribution. Another test (Table 3.1.4) shows that variance of the $\mathrm{tMST}$ results are homogeneous and satisfy the conditions for doing the t-test. 


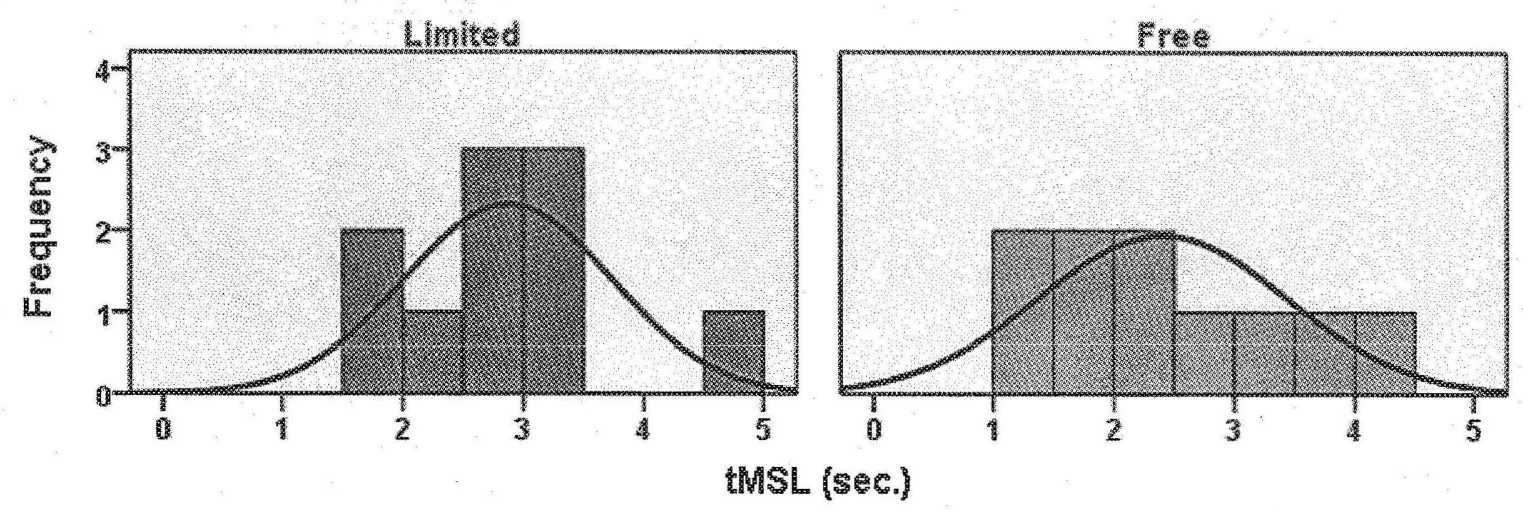

Figure 3.1.1: Time on Maximum Step (tMSL) Test Results Distribution

The MSL test measures the respondents' mobility, balance, and risk of falls (Cho, Scarpace \& Alexander, 2004). Consequently from these results it can be suggested that arms use improves mobility, control of postural balance and decreases the risk of falling as measured by the performance on the MSL tests. This information is significant for precaution during daily activities, for risk assessments, diagnostic, and for balance rehabilitation.

\section{Length of Maximum Step Length (IMSL) Test}

In addition to time, the MSL test measures step length. The study shows (Table 3.1.5) that the average length of the step increased by $12 \mathrm{~cm}(10.8 \%)$ when arms were used freely. The paired $t$-test shows that this difference is significant $(t=-5.840, p<0.001)$.

Table 3.1.5: Mean Differences between the Average Length of Maximum Step Test Obtained with Limited and Free Arm Movements

\begin{tabular}{|l|c|c|c|c|}
\hline IMST & $\begin{array}{c}\text { Limited Arm } \\
\text { Movements }\end{array}$ & $\begin{array}{c}\text { Free Arm } \\
\text { Movements }\end{array}$ & t-test & $\begin{array}{c}\text { Sig. } \\
\text { (2-tailed) }\end{array}$ \\
\hline Mean Step Length $(\mathrm{cm})$ & 110.70 & 122.70 & -5.840 & .001 \\
\hline
\end{tabular}


Table 3.1.6: Length of Maximum Step Test (IMST): Descriptive Statistics

\begin{tabular}{|l|c|c|c|c|}
\hline \multirow{2}{*}{ Statistic (cm) } & \multicolumn{2}{|c|}{ Limited Arm Movements } & \multicolumn{2}{c|}{ Free Arm Movements } \\
\cline { 2 - 5 } & Statistic & Std. Error & Statistic & Std. Error \\
\hline Mean & 110.70 & 5.315 & 122.70 & 6.733 \\
95\% C.I., Lower Bound & 98.68 & & 107.47 & \\
95\% C.I., Upper Bound & 122.72 & & 137.93 & \\
5\% Trimmed Mean & 110.67 & & 122.44 & \\
Median & 106.00 & & 121.00 & \\
Variance & 282.456 & & 453.344 & \\
Std. Deviation & 16.806 & & 21.292 & \\
Minimum & 85 & & 93 & \\
Maximum & 137 & & 157 & \\
Range & 52 & & 64 & \\
Interquartile Range & 26 & & 37 & \\
Skewness & .148 & .687 & .202 & .687 \\
Kurtosis & -.909 & 1.334 & -.901 & 1.334 \\
\hline
\end{tabular}

Table 3.1.7: Distribution Normality for Length of Maximum Step Test (IMST)

\begin{tabular}{|c|l|c|c|c|c|c|c|}
\hline \multirow{2}{*}{} & \multirow{2}{*}{ Test type } & \multicolumn{3}{|c|}{ Kolmogorov-Smirnov } & \multicolumn{3}{c|}{ Shapiro-Wilk } \\
\cline { 3 - 8 } IMST & Statistic & df & Sig. & Statistic & df & Sig. \\
\hline \multirow{2}{*}{$\begin{array}{l}\text { Limited Arm } \\
\text { Movements }\end{array}$} & .187 & 10 & $.200^{*}$ & .957 & 10 & .755 \\
& $\begin{array}{l}\text { Free Arm } \\
\text { Movements }\end{array}$ & .105 & 10 & $.200^{*}$ & .966 & 10 & .847 \\
\hline
\end{tabular}

Table 3.1.8: Test of Homogeneity of Variance of Maximum Step Test (IMST)

\begin{tabular}{|l|c|c|c|c|}
\hline IMST & Levene Statistic & df1 & df & Sig. \\
\hline Based on Mean & .455 & 1 & 18 & .508 \\
Based on Median & .565 & 1 & 18 & .462 \\
Based on Median and with adjusted df & .565 & 1 & 17.857 & .462 \\
Based on trimmed mean & .457 & 1 & 18 & .508 \\
\hline
\end{tabular}

According to the Kolmogorov-Smirnov and Shapiro-Wilk tests (Table 3.1.7), both free and limited arm result distributions for the IMST test can be assumed normally distributed. Another test (Table 3.1.8) shows that variance of the IMST results is homogeneous and satisfies the condition for doing the t-test analysis. 

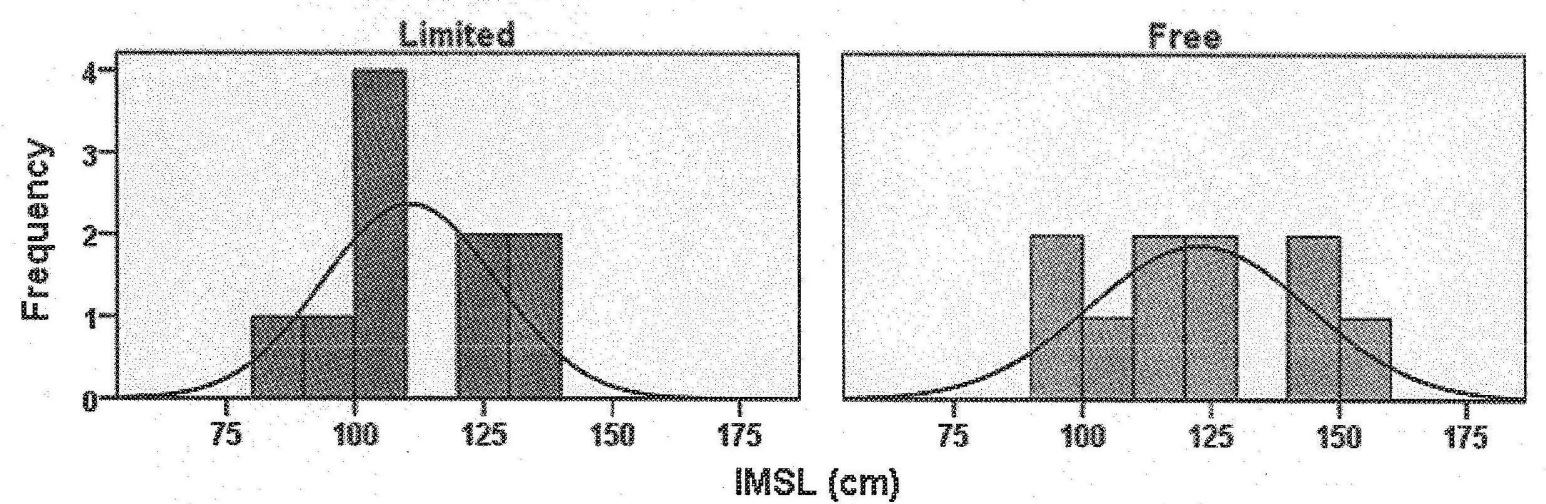

Figure 3.1.2: Length of Maximum Step Length (IMSL) Test Results Distribution

The increase in the step length with the free arm movements suggests that there is an increase in the region of the comfort and perhaps the region of stability during the step. This may be attributed to the increased readiness and comfort which allows the person to take the bigger step as well as to the improved lateral balance needed during the task of stepping forward.

\section{Speed of Maximum Step Length (sMSL) Test}

The study shows that participants achieved the biggest improvements with free arm use on the speed of Maximum Step Test (sMST). The speed parameter was computed from the distance and time measures. The average speed (sMST) increased by $21 \mathrm{~cm} / \mathrm{sec}(40 \%)$ when arms were used freely $(t=3.199, p<0.011)$.

Table 3.1.9: Mean Differences between Speed of Maximum Step Test (sMST) Test Obtained with Limited and Free Arm Movements

\begin{tabular}{|l|c|c|c|c|}
\hline sMST & $\begin{array}{c}\text { Limited Arm } \\
\text { Movements }\end{array}$ & $\begin{array}{c}\text { Free Arm } \\
\text { Movements }\end{array}$ & t-test & $\begin{array}{c}\text { Sig. } \\
\text { (2-tailed) }\end{array}$ \\
\hline Mean Step Speed $(\mathrm{cm} / \mathrm{sec}$ ) & 42.92 & 64.1274 & -3.199 & .011 \\
\hline
\end{tabular}


Table 3.1.10: Speed of Maximum Step Length (sMST) Test: Descriptive Statistics

\begin{tabular}{|l|c|c|c|c|}
\hline \multirow{2}{*}{ Statistic (cm/sec) } & \multicolumn{2}{|c|}{ Limited Arm Movements } & \multicolumn{2}{|c|}{ Free Arm Movements } \\
\cline { 2 - 5 } & Statistic & Std. Error & Statistic & Std. Error \\
\hline Mean & 42.924 & 5.8247 & 64.127 & 11.9831 \\
95\% C.I., Lower Bound & 29.748 & & 37.020 & \\
95\% C.I., Upper Bound & 56.101 & & 91.235 & \\
5\% Trimmed Mean & 42.448 & & 62.408 & \\
Median & 39.207 & & 53.817 & \\
Variance & 339.276 & & 1435.943 & \\
Std. Deviation & 18.4194 & & 37.8938 & \\
Minimum & 19.6 & & 23.4 & \\
Maximum & 74.9 & & 135.8 & \\
Range & 55.3 & & 112.4 & \\
Interquartile Range & 24.6 & & 58.5 & \\
Skewness & .944 & .687 & .895 & .687 \\
Kurtosis & .046 & 1.334 & -.214 & 1.334 \\
\hline
\end{tabular}

Table 3.1.11: Distribution Normality for Speed of Maximum Step Length (sMST) Test

\begin{tabular}{|c|l|c|c|c|c|c|c|}
\hline \multirow{2}{*}{} & \multirow{2}{*}{ Test type } & \multicolumn{3}{|c|}{ Kolmogorov-Smimov } & \multicolumn{3}{|c|}{ Shapiro-Wilk } \\
\cline { 2 - 8 } & Statistic & df & Sig. & Statistic & df & Sig. \\
\hline \multirow{2}{*}{ Limited Arm } & $\begin{array}{l}\text { Movements } \\
\text { Free Arm } \\
\text { Movements }\end{array}$ & .201 & 10 & .200 & .881 & 10 & .134 \\
& & .186 & 10 & .200 & .903 & 10 & .238 \\
\hline
\end{tabular}

Table 3.1.12: Test of Homogeneity of Variance for Speed of Maximum Step Length (sMST) Test

\begin{tabular}{|l|c|c|c|c|}
\hline SMST & Levene Statistic & $\mathrm{d} 1$ & $\mathrm{dI}$ & Sig. \\
\hline Based on Mean & 4.866 & 1 & 18 & .041 \\
Based on Median & 3.714 & 1 & 18 & .070 \\
Based on Median and with adjusted df & 3.714 & 1 & 13.673 & .075 \\
Based on trimmed mean & 4.481 & 1 & 18 & .048 \\
\hline
\end{tabular}

The Kolmogorov-Smimov and Shapiro-Wilk tests (Table 3.1.11) indicate that the sMST test results are normally distributed. Another test (Table 3.1.12) shows that the variance of the sMST results has a small tendency towards non-homogeneity. Less restrictive tests based on the 
median and adjusted median show that the variance is homogenous. Exploratory analysis shows that some participants had a vast increase in speed which contributed to the differences variance.
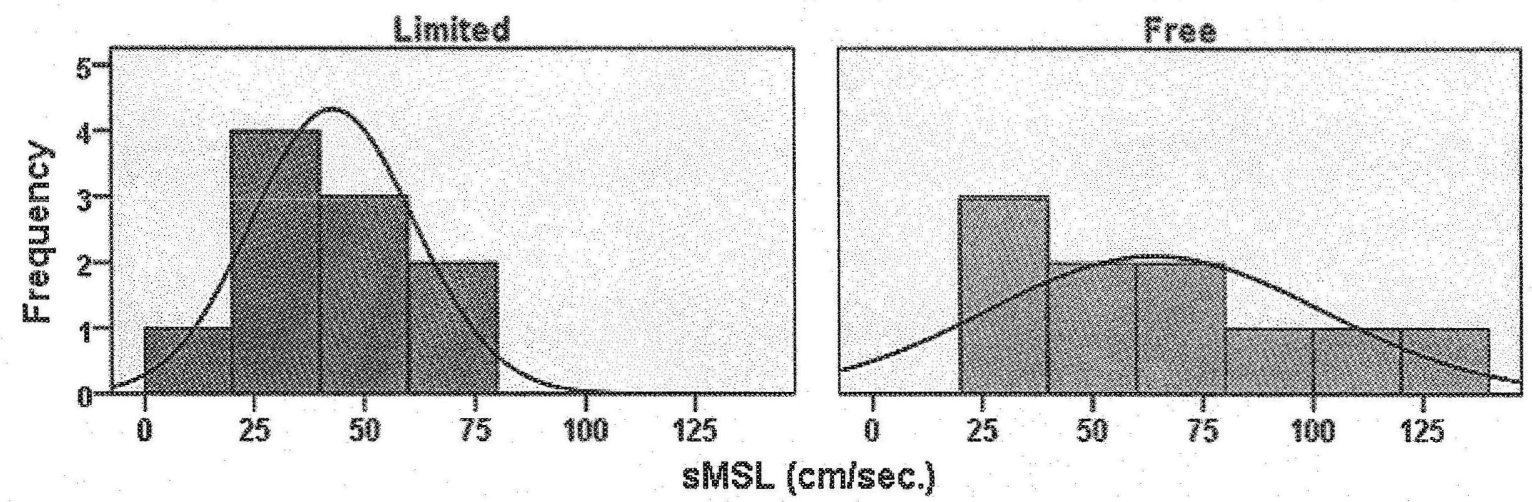

Figure 3.1.3: Speed of Maximum Step Length (sMSL) Test Results Distribution

Since the speed of the Maximum Step Test (sMSL) improves the most when arms are used freely, it is likely that therapeutic programs for balance rehabilitation can improve mobility and balance, and minimize the risk of falls through improving their speed on the MSL test. This finding also emphasizes the need for risk assessment and valid diagnostics of dynamic postural balance and the effects of arm movements during balancing tasks, since the arm movements have a significant effect on the outcomes of the MSL test performance.

\section{Step Test (ST)}

The Step Test (ST) requires participants to stand on one leg, $5 \mathrm{~cm}$ from an $8.5-\mathrm{cm}$ high block positioned against a wall. Participants were required to step on and off the block (with both feet, one at a time) as many times as possible during the 15 seconds period, and the number of steps was noted by the investigator. The ST shows (Table 3.1.13) an average increase of 3.6 steps $(29.8 \%)$ during the fifteen seconds period $(t=-3.478, p<0.007)$ with the free arm use. 
Table 3.1,13: Mean differences between the number of steps on the Step Test (ST) Obtained with Limited and Free Arm Movements

\begin{tabular}{|l|c|c|c|c|}
\hline ST & $\begin{array}{c}\text { Limited Arm } \\
\text { Movements }\end{array}$ & $\begin{array}{c}\text { Free Arm } \\
\text { Movements }\end{array}$ & t-test & $\begin{array}{c}\text { Sig. } \\
\text { (2-tailed) }\end{array}$ \\
\hline Mean number of steps & 12.10 & 15.70 & -3.478 & .007 \\
\hline
\end{tabular}

Table 3.1.14: Time on the Rapid Step Test (ST): Descriptive Statistics

\begin{tabular}{|l|c|c|c|c|}
\hline \multirow{2}{*}{ Statistic (steps) } & \multicolumn{3}{|c|}{ Limited Arm Movements } & \multicolumn{2}{c|}{ Free Arm Movements } \\
\cline { 2 - 5 } & Statistic & Std. Error & Statistic & Std. Error \\
\hline Mean & 12.10 & .823 & 15.70 & 1.713 \\
$95 \%$ C.I., Lower Bound & 10.24 & & 11.82 & \\
95\% C.I., Upper Bound & 13.96 & & 19.58 & \\
5\% Trimmed Mean & 12.00 & & 15.22 & \\
Median & 11.50 & & 14.00 & \\
Variance & 6.767 & & 29.344 & \\
Std. Deviation & 2.601 & & 5.417 & \\
Minimum & 9 & & 11 & \\
Maximum & 17 & & 29 & \\
Range & 8 & & 18 & \\
Interquartile Range & 4 & & 7 & \\
Skewness & 1.000 & .687 & 1.794 & .687 \\
Kurtosis & .154 & 1.334 & 3.984 & 1.334 \\
\hline
\end{tabular}

Table 3.1.15: Distribution Normality for Time on the Rapid Step Test (ST)

\begin{tabular}{|l|l|c|c|c|c|c|c|}
\hline \multirow{2}{*}{} & & \multicolumn{3}{|c|}{ Kolmogorov-Smirnov } & \multicolumn{3}{|c|}{ Shapiro-Wilk } \\
\cline { 2 - 8 } & Test type & Statistic & df & Sig. & Statistic & df & Sig. \\
\hline \multirow{2}{*}{ RS } & $\begin{array}{l}\text { Limited Arm } \\
\text { Movements }\end{array}$ & .215 & 10 & $.200^{*}$ & .892 & 10 & .178 \\
& $\begin{array}{l}\text { Free Arm } \\
\text { Movements }\end{array}$ & .236 & 10 & .123 & .796 & 10 & .013 \\
\hline
\end{tabular}

Table 3.1.16: Test of Homogeneity of Variance for Time on the Rapid Step Test (ST)

\begin{tabular}{|l|c|c|c|c|}
\hline RS & Levene Statistic & df1 & df2 & Sig. \\
\hline Based on Mean & 2.322 & 1 & 18 & .145 \\
Based on Median & 1.158 & 1 & 18 & .296 \\
Based on Median and with adjusted df & 1.158 & 1 & 11.917 & .303 \\
Based on trimmed mean & 2.027 & 1 & 18 & .172 \\
\hline
\end{tabular}


The Kolmogorov-Smirnov and Shapiro-Wilk tests (Table 3.1.15) indicate that the RS tests results also follow normal distribution. Another test (Table 3.1.16) shows that variance of the ST results is homogeneous and satisfies the condition for doing the t-test analysis.
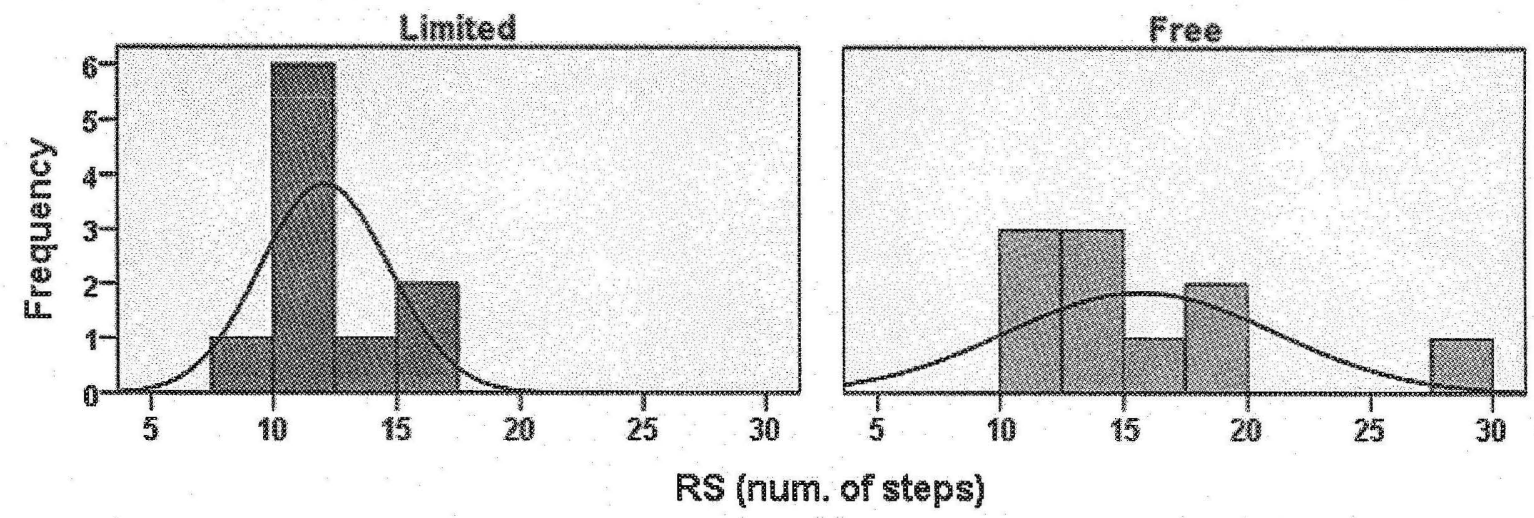

Figure 3.1.4: Time on the Rapid Step Test (ST) Results Distribution

Many studies have shown that rapid stepping has a significant impact on balance through the change of support reactions as a balance recovery mechanism (e.g. Maki, et al., 1996). Hence the RS test is important to examine with regards to balance and falls prevention. The results demonstrate that free or improved arm movement can increase the rapid stepping abilities that have been associated with a lower risk of falling (Maki et al., 1994a). These findings also suggest that arm movements can decrease the risk of falls thought rapid stepping reaction improvements.

\section{Timed Up and Go (TUG) Test}

The Timed, Up, and Go Test (TUG) requires participants to quickly and safely stand up from a chair, walk 3 meters forward, turn around, go back to original position and sit down on the chair. The Timed Up and Go Test (TUG) showed an average speed increase of 0.73 seconds (11.2\%) with free arm usage. As Table 3.1 .17 shows, this difference is statistically significant $(t=3.803, p<0.004)$. 
Table 3.1.17: Mean differences between the time on TUG test obtained with Limited and Free Arm Movements

\begin{tabular}{|l|c|c|c|c|}
\hline TUG & $\begin{array}{c}\text { Limited Arm } \\
\text { Movements }\end{array}$ & $\begin{array}{c}\text { Free Arm } \\
\text { Movements }\end{array}$ & -test & $\begin{array}{c}\text { Sig. } \\
\text { (2-tailed) }\end{array}$ \\
\hline Mean TUG Speed (sec.) & 6.54 & 5.81 & 3.803 & .004 \\
\hline
\end{tabular}

Table 3.1.18: Time on the Timed Up and Go Test (TUG): Descriptive Statistics

\begin{tabular}{|l|c|c|c|c|}
\hline \multirow{2}{*}{ TUG (sec.) } & \multicolumn{3}{|c|}{ Limited Arm Movements } & \multicolumn{2}{c|}{ Free Arm Movements } \\
\cline { 2 - 5 } & Statistic & Std. Error & Statistic & Std. Error \\
\hline Mean & 6.5410 & .43465 & 5.8140 & .29681 \\
$95 \%$ C.I., Lower Bound & 5.5578 & & 5.1426 & \\
$95 \%$ C.I., Upper Bound & 7.5242 & & 6.4854 & \\
$5 \%$ Trimmed Mean & 6.4861 & & 5.7861 & \\
Median & 6.1400 & & 5.7200 & \\
Variance & 1.889 & & .881 & \\
Std. Deviation & 1.37449 & & .93858 & \\
Minimum & 5.04 & & 4.44 & \\
Maximum & 9.03 & & 7.69 & \\
Range & 3.99 & & 3.25 & \\
Interquartile Range & 2.39 & & 1.37 & \\
Skewness & .725 & .687 & .638 & .687 \\
Kurtosis & -.732 & 1.334 & .528 & 1.334 \\
\hline
\end{tabular}

Table 3.1.19: Distribution Normality for Time on the Timed Up and Go Test (TUG)

\begin{tabular}{|c|l|c|c|c|c|c|c|}
\hline \multirow{2}{*}{} & \multirow{2}{*}{ Test type } & \multicolumn{3}{|c|}{ Kolmogorov-Smirnov } & \multicolumn{3}{c|}{ Shapiro-Wilk } \\
\cline { 2 - 8 } & Statistic & df & Sig. & Statistic & df & Sig. \\
\hline \multirow{2}{*}{ LUmited Arm } & $\begin{array}{l}\text { Movements } \\
\text { Free Arm } \\
\text { Movements }\end{array}$ & .210 & 10 & $.200^{*}$ & .908 & 10 & .267 \\
Movem & .131 & 10 & $.200^{*}$ & .973 & 10 & .917 \\
\hline
\end{tabular}

Table 3.1.20: Test of Homogeneity of Variance for TUG Test

\begin{tabular}{|l|c|c|c|c|}
\hline TUG & Levene Statistic & df1 & df2 & Sig. \\
\hline Based on Mean & 2.142 & 1 & 18 & .161 \\
Based on Median & 1.619 & 1 & 18 & .219 \\
Based on Median and with adjusted df & 1.619 & 1 & 15.871 & .222 \\
Based on trimmed mean & 1.993 & 1 & 18 & .175 \\
\hline
\end{tabular}


According to the Kolmogorov-Smirnov and Shapiro-Wilk tests (Table 3.1.18) the TUG test responses follow the normal distribution. Another test (Table 3.1.20) shows that variance of the TUG results are homogeneous and satisfies the condition for doing the t-test analysis.

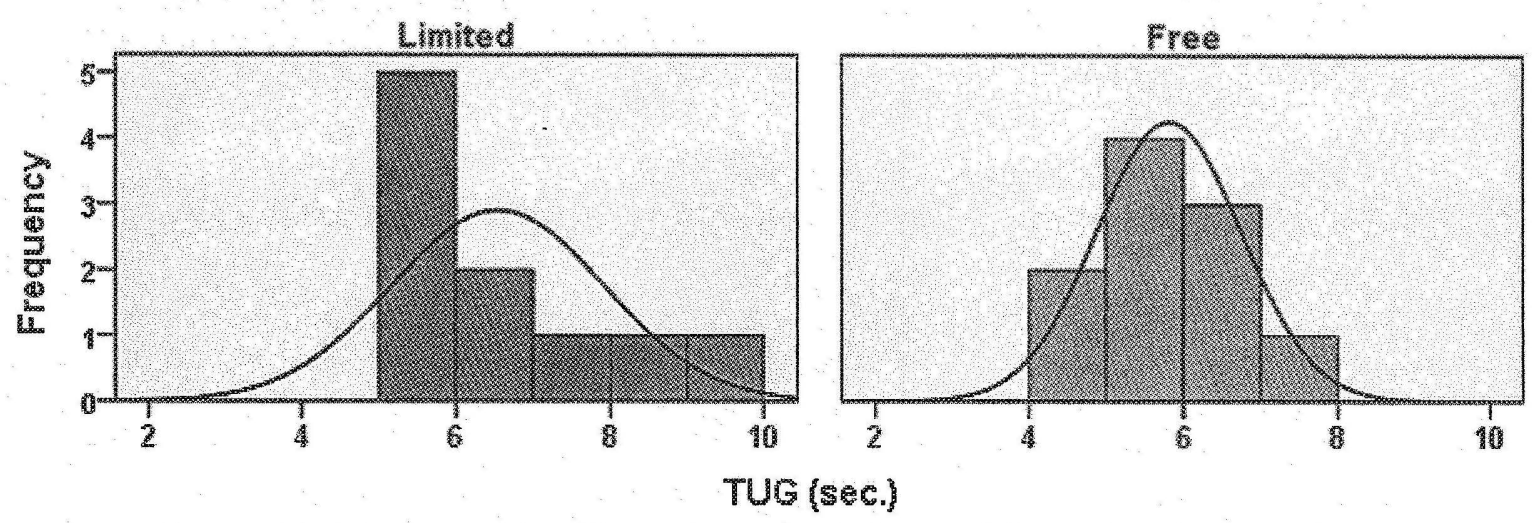

Figure 3.1.5: Time on the Timed Up and Go Test (TUG): Results Distribution

The results show that arm movements have a significant impact on the ability to perform sequential locomotor tasks that incorporate walking and turning tasks (Morris, Morris \& lansek, 2001). In this way the arm movements may positively be contributing to the decreased likelihood of falling (Morris, Morris \& lansek, 2001) through examining dynamic common tasks in the TUG test.

\section{Walk along an Elliptical Line (WEL):}

The Walk along an Elliptical Line (WEL) test requires the participants to walk along the perimeter of an ellipse marked on the floor and stop when they return to the original starting position. The test (Table 3.1.21) gave no conclusive results $(t=1.101, p<0.300)$ although there is a trend showing increased walking speed. 
Table 3.1.21: Mean differences between the time on the WEL obtained with Limited and Free Arm Movements

\begin{tabular}{|l|c|c|c|c|}
\hline WEL & $\begin{array}{c}\text { Limited Arm } \\
\text { Movements }\end{array}$ & $\begin{array}{c}\text { Free Arm } \\
\text { Movements }\end{array}$ & t-test & $\begin{array}{c}\text { Sig. } \\
\text { (2-tailed) }\end{array}$ \\
\hline Mean WEL Speed (sec.) & 7.16 & 6.78 & 1.101 & .300 \\
\hline
\end{tabular}

Table 3.1.22: Time on the Walk along Elliptical Line Test (WEL): Descriptive Statistics

\begin{tabular}{|l|c|c|c|c|}
\hline \multirow{2}{*}{ Statistic (sec.) } & \multicolumn{2}{|c|}{ Limited Arm Movements } & \multicolumn{2}{|c|}{ Free Arm Movements } \\
\cline { 2 - 5 } & Statistic & Std. Error & Statistic & Std. Error \\
\hline Mean & 7.1610 & .18439 & 6.7760 & .28629 \\
$95 \%$ C.I., Lower Bound & 6.7439 & & 6.1284 & \\
95\% C.I., Upper Bound & 7.5781 & & 7.4236 & \\
5\% Trimmed Mean & 7.1300 & & 6.8628 & \\
Median & 7.2200 & & 7.0050 & \\
Variance & .340 & & .820 & \\
Std. Deviation & .58310 & & .90532 & \\
Minimum & 6.50 & & 4.40 & \\
Maximum & 8.38 & & 7.59 & \\
Range & 1.88 & & 3.19 & \\
Interquartile Range & .93 & & .75 & \\
Skewness & .767 & .687 & -2.335 & .687 \\
Kurtosis & .869 & 1.334 & 6.236 & 1.334 \\
\hline
\end{tabular}

Table 3.1.23: Distribution Normality for Time on the Walk along Elliptical Line Test (WEL)

\begin{tabular}{|l|l|c|c|c|c|c|c|}
\hline \multirow{2}{*}{} & \multirow{2}{*}{ Test type } & \multicolumn{3}{|c|}{ Kolmogorov-Smimov } & \multicolumn{3}{|c|}{ Shapiro-Wilk } \\
\cline { 2 - 8 } WEL & Statistic & df & Sig. & Statistic & df & Sig. \\
\hline \multirow{3}{*}{ Limited Arm } & .149 & 10 & $.200 *$ & .912 & 10 & .296 \\
& $\begin{array}{l}\text { Movements } \\
\text { Free Arm } \\
\text { Movements }\end{array}$ & .259 & 10 & .055 & .734 & 10 & .002 \\
\hline
\end{tabular}

Exploratory analysis of the WEL test and Kolmogorov-Smirnov and Shapiro-Wilk tests (Table 3.1.23) shows that the distribution of the results achieved on this test with limited arms is normally distributed while distribution of test results with free arm movements is significantly different from normal distribution. Graphical representation of the results shows greater variability of the free arm movements on the WEL test and increased standard error (Table 3.1.22) that might have contributed to the inconclusive result for the WEL test. 


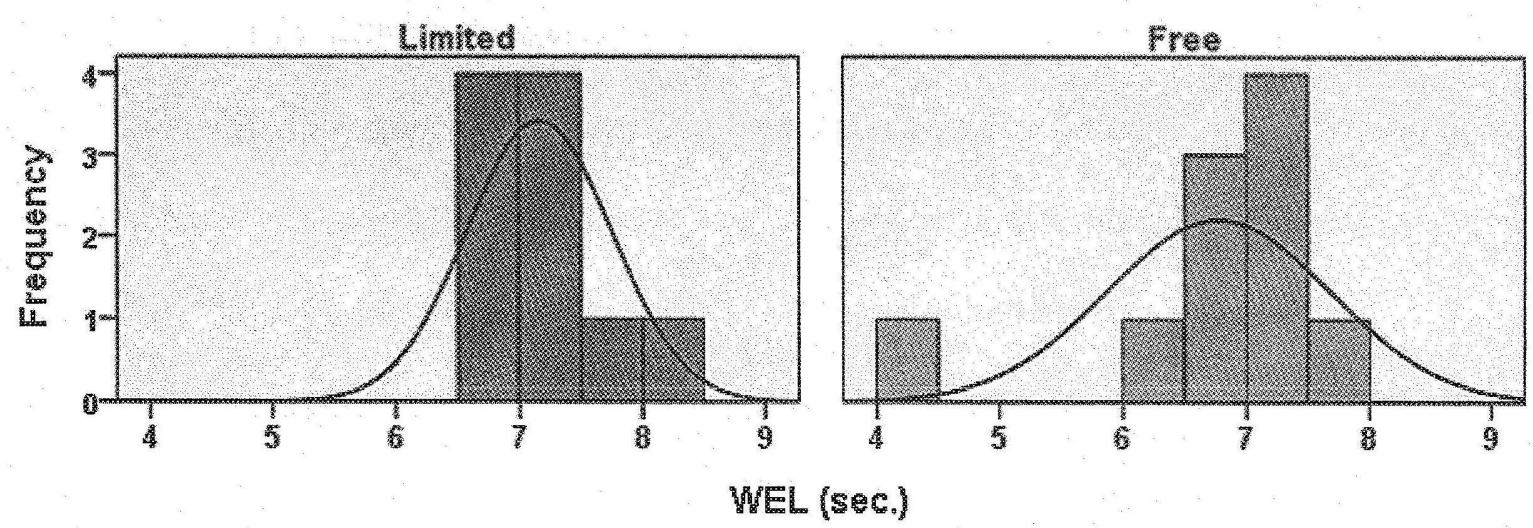

Figure 3.1.6: Time on the Walk along Elliptical Line Test (WEL) Results Distribution

The lack of difference between performance on the WEL test with limited and free arm movements could be explained by the fact that the walking test is not sensitive enough to detect the changes of the effects of arms. Similarly it can be argued that the test gait speed is not significantly affected by the arm movements as measured by the WEL test.

\section{Concluding Remarks: Impact of Arm Movements on Classic Balance Tests}

The paired sample t-test analysis for each of the classic balance tests, which compares the performance during restricted arm use (the arms against the body) and free arm use, shows significant improvements in regard to the average performance on five out of the six classic balance tests (Figure 3.1.7). In summary, the results show that the average step time (tMSL) decreased by 0.47 seconds $(16.4 \%)$ with the free arm movements $(t=3.217, p<0.011)$ and that the step length (IMSL) increased by $12 \mathrm{~cm}(10.8 \%)$ when arms were allowed to move $(t=-5.840$, $\mathrm{p}<0.001)$. The speed on the MSL test also had the biggest improvements $(40 \%)$ when arms were used $(t=-3.199, p<0.011)$. The Step Test (ST) also shows an increase of 3.6 steps $(29.8 \%)$ during a fifteen second period $(t=3.478, p<0.007)$, and the Timed Up and Go Test (TUG) showed a time increase of 0.73 seconds $(11.2 \%)$ with active arm usage $(t=3.803, p<0.004)$. 
The results achieved on these tests suggest increased performance on the standard balance tests and better balancing abilities with active arm usage. The results suggest a higher speed, better confidence and readiness as well as the increase in the stability regions and balance, as indicated by the performed tests results. The Walk along an Elliptical Line (WEL) Test gave no conclusive results $(t=1.101, p<0.300)$ although it showed a trend towards a higher speed of performance.

Table 3.1.24: Mean differences between results on Standard Balance tests obtained with Limited and Free Arm Movements (t-tests)

\begin{tabular}{|l|c|c|c|c|}
\hline & $\begin{array}{c}\text { Limited Arm } \\
\text { Movements (Mean) }\end{array}$ & $\begin{array}{c}\text { Free Arm } \\
\text { Movements (Mean) }\end{array}$ & t-test & $\begin{array}{c}\text { Sig. } \\
\text { (2-tailed) }\end{array}$ \\
\hline MSL Time (sec.) & 2.87 & 2.40 & 3.217 & .011 \\
MSL Distance (cm.) & 110.70 & 122.70 & -5.840 & .001 \\
MSL Speed & 42.92 & 64.13 & -3.199 & .011 \\
ST (steps) & 12.10 & 15.70 & -3.478 & .007 \\
TUG (sec.) & 6.54 & 5.81 & 3.803 & .004 \\
WLL (sec.) & 7.16 & 6.78 & 1.101 & .300 \\
\hline
\end{tabular}

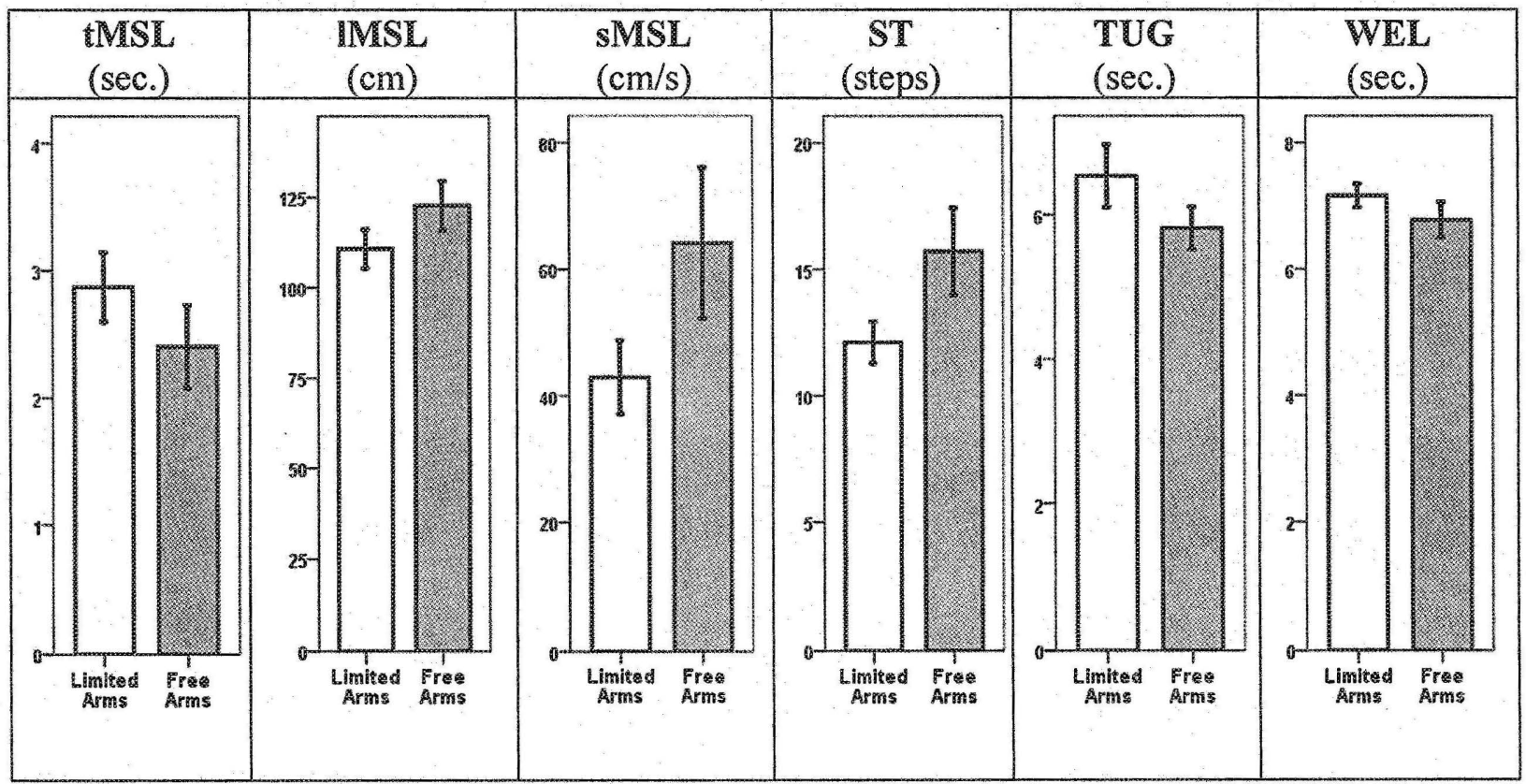

Figure 3.1.7: Classic Balance tests with Limited and Free Arm Movements: Means and Standard Errors Plot. 
The results of the achieved increase in performance on the classic balance tests with free arms show that arm movements have a significant impact on the maintenance of balance during balancing tasks. These results provide a strong indication that diagnostic and training of postural balance can improve maintenance of postural balance during activities of daily living and can decrease the risk of falls. These findings indicate the need to further examine the specific actions of the arm movements during balancing and their impacts on the trunk (CoM) movements. 


\subsection{Classic Balance Tests and Trunk Movements (CoM)}

A growing number of studies that use electromyographic, video, accelerometeric and force-plate measurements show that arm and trunk movements have significant impacts on postural balance (Allum et al., 2002; Yamazaki et al., 2005). These studies usually require the use of complex and expensive laboratory equipment suitable for experimental study, but less applicable for studying activities during daily living out of a laboratory environment. One objective of my study is to determine the impact of arm movements on postural balance using portable accelerometer-based instruments.

Comparisons of performance on the majority of the classic balance tests using limited and free arm movements presented in the previous section shows significantly improved performance with free use of arms. Arm movements have been shown to have a significant impact on trunk movements (Yamazaki et al., 2005); my study further examines these associations to determine the effects of arm movements on dynamic postural balance strategies.

To explore the role of arm movements on different systems of dynamic balance maintenance, my study examines the associations between classic balance tests performed with limited and free arm movements and the magnitude of the centre of mass movements (CoM VMU).

\section{Time on Maximum Step Length (tMSL) Test}

Correlation analysis (Table 3.2.1) shows a significant association between movements of the centre of mass (CoM) with the time on the Maximum Step Length (tMSL) test. The associations between CoM and tMSL with limited $(r=-0.812, P<0.01)$ and free $(r=-0.774, P<0.01)$ arm movements are significant and show that participants who achieve a shorter time on the tMSL test have a greater magnitude of CoM movement. 
Table 3.2.1 Correlations between Results on the Time on Maximum Step Length (tMSL) Test and Trunk Movements with Limited and Free Arm Movements

\begin{tabular}{|l|c|c|}
\hline Correlations & CoM VMU & $\begin{array}{c}\text { Sigo } \\
\text { (two-tailed) }\end{array}$ \\
\hline tMSL with Limited Arm Movements & $-.812^{* *}$ & .004 \\
\hline tMSL with Free Arm Movements & $-.774 * *$ & .009 \\
\hline
\end{tabular}

Legend: ** Correlation significant at the 0.01 (two-tailed); * at the 0.05 level (two-tailed).

Scatterplots (Figure 3.2.1) show a similar intensity of associations between CoM movements and the time on the MSL. Comparison of the scatterplots shows faster performance on the MSL test with free arm use.
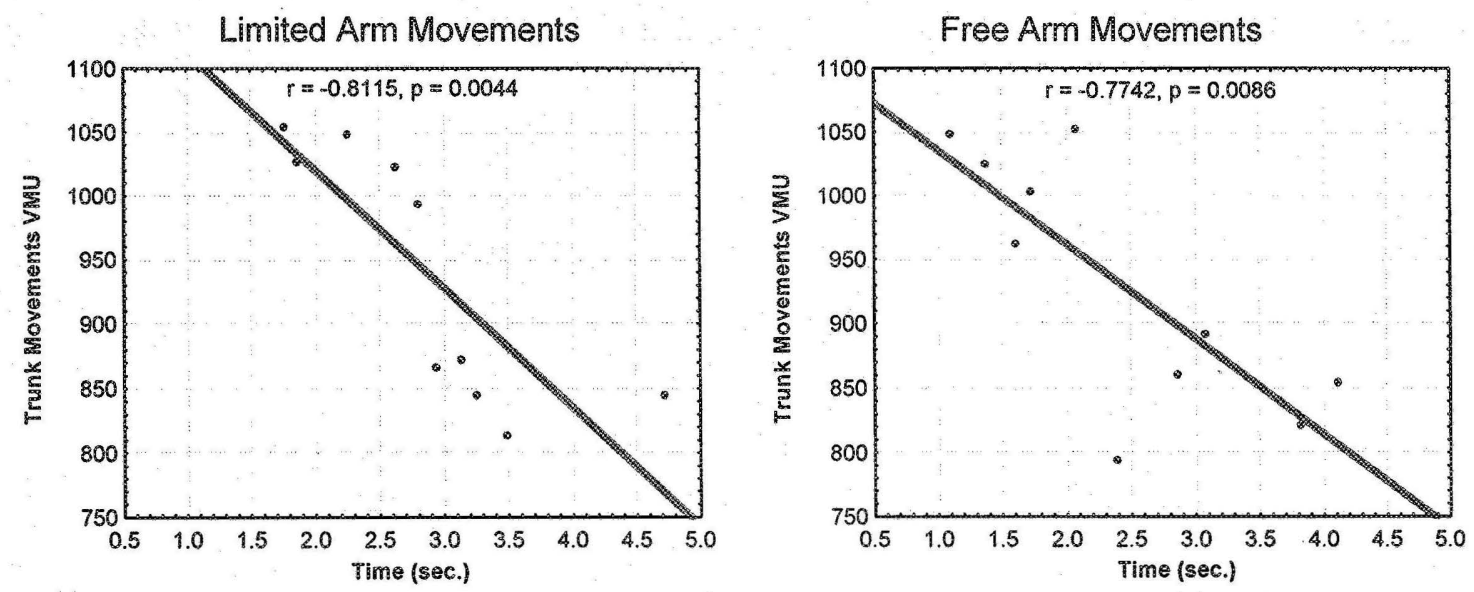

Figure 3.2.1 Scatterplot of Results on the Time on Maximum Step Length (tMSL) Test and Trunk Movements with Limited and Free Arm Movements.

The results show that CoM movements have a significant association with the MSL test. The results indicate that free arm movements during balancing tasks improve CoM mobility and its control.

\section{Length of Maximum Step Length (IMSL) Test}

In addition to the shorter MSL time, correlation analysis (Table 3.2.2) shows a significant association between movements of the centre of mass $(\mathrm{CoM})$ and the time on the Maximum Step Length (IMSL) test. The analysis shows that the association between CoM and IMSL with free 
arm movements $(r=0.745, P<0.01)$ is significant. The analysis shows that there is no statistically significance correlation between CoM with limited arm movements.

Table 3.2.2 Correlations between Results on the Length of Maximum Step Length (IMSL) Test and Trunk Movements with Limited and Free Arm Movements.

\begin{tabular}{|l|c|c|}
\hline Correlations & CoM VMU & $\begin{array}{c}\text { Sig. } \\
\text { (two-tailed) }\end{array}$ \\
\hline IMSL with Limited Arm Movements & .609 & .062 \\
\hline IMSL with Free Arm Movements & $.745^{*}$ & .013 \\
\hline
\end{tabular}

Legend: ** Correlation significant at the 0.01 (two-tailed); * at the 0.05 level (two-tailed).

Scatterplots (Figure 3.2.2) show that participants increased the length of the MSL test from a range of 80 to $140 \mathrm{~cm}$ when performing it with limited arms, to a range of 90 to $160 \mathrm{~cm}$ when using their arms freely.
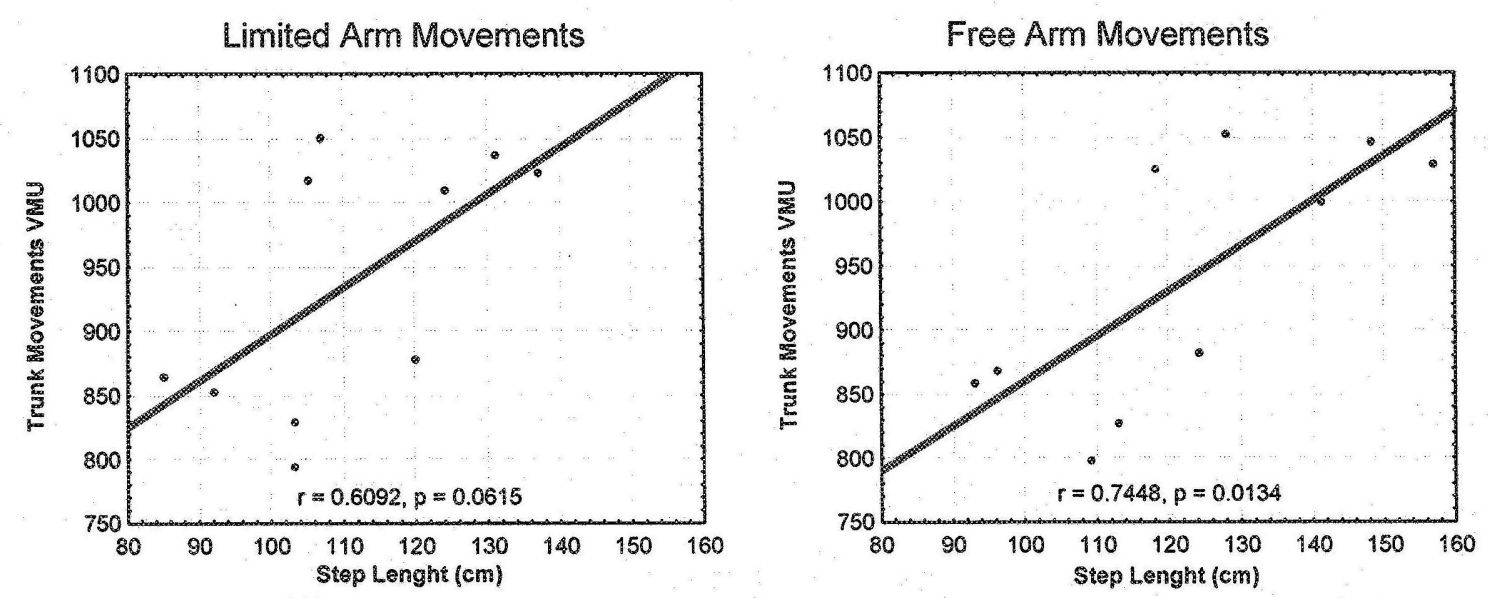

Figure 3.2.2 Correlations between Results on the Length of Maximum Step Length (IMSL)

Test and Trunk Movements with Limited and Free Arm Movements.

These results show that arm movements contribute to increased mobility, which is an important component of postural balance.

\section{Speed of Maximum Step Length (sMSL) Test}

Correlation analysis (Table 3.2.3) shows significant associations between movements of the centre of mass (CoM) and Speed on the Maximum Step Length (sMSL) Test. The associations between CoM and SMSL with limited $(r=0.756, P<0.011)$ and free $(r=0.809$, 
$\mathrm{P}<0.005)$ arm movements are significant and show that participants who achieve greater speed on the sMSL test have greater magnitude of CoM movements. The analysis also shows that this association is stronger when participants used their arms freely.

Table 3.2.3: Correlations between the Speed of Maximum Step Length (sMSL) Test and Trunk Movements with Limited and Free Arm Movements.

\begin{tabular}{|l|c|c|}
\hline Correlations & CoM VMU & $\begin{array}{c}\text { Sig. } \\
\text { (two-tailed) }\end{array}$ \\
\hline sMSL with Limited Arm Movements & $.756^{*}$ & .011 \\
\hline sMSL with Free Arm Movements & $.809^{* *}$ & .005 \\
\hline
\end{tabular}

Legend: ** Correlation significant at the 0.01 (two-tailed); * at the 0.05 level (two-tailed).

Scatterplots (Figure 3.2.3) show the greatest improvements with free arm use on the speed of the Maximum Step Test (sMST). These results are consistent with those comparing the mean speed increase in the previous section (Table 3.1.9).
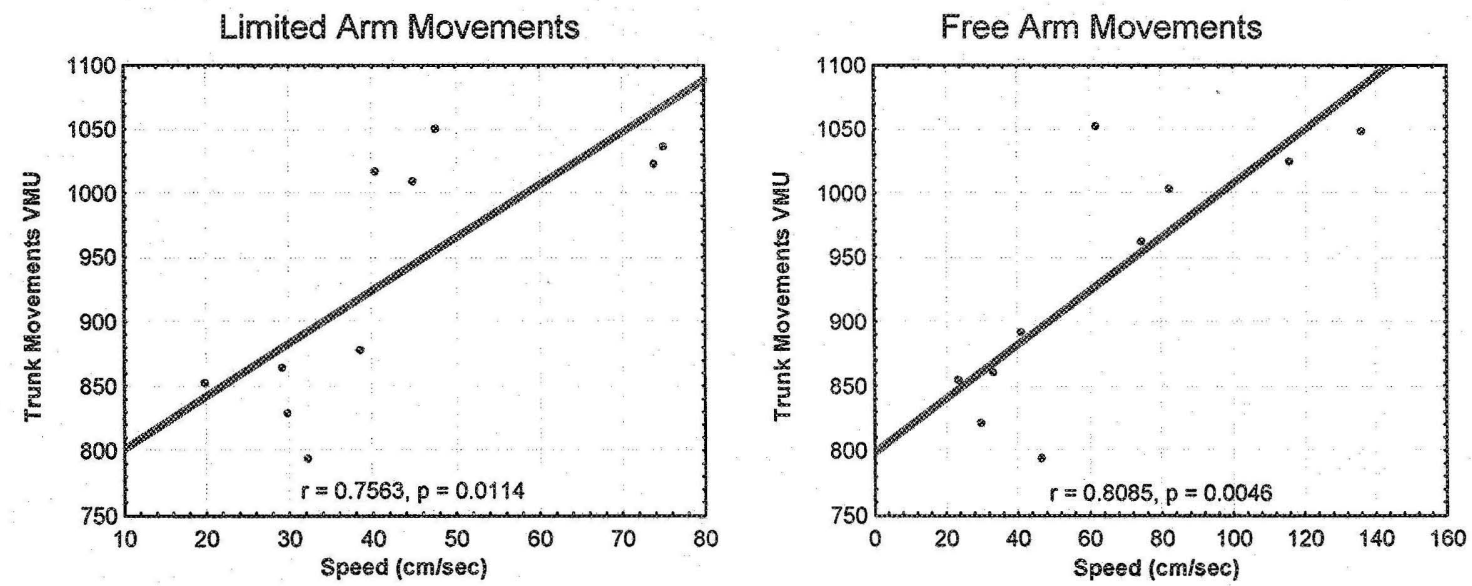

Figure 3.2.3: Scatterplot of Results on the Speed of Maximum Step Length (sMSL) Test and Trunk Movements (CoM VMU) with Limited and Free Arm Movements.

In summary, the results show that CoM movements have a significant association with the speed of the MSL test, and indicate that speed significantly determines participants' mobility and postural balance (Cho, Scarpace \& Alexander, 2004). The results provide strong indications that arm movements contribute to an improved speed of ambulation and CoM mobility, and can hence decrease the risk of falls. This finding is relevant for balance rehabilitation programs and for usual daily activities, particularly among the elderly and people with impaired balance. 
Step Test (ST)

Correlation analysis (Table 3.2.4) shows that associations between movements of the centre of mass $(\mathrm{CoM})$ and the Step Test $(\mathrm{ST})$ with limited $(r=-0.812, \mathrm{P}<0.01)$ and free $(r=-0.774$, $\mathrm{P}<0.01)$ arm movements are not statistically significant.

Table 3.2.4: Correlations between the Step Test (ST) and Trunk Movements with Limited and Free Arm Movements.

\begin{tabular}{|l|c|c|}
\hline Correlations & CoM VMU & $\begin{array}{c}\text { Sig. } \\
\text { (two-tailed) }\end{array}$ \\
\hline RS with Limited Arm Movements & -.273 & n.s. \\
\hline RS with Free Arm Movements & -.299 & n.s. \\
\hline
\end{tabular}

Legend: ** Correlation significant at the 0.01 (two-tailed); * at the 0.05 level (two-tailed).

Scatterplots (Figure 3.2.4) show an increased number of steps when arms are used freely. Such a great variability increase could be one of the reasons for the lack of significant associations. However, these results require further investigation.
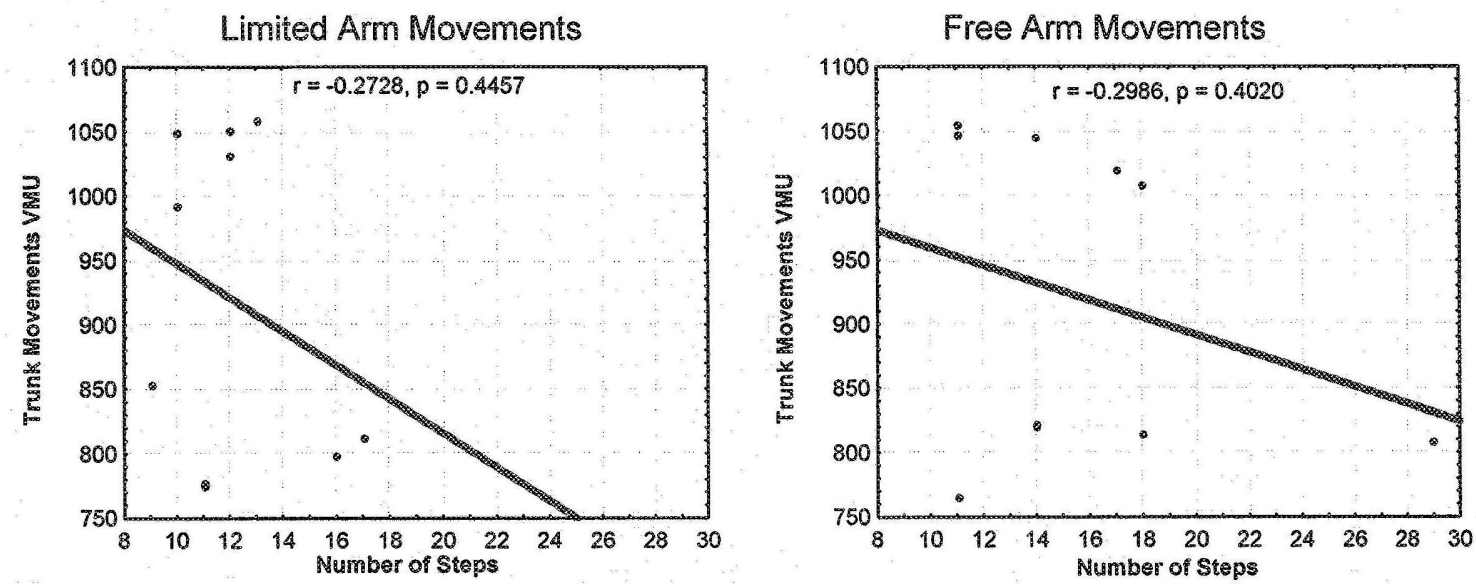

Figure 3.2.4: Scatterplot of Results on the Step Test (ST) and Trunk Movements (CoM VMU) with Limited and Free Arm Movements.

The results show that CoM movements are not significantly associated with the Step Test (ST), indicating that increased CoM mobility is not significantly associated with rapid stepping tasks. Despite the lack of statistical significance, stepping reactions are very important in 
everyday life as well as in falls prevention, as shown by Maki \& Mcllroy (2006). However, it can be argued that stepping reactions are less influenced by CoM dynamics.

\section{Timed Up and Go (TUG) Test}

Correlation analysis (Table 3.2.5) shows a significant association between movements of the centre of mass (CoM) and the Timed Up and Go (TUG) test. The associations between CoM and the TUG test with limited $(r=0.831, P<0.003)$ and free $(r=0.814, P<0.004)$ arm movements are significant and show that participants who achieve shorter times on the TUG test have greater magnitudes of CoM movements.

Table 3.2.5: Correlations between the Timed Up and Go (TUG) Test and Trunk Movements with Limited and Free Arm Movements.

\begin{tabular}{|l|c|c|}
\hline Correlations & CoM VMU & $\begin{array}{c}\text { Sig. } \\
\text { (two-tailed) }\end{array}$ \\
\hline TUG with Limited Arm Movements & $.831^{* *}$ & .003 \\
\hline TUG with Free Arm Movements & $.814^{* *}$ & .004 \\
\hline
\end{tabular}

Legend: ** Correlation significant at the 0.01 (two-tailed); $*$ at the 0.05 level (two-tailed).

Scatterplots (Figure 3.2.5) show decreased time for the TUG test with free arm movements and significant associations between CoM movements and the time on TUG test performance in both arm movement situations.
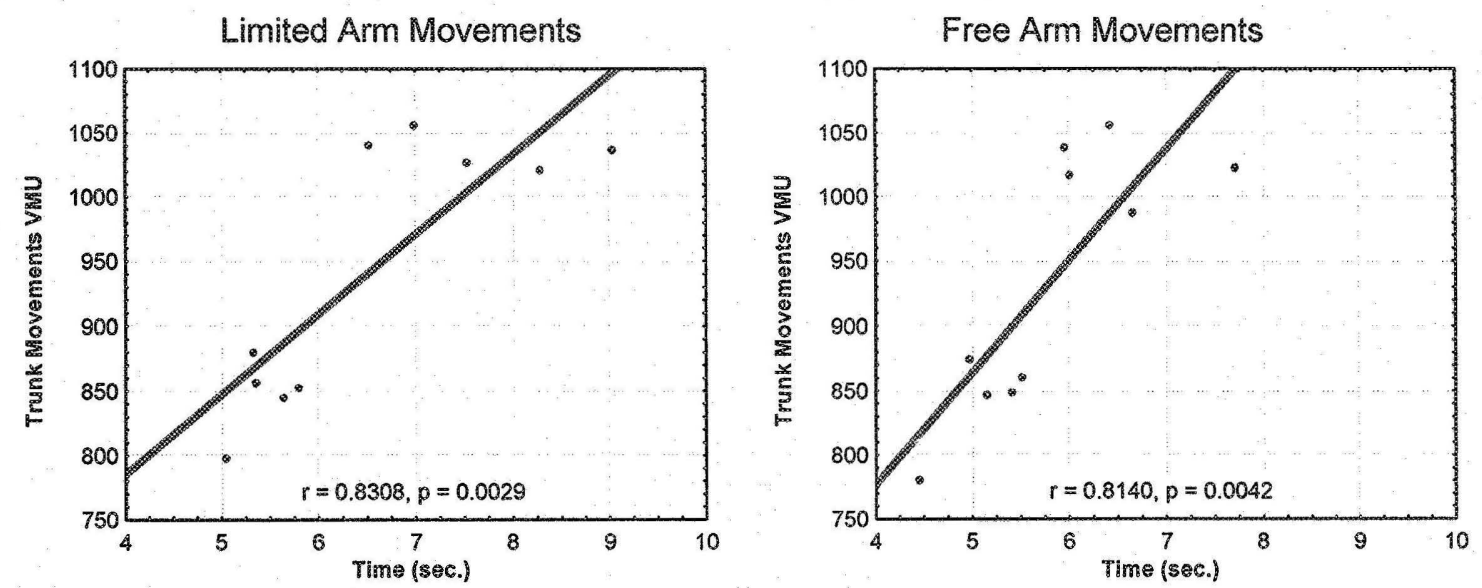

Figure 3.2.5: Scatterplot of Results on the Timed Up and Go Test (TUG) and Trunk Movements with Limited and Free Arm Movements. 
These results show that the magnitude of CoM movements is significantly associated with the TUG test, which measures the ability to perform sequential locomotor tasks like walking and turning more effectively (Morris, Morris \& Iansek, 2001). They also show the increased speed of the TUG test and more homogenous results that indicate the possibility for improving dynamic postural balance.

\section{Concluding remarks: Associations between Arm movements and CoM}

Through the application of accelerometer-based tests, it is possible to examine balance maintenance on a balance board, as well as the specific impact of arm movements on the movements of the centre of mass $(\mathrm{CoM})$. This section discusses the associations that were found between classic balance tests and the magnitude of CoM movements, as well as indications that the magnitude of CoM movements increases when participants use arms freely during balancing tasks. The results suggest that arm movements contribute to the increased magnitude of trunk movements, which are required to adjust the centre of mass to the base of support, most likely through an increased counterbalancing mechanism. The greater control of trunk speed and the rigidity of trunk movements were also shown to be significant determinants of postural balance (Maki \& Mcliroy, 1994, 2006; Allum et al., 2002; Yamazaki et al., 2005).

It has been shown thus far that arm movements have a positive impact on postural balance and CoM dynamics. Now, specific arm movement mechanisms and strategies during dynamic balance remain to be examined in more detail.

The next section will investigate the mechanisms of arm movements specifically for balance maintenance and recovery and the role of arm dominance in dynamic balance. 


\subsection{Balance Board Tests and Arm Movements Tests}

The objective of this part of my study is to determine the role that arm movements play during maintenance of dynamic balance. Furthermore, this section examines the impact of arm movements on balance, with specific emphasis on arm dominance in balance maintenance during different balancing tasks.

\section{Arm Movements during Complex (CBB) Balance Board Test}

Analysis of the magnitude of accelerations for arm movements during balancing tasks (Table 3.3.1), based on a one-way ANOVA, shows that the average magnitude of arm movements (VMU) are different and statistically significant $(F=133.829, \mathrm{P}<0.001)$. Further analysis using a two-way ANOVA shows that the interaction between arm movements during stable and recovery periods for both dominant and non-dominant arms are statistically significant $(\mathrm{F}=10.776, \mathrm{P}<0.001)$.

A comparison of stable and recovery regions during balancing tasks (Table 3.3.1) that includes both arms (recovery regions for left and right and stable regions for left and right arm movements) shows that these summarized measures are not statistically significant ( $F=8.936$, n.s.). Also, a comparison of arm movements that summarizes the averages for recovery and stable periods is not statistically significant $(\mathrm{F}=27.405$, n.s. $)$.

In summary, this analysis shows that the average magnitude of arm acceleration is significant, while comparisons of aggregated data for regions of balance or aggregated data for arm movements and non-dominant arms are not significant. 
Table 3.3.1 Analysis Variance for Arms Acceleration (VMU) during Periods of Stable and Balance Recovery during the CBB Test

\begin{tabular}{|l|c|c|}
\hline Analysis & $\mathbf{F}$ & Sig. \\
\hline One-Way ANOVA & 133.829 & 0.001 \\
\hline Two-Way ANOVA & $\mathbf{F}$ & Sig. \\
\hline Regions & 8.936 & $.206-$ n.s. \\
\hline Arms & 27.405 & $.120-$ n.s. \\
\hline Interaction Regions x Arms & 10.776 & 0.001 \\
\hline
\end{tabular}

Analysis of the results of arm movements during the complex balance board (CBB) test (Table 3.3.2) shows that the non-dominant arm has a greater average acceleration than the dominant arm during both recovery and stable periods. During periods of balance recovery, the dominant arm exerts greater average motion (VMU=3.91) than during stable periods (VMU =3.82). Conversely, during balance recovery, the non-dominant arm makes slightly greater average movements $(V M U=4.00)$ than during periods of stable balance $(V M U=3.96)$.

Table 3.3.2: Magnitude of Movements of Dominant and Non-dominant Arm Acceleration during the CBB Test

\begin{tabular}{|l|l|c|}
\hline Region & Arm & Mean VMU \\
\hline Stable & Right (dominant) & 3.82 \\
\cline { 2 - 3 } & Left & 3.96 \\
\hline \multirow{2}{*}{ Recovery } & Right (dominant) & 3.91 \\
\cline { 2 - 3 } & Left & 4.00 \\
\hline
\end{tabular}

In addition to differences between averages of arm movements, the analysis shows an apparent variability in the movements of both dominant and non-dominant arms during the $\mathrm{CBB}$ test (Table 3.3.3). Levene's Test for Equality of Variances shows that:

- Variance of dominant arm movements during both stable ( 0.3456 vs. 0.1866 , Levene's Test $\mathrm{F}=955.345 * * *)$ and recovery $(0.2579$ vs. 0.1966, Levene's Test $\mathrm{F}=39.099 * * *)$ periods is significantly greater than that for the non-dominant arm.

- Variance of dominant arm movements during stable (.3456) periods is greater than variance of movements during recovery periods $(0.2579$, Levene's $\mathrm{Test} F=351.941 * * *)$. 
- By contrast, variance of non-dominant arm movements is similar in both recovery (.1866) and stable $\left(.1966\right.$, Levene's Test $\left.F=1.158^{n . s}\right)$ periods of balancing tasks.

Table 3.3.3: Variability of Acceleration of Dominant and Non-dominant Arms for the CBB Test

\begin{tabular}{|l|l|c|}
\hline Region & Arm & S.D. VMU \\
\hline Stable & Right (dominant) & .3457 \\
\cline { 2 - 3 } & Left & .1866 \\
\hline \multirow{2}{*}{ Recovery } & Right (dominant) & .2579 \\
\cline { 2 - 3 } & Left & .1966 \\
\hline
\end{tabular}

The graphical representation of variations during balancing tasks on the complex balance board (Figure 3.3.1) visibly demonstrates the greater variability in the movement of the dominant than the non-dominant arm. The same graph also shows that during balance recovery, the overall movements for both arms slightly increase compared to the stable balance periods.

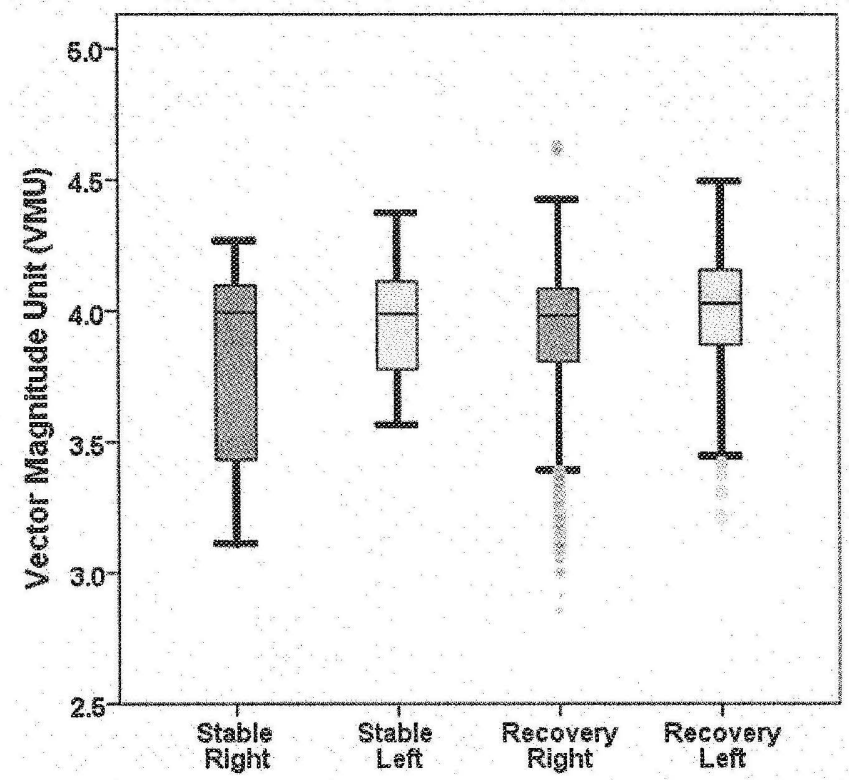

Figure 3.3.1: Variability of Dominant and Non-dominant Arms for the CBB Test.

\section{Individual Arm Movements Strategies during the CBB Test}

Further analyses were conducted for each individual participant by examining their arm movement dynamics (e.g. Figure 3.3.2) and the effects on the stability scores. The stability 
scores were computed by examining the percentage of balance time in the stable region. It is considered that better performance means longer stable periods of balance maintenance during the test.

Interpretations of the arm movement dynamics include the comparison of intensity of movements (VMU) for dominant and non-dominant arms in the stable and recovery regions. The analysis also includes comparisons of variability of movements and coordination between dominant and non-dominant arms.

A series of analyses of the arm movements during the Complex Balance Board (CBB) Test shows that participants who used both arms equally during the recovery and stable phases achieved better results (Subjects A1, A2 and A3). The analysis also shows that in order to achieve better results, the greater overall use of arms is beneficial.

As the results from Subject A4 show, it seems that greater discrepancy between dominant and non-dominant arm movements, as well as a low intensity of arm movements during the stable period, lead to less efficient control of dynamic balance during complex balance tasks. Overall, these results indicate that, as long as both arms perform coordinated movements to a similar extent and as such cancel out the moments, the outcomes for complex dynamic postural balance are better.

The subsequent results are for the CBB test and arm movement dynamics for each of the participants (Subject A1-A4) that were discussed in the preceding interpretation. 


\section{Subject A1}

One-way Analysis of Variance (ANOVA) and Tukey's Test for Mean Differences

Table 3.3.4: Descriptive Statistics

\begin{tabular}{|l|l|l|l|l|}
\hline & N & Mean & S.D. & Std. Error \\
\hline Recovery/Right & 171 & 3.881282 & .1144714 & .0087538 \\
\hline Recovery/Left & 171 & 4.170343 & .0679784 & .0051984 \\
\hline Stable/Right & 447 & 3.875901 & .1872514 & .0088567 \\
\hline Stable/Left & 447 & 4.156603 & .1184147 & .0056008 \\
\hline Total & 1236 & 4.018897 & .2005704 & .0057050 \\
\hline
\end{tabular}

Table 3.3.5: Post Hoc Tests (Tukey HSD)

\begin{tabular}{|l|l|l|l|l|}
\hline (I) Arm/Region & (J) Arm/Region & Mean (I-J) & Std. Error & Sig. \\
\hline Recovery/Right & Recovery/Left & $-.2890608^{*}$ & .0153765 & .000 \\
& Stable/Right & .0053805 & .0127844 & .975 \\
& Stable/Left & $-.2753210^{*}$ & .0127844 & .000 \\
\hline Recovery/Left & Recovery/Right & $.2890608^{*}$ & .0153765 & .000 \\
& Stable/Right & $.2944413^{*}$ & .0127844 & .000 \\
& Stable/Left & .0137398 & .0127844 & .705 \\
\hline Stable/Right & Recovery/Right & -.0053805 & .0127844 & .975 \\
& Recovery/Left & $-.2944413^{*}$ & .0127844 & .000 \\
& Stable/Left & $-.2807016^{*}$ & .0095104 & .000 \\
\hline Stable/Left & Recovery/Right & $.2753210^{*}$ & .0127844 & .000 \\
& Recovery/Left & -.0137398 & .0127844 & .705 \\
& Stable/Right & $.2807016^{*}$ & .0095104 & .000 \\
\hline
\end{tabular}

\section{Stability Score $=72.3 \%$}

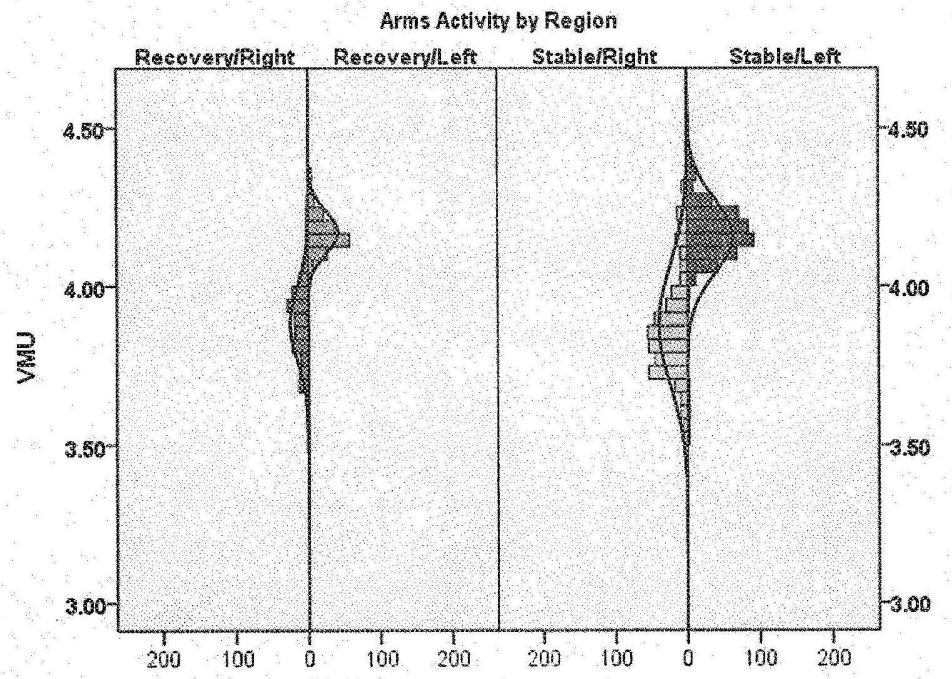

Figure 3.3.2: Arm Dynamics Histogram by Balance Regions for Subject A1 - CBB Test. 


\section{Subject A2}

One-way Analysis of Variance (ANOVA) and Tukey's Test for Mean Differences

Table 3.3.6: Descriptive Statistics

\begin{tabular}{|l|l|l|l|l|}
\hline & $\mathrm{N}$ & Mean & S.D. & Std. Error \\
\hline Recovery/Right & 540 & 4.042552 & .0650279 & .0027984 \\
\hline Recovery/Left & 540 & 3.760526 & .1099008 & .0047294 \\
\hline Stable/Right & 430 & 4.036467 & .0696446 & .0033586 \\
\hline Stable/Left & 430 & 3.806747 & .1081854 & .0052172 \\
\hline Total & 1940 & 3.910435 & .1588142 & .0036057 \\
\hline \multicolumn{5}{|c}{ ANOVA, F $=1340.685, \mathrm{P}<0.001$} \\
\end{tabular}

Table 3.3.7: Post Hoc Tests (Tukey HSD)

\begin{tabular}{|l|l|l|l|l|}
\hline (I) Arm/Region & (J) Arm/Region & Mean (I-J) & Std. Error & Sig. \\
\hline Recovery/Right & Recovery/Left & $.2820267^{*}$ & .0055137 & .000 \\
& Stable/Right & .0060857 & .0058557 & .726 \\
& Stable/Left & $.2358055^{*}$ & .0058557 & .000 \\
\hline Recovery/Left & Recovery/Right & $-.2820267^{*}$ & .0055137 & .000 \\
& Stable/Right & $-.2759410^{*}$ & .0058557 & .000 \\
& Stable/Left & $-.0462212^{*}$ & .0058557 & .000 \\
\hline Stable/Right & Recovery/Right & -.0060857 & .0058557 & .726 \\
& Recovery/Left & $.2759410^{*}$ & .0058557 & .000 \\
& Stable/Left & $.2297198^{*}$ & .0061788 & .000 \\
\hline Stable/Left & Recovery/Right & $-.2358055^{*}$ & .0058557 & .000 \\
& Recovery/Left & $.0462212^{*}$ & .0058557 & .000 \\
& Stable/Right & $-.2297198^{*}$ & .0061788 & .000 \\
\hline
\end{tabular}

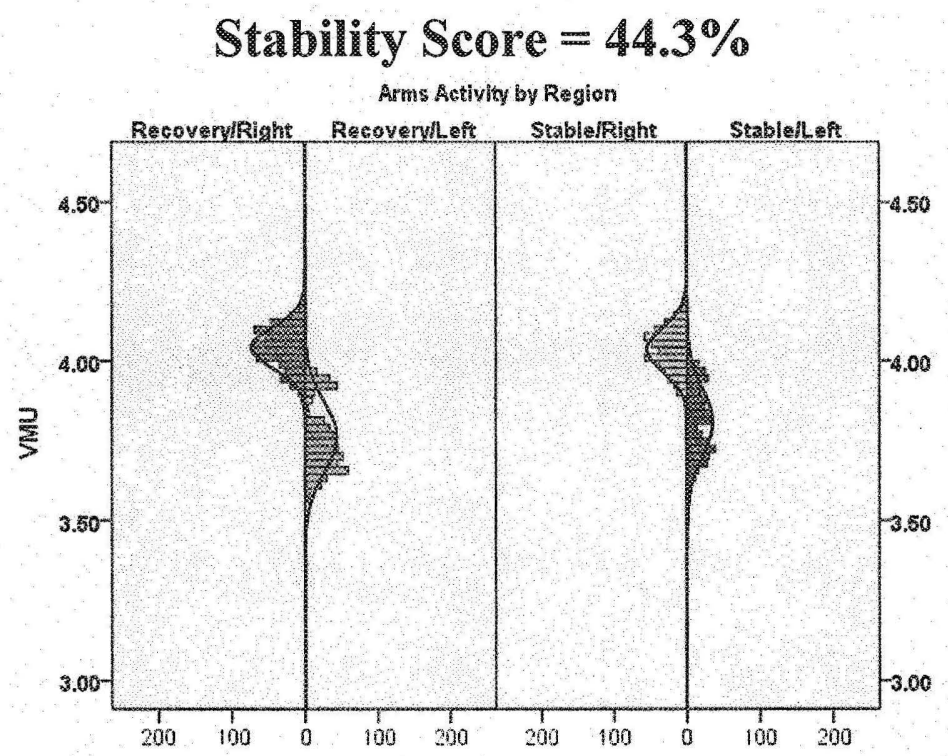

Figure 3.3.3: Arm Dynamics Histogram by Balance Regions for Subject A2 - CBB Test. 


\section{Subject A3}

One-way Analysis of Variance (ANOVA) and Tukey's Test for Mean Differences

Table 3.3.8: Descriptive Statistics

\begin{tabular}{|l|l|l|l|l|}
\hline & $\mathrm{N}$ & Mean & S.D. & Std. Error \\
\hline Recovery/Right & 250 & 4.135635 & .0311414 & .0019696 \\
\hline Recovery/Left & 250 & 3.994599 & .0415613 & .0026286 \\
\hline Stable/Right & 354 & 4.061048 & .0981867 & .0052186 \\
\hline Stable/Left & 354 & 3.979211 & .1703314 & .0090530 \\
\hline Total & 1208 & 4.038750 & .1240746 & .0035698 \\
\hline \multicolumn{5}{c}{ ANOVA, F $=119.561, \mathrm{P}<0.001$} \\
\end{tabular}

Table 3.3.9: Post Hoc Tests (Tukey HSD)

\begin{tabular}{|l|l|l|l|l|}
\hline (I) Arm/Region & (J) Arm/Region & Mean (I-J) & Std. Error & Sig. \\
\hline Recovery/Right & Recovery/Left & $.1410364 *$ & .0097532 & .000 \\
& Stable/Right & $.0745872 *$ & .0090084 & .000 \\
& Stable/Left & $.1564245^{*}$ & .0090084 & .000 \\
\hline Recovery/Left & Recovery/Right & $-.1410364 *$ & .0097532 & .000 \\
& Stable/Right & $-.0664492 *$ & .0090084 & .000 \\
& Stable/Left & .0153881 & .0090084 & .320 \\
\hline Stable/Right & Recovery/Right & $-.0745872 *$ & .0090084 & .000 \\
& Recovery/Left & $.0664492 *$ & .0090084 & .000 \\
& Stable/Left & $.0818373 *$ & .0081962 & .000 \\
\hline Stable/Left & Recovery/Right & $-.1564245^{*}$ & .0090084 & .000 \\
& Recovery/Left & -.0153881 & .0090084 & .320 \\
& Stable/Right & $-.0818373 *$ & .0081962 & .000 \\
\hline
\end{tabular}

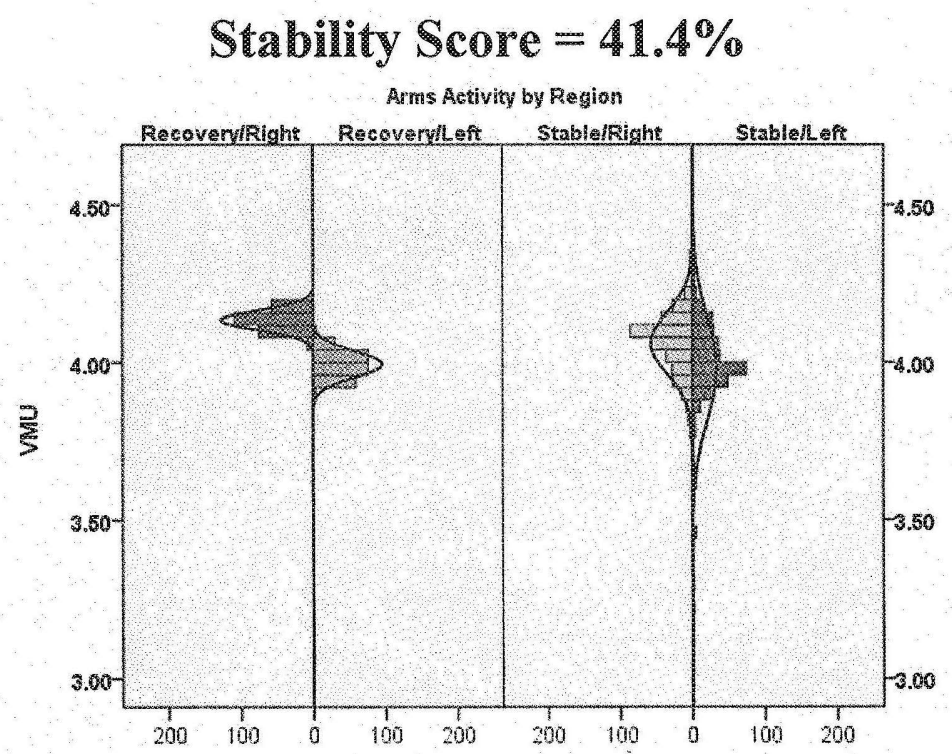

Figure 3.3.4: Arm Dynamics Histogram by Balance Regions for Subject A3 - CBB Test. 


\section{Subject $\mathbf{A} 4$}

One-way Analysis of Variance (ANOVA) and Tukey's Test for Mean Differences

Table 3.3.10: Descriptive Statistics

\begin{tabular}{|l|l|l|l|l|}
\hline & $\mathrm{N}$ & Mean & S.D. & Std. Error \\
\hline Recovery/Right & 427 & 3.325114 & .0984962 & .0047666 \\
\hline Recovery/Left & 427 & 4.101250 & .0798737 & .0038654 \\
\hline Stable/Right & 180 & 3.378546 & .1887353 & .0140675 \\
\hline Stable/Left & 180 & 4.132644 & .1217304 & .0090732 \\
\hline Total & 1214 & 3.725759 & .4021014 & .0115405 \\
\hline \multicolumn{5}{|c}{ ANOVA, F $=4578.225, \mathrm{P}<0.001$} \\
\end{tabular}

Table 3.3.11: Post Hoc Tests (Tukey HSD)

\begin{tabular}{|l|l|l|l|l|}
\hline (I) Arm/Region & (J) Arm/Region & Mean (I-J) & Std. Error & Sig. \\
\hline Recovery/Right & Recovery/Left & $-.7761368^{*}$ & .0078401 & .000 \\
& Stable/Right & $-.0534320^{*}$ & .0101804 & .000 \\
& Stable/Left & $-.8075303^{*}$ & .0101804 & .000 \\
\hline Recovery/Left & Recovery/Right & $.7761368^{*}$ & .0078401 & .000 \\
& Stable/Right & $.7227048^{*}$ & .0101804 & .000 \\
& Stable/Left & $-.0313935^{*}$ & .0101804 & .011 \\
\hline Stable/Right & Recovery/Right & $.0534320^{*}$ & .0101804 & .000 \\
& Recovery/Left & $-.7227048^{*}$ & .0101804 & .000 \\
& Stable/Left & $-.7540983^{*}$ & .0120754 & .000 \\
\hline Stable/Left & Recovery/Right & $.8075303^{*}$ & .0101804 & .000 \\
& Recovery/Left & $.0313935^{*}$ & .0101804 & .011 \\
& Stable/Right & $.7540983^{*}$ & .0120754 & .000 \\
\hline
\end{tabular}

Stability Score $=29.6 \%$

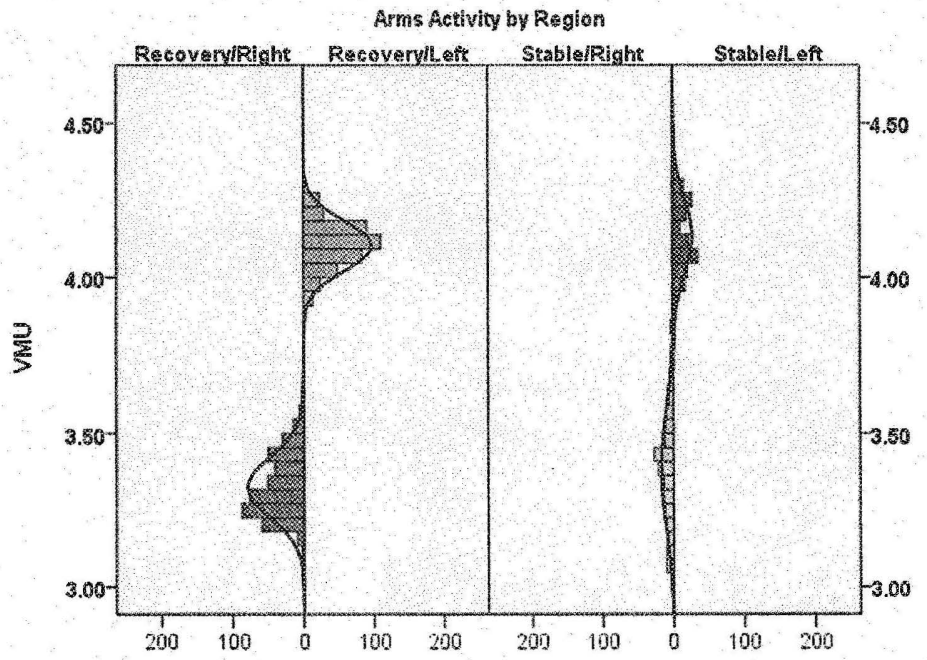

Figure 3.3.5: Arm Dynamics Histogram by Balance Regions for Subject A4 - CBB Test. 


\section{Arm Activity during Anterior-Posterior (AP) Balance Board Test}

In the analysis of variance (Table 3.3.12), a one-way ANOVA shows that the overall mean differences are statistically significant $(\mathrm{F}=36.366, \mathrm{P}<0.001)$. A more specific, two-way ANOVA indicates that interaction differences for both arms during different balancing regions are significant $(F=92.108, \mathrm{P}<0.001)$, while comparing aggregated arm movements that do not reflect the specific phase or period of balance maintenance is not statistically significant.

Table 3.3.12 Analysis Variance for Arms Acceleration (VMU) during Periods of Stable and Periods of Balance Recovery during the AP Test

\begin{tabular}{|l|c|c|}
\hline Analysis & Sig. \\
\hline One-Way ANOVA & 36.366 & .001 \\
\hline Two-Way ANOVA & F & Sig. \\
\hline Regions & .064 & $.842-$ n.s \\
\hline Arms & .388 & $.645-$ n.s \\
\hline Interaction Regions x Arms & 92.108 & .001 \\
\hline
\end{tabular}

Analysis of the results evaluating the magnitude of arm acceleration during the AP balance board test (Table 3.3.14) shows that the dominant arm (VMU=3.74) applies lower acceleration during periods of balance recovery than the non-dominant arm (VMU=3.93). Contrarily, during periods of stable balance on the anterior-posterior test the dominant arm applies a slightly higher acceleration (VMU =3.89) than the non-dominant arm $(V M U=3.88)$.

Arm movements during the stable phase of the anterior-posterior balance board test yield slightly contradictory results to those of all other tests. This finding requires further attention through similar studies examining the anterior-posterior balance mechanisms.

Table 3.3.14 Magnitude of Movements of Dominant and Non-dominant Arm Acceleration during the AP Test

\begin{tabular}{|l|l|c|}
\hline Region & Arm & Mean VMU \\
\hline Stable & Right (dominant) & 3.89 \\
\cline { 2 - 3 } & Left & 3.84 \\
\hline \multirow{2}{*}{ Recovery } & Right (dominant) & 3.74 \\
\cline { 2 - 3 } & Left & 3.93 \\
\hline
\end{tabular}


Similarly, both the dominant and non-dominant arms during the anterior-posterior balance board test (Table 3.3.15) show relatively small variability of movements. Levene's Test for Equality of Variances shows that:

- Variance of dominant arm movements during both stable (.4200 vs. .3818 , Levene's Test F= $\left.17.563^{* * *}\right)$ and recovery (.4037 vs. .3748 , Levene's Test $\left.\mathrm{F}=39.31 .027^{* * *}\right)$ periods is significantly greater than variance of movements for the non-dominant arm.

- Variance of dominant arm movements during the stable (.4200) period is greater than that of movements during the recovery period $\left(.4037\right.$ Levene's Test $\left.\mathrm{F}=1.010^{\text {n.s. }}\right)$.

- By contrast, the variance of non-dominant arm movements is similar in both stable (.3818) and recovery $\left(.3748\right.$, Levene's Test $\left.\mathrm{F}=17.114^{\mathrm{n} . \mathrm{s}}\right)$ periods.

Despite the fact that these differences are relatively small, three out of four tests confirmed that they exist at a statistically significant level.

Table 3.3.15: Variability of Acceleration of Dominant and Non-dominant Arms for the AP Test

\begin{tabular}{|l|l|c|}
\hline Region & Arm & S.D. VMU \\
\hline \multirow{2}{*}{ Stable } & Right (dominant) & .4200 \\
\cline { 2 - 3 } & Left & .3818 \\
\hline \multirow{2}{*}{ Recovery } & Right (dominant) & .4037 \\
\cline { 2 - 3 } & Left & .3748 \\
\hline
\end{tabular}

The graphical representation of variations during balancing tasks on the AP balance board test (Figure 3.3.6) demonstrates the greater variability of acceleration of the dominant arm than of the non-dominant arm during the recovery periods, implying greater control by the dominant arm. The graph also shows that there is no significant difference during the stable phase between dominant and non-dominant arm acceleration. 


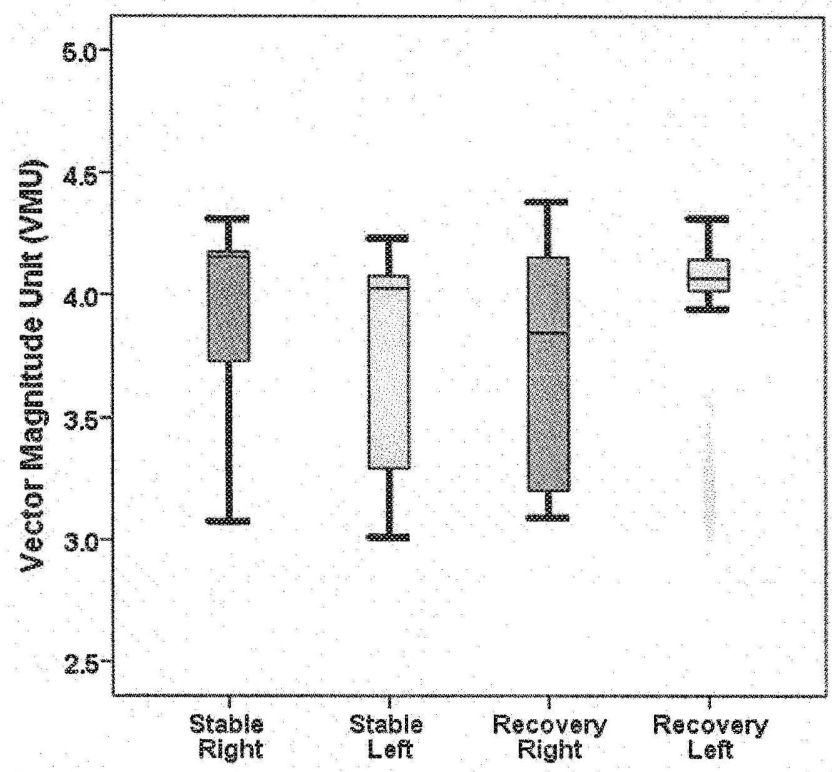

Figure 3.3.6: Variability of Dominant and Non-dominant Arms for the AP Test.

\section{Individual Arm Movements Strategies during the AP Test}

The results from the Anterior-Posterior (AP) Balance Board Test are to some extent different than those from the complex and lateral balance board tests, but also show some similar tendencies.

The best results were achieved by the participants who exerted a similar intensity of movements with both dominant and non-dominant arms (Subjects B1 and B2). Also, better results were attained by those who used their arms to a similar extent during both balance phases (Subjects B2 and B1).

Worse results were achieved by the participants with a greater discrepancy between dominant and non-dominant arm movement intensity (Subjects B3 and B4), possibly by the induced momentum shifts. Also, the respondents who had difficulty maintaining anteriorposterior balance showed a greater discrepancy of arm movements during recovery and stable phases of balance (Subjects B4 and B3). 
The worst results on the AP balance board test were achieved by the subject with the lowest intensity of arm movements during both phases of balancing tasks (Subject B4). In addition to low intensity, the same subject also demonstrated a visible difference between the magnitude of dominant and non-dominant arm movements, as well as a greater difference between arm movements during different phases of balance maintenance.

The subsequent results are for the AP test and arm movement dynamics for each of the participants (Subject B1-B4) that were discussed in the preceding interpretation. 


\section{Subject B1}

One-way Analysis of Variance (ANOVA) and Tukey's Test for Mean Differences

Table 3.3.16: Descriptive Statistics

\begin{tabular}{|l|l|l|l|l|}
\hline & $\mathrm{N}$ & Mean & S.D. & Std. Error \\
\hline Recovery/Right & 305 & 3.828339 & .0862435 & .0049383 \\
\hline Recovery/Left & 305 & 4.138364 & .0514050 & .0029434 \\
\hline Stable/Right & 325 & 3.764605 & .1259580 & .0069869 \\
\hline Stable/Left & 325 & 4.181533 & .0522299 & .0028972 \\
\hline Total & 1260 & 3.978047 & .2032829 & .0057268 \\
\hline
\end{tabular}

ANOVA $F=1977.924, P<0.001$

Table 3.3.17: Post Hoc Tests (Tukey HSD)

\begin{tabular}{|l|l|l|l|l|}
\hline (I) Arm/Region & (D) Arm/Region & Mean (I-J) & Std. Error & Sig. \\
\hline Recovery/Right & Recovery/Left & $-.3100249^{*}$ & .0068884 & .000 \\
& Stable/Right & $.0637338^{*}$ & .0067816 & .000 \\
& Stable/Left & $-.3531945^{*}$ & .0067816 & .000 \\
\hline Recovery/Left & Recovery/Right & $.3100249^{*}$ & .0068884 & .000 \\
& Stable/Right & $.3737587^{*}$ & .0067816 & .000 \\
& Stable/Left & $-.0431696^{*}$ & .0067816 & .000 \\
\hline Stable/Right & Recovery/Right & $-.0637338^{*}$ & .0067816 & .000 \\
& Recovery/Left & $-.3737587^{*}$ & .0067816 & .000 \\
& Stable/Left & $-.4169283^{*}$ & .0066731 & .000 \\
\hline Stable/Left & Recovery/Right & $.3531945^{*}$ & .0067816 & .000 \\
& Recovery/Left & $.0431696^{*}$ & .0067816 & .000 \\
& Stable/Right & $.4169283^{*}$ & .0066731 & .000 \\
\hline
\end{tabular}

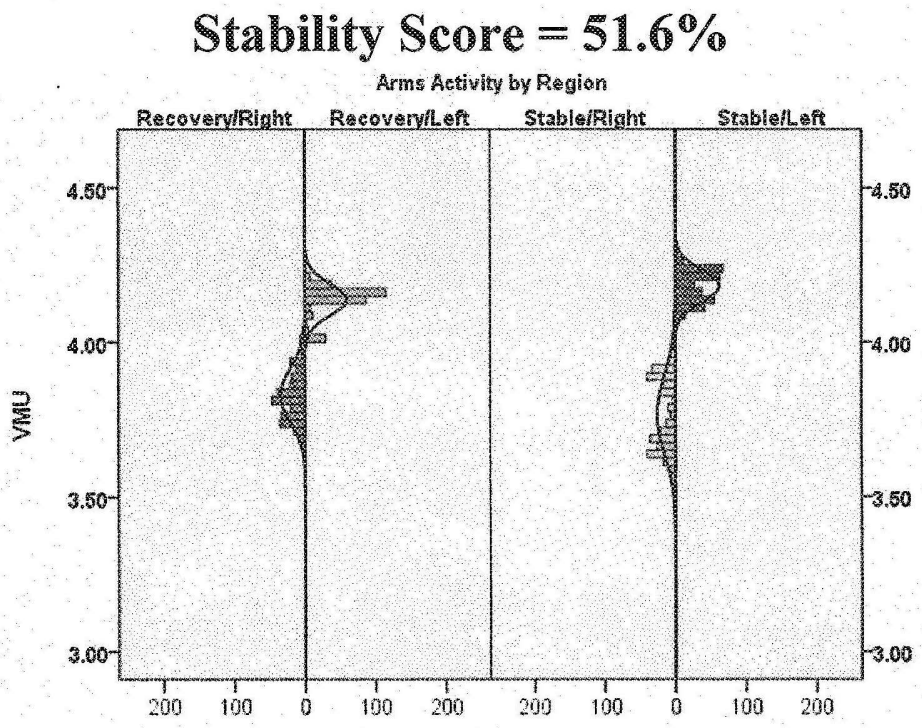

Figure 3.3.7: Arm Dynamics Histogram by Balance Regions for Subject B1 - AP Test. 


\section{Subject B2}

One-way Analysis of Variance (ANOVA) and Tukey's Test for Mean Differences

Table 3.3.18: Descriptive Statistics

\begin{tabular}{|l|l|l|l|l|}
\hline & $\mathrm{N}$ & Mean & S.D. & Std. Error \\
\hline Recovery/Right & 377 & 3.164749 & .0309452 & .0015938 \\
\hline Recovery/Left & 377 & 4.058461 & .0313604 & .0016151 \\
\hline Stable/Right & 243 & 3.159605 & .0289981 & .0018602 \\
\hline Stable/Left & 243 & 4.067367 & .0390473 & .0025049 \\
\hline Total & 1240 & 3.612342 & .4509718 & .0128067 \\
\hline
\end{tabular}

ANOVA $F=79304.828, \mathrm{P}<0.001$

Table 3.3.19: Post Hoc Tests (Tukey HSD)

\begin{tabular}{|l|l|l|l|l|}
\hline (I) Arm/Region & (J) Arm/Region & Mean (I-J) & Std. Error & Sig. \\
\hline Recovery/Right & Recovery/Left & $-.8937122^{*}$ & .0023643 & .000 \\
& Stable/Right & .0051439 & .0026704 & .217 \\
& Stable/Left & $-.9026187^{*}$ & .0026704 & .000 \\
\hline Recovery/Left & Recovery/Right & $.8937122^{*}$ & .0023643 & .000 \\
& Stable/Right & $.8988561^{*}$ & .0026704 & .000 \\
& Stable/Left & $-.0089065^{*}$ & .0026704 & .005 \\
\hline Stable/Right & Recovery/Right & -.0051439 & .0026704 & .217 \\
& Recovery/Left & $-.8988561^{*}$ & .0026704 & .000 \\
& Stable/Left & $-.9077626^{*}$ & .0029448 & .000 \\
\hline Stable/Left & Recovery/Right & $.9026187^{*}$ & .0026704 & .000 \\
& Recovery/Left & $.0089065^{*}$ & .0026704 & .005 \\
& Stable/Right & $.9077626^{*}$ & .0029448 & .000 \\
\hline
\end{tabular}

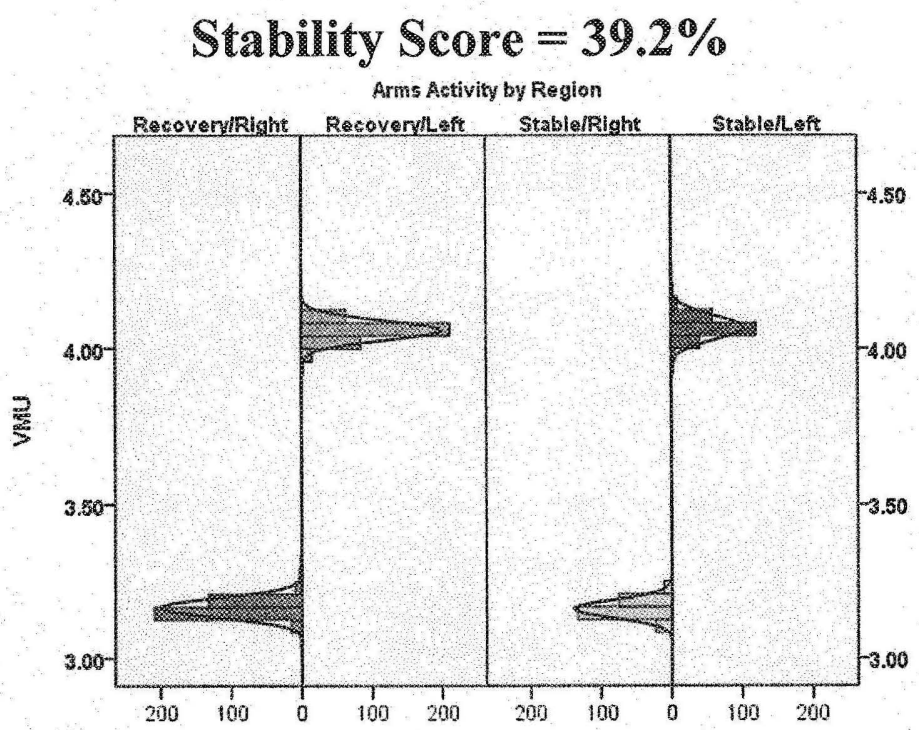

Figure 3.3.8: Arm Dynamics Histogram by Balance Regions for Subject B2 - AP Test. 


\section{Subject B3}

One-way Analysis of Variance (ANOVA) and Tukey's Test for Mean Differences

Table 3.3.20: Descriptive Statistics

\begin{tabular}{|l|l|l|l|l|}
\hline & $\mathrm{N}$ & Mean & S.D. & Std. Error \\
\hline Recovery/Right & 420 & 4.225575 & .0281911 & .0013756 \\
\hline Recovery/Left & 420 & 3.203574 & .0854474 & .0041694 \\
\hline Stable/Right & 181 & 4.154901 & .0892861 & .0066366 \\
\hline Stable/Left & 181 & 3.199831 & .0968559 & .0071992 \\
\hline Total & 1202 & 3.703369 & .5070348 & .0146247 \\
\hline \multicolumn{5}{|c|}{ ANOVA F $=18523.589, \mathrm{P}<0.001$} \\
\end{tabular}

Table 3.3.21: Post Hoc Tests (Tukey HSD)

\begin{tabular}{|l|lllll|}
\hline (I) Arm/Region & J) Arm/Region & Mean (I-J) & Std. Error & Sig. \\
\hline Recovery/Right & Recovery/Left & $1.0220005^{*}$ & .0050891 & .000 \\
& Stable/Right & $.0706737^{*}$ & .0065573 & .000 \\
& Stable/Left & $1.0257438^{*}$ & .0065573 & .000 \\
\hline Recovery/Left & Recovery/Right & $-1.0220005^{*}$ & .0050891 & .000 \\
& Stable/Right & $-.9513268^{*}$ & .0065573 & .000 \\
& Stable/Left & .0037433 & .0065573 & .941 \\
\hline Stable/Right & Recovery/Right & $-.0706737^{*}$ & .0065573 & .000 \\
& Recovery/Left & $.9513268^{*}$ & .0065573 & .000 \\
& Stable/Left & $.9550702^{*}$ & .0077523 & .000 \\
\hline Stable/Left & Recovery/Right & $-1.0257438^{*}$ & .0065573 & .000 \\
& Recovery/Left & -.0037433 & .0065573 & .941 \\
& Stable/Right & $-.9550702^{*}$ & .0077523 & .000 \\
\hline
\end{tabular}

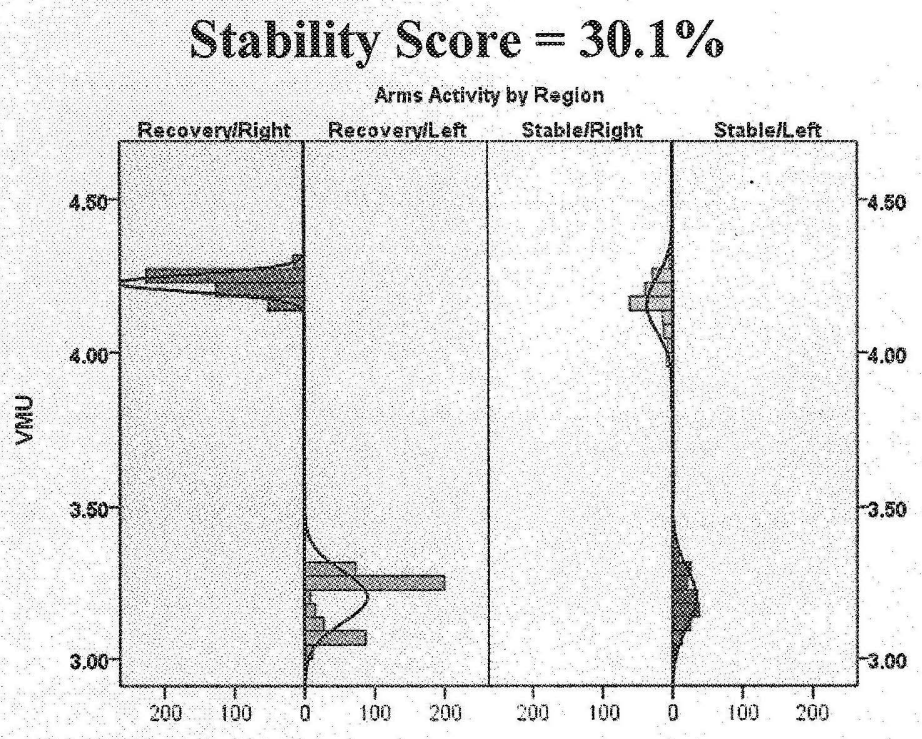

Figure 3.3.9: Arm Dynamics Histogram by Balance Regions for Subject B3 - AP Test. 


\section{Subject B4}

One-way Analysis of Variance (ANOVA) and Tukey's Test for Mean Differences

Table 3.3.22: Descriptive Statistics

\begin{tabular}{|l|l|l|l|l|}
\hline & $\mathrm{N}$ & Mean & S.D. & Std. Error \\
\hline Recovery/Right & 532 & 4.158613 & .0071399 & .0003096 \\
\hline Recovery/Left & 532 & 4.026375 & .0099957 & .0004334 \\
\hline Stable/Right & 148 & 4.159813 & .0103454 & .0008504 \\
\hline Stable/Left & 148 & 4.023540 & .0101410 & .0008336 \\
\hline Total & 1360 & 4.092316 & .0671988 & .0018222 \\
\hline
\end{tabular}

Table 3.3.23: Post Hoc Tests (Tukey HSD)

\begin{tabular}{|l|l|l|l|l|}
\hline (I) Arm/Region & (J)Arm/Region & Mean (I-J) & Std. Error & Sig. \\
\hline Recovery/Right & Recovery/Left & $.1322374^{*}$ & .0005547 & .000 \\
& Stable/Right & -.0012001 & .0008407 & .482 \\
& Stable/Left & $.1350729^{*}$ & .0008407 & .000 \\
\hline Recovery/Left & Recovery/Right & $-.1322374^{*}$ & .0005547 & .000 \\
& Stable/Right & $-.1334375^{*}$ & .0008407 & .000 \\
& Stable/Left & $.0028355^{*}$ & .0008407 & .004 \\
\hline Stable/Right & Recovery/Right & .0012001 & .0008407 & .482 \\
& Recovery/Left & $.1334375^{*}$ & .0008407 & .000 \\
& Stable/Left & $.1362730^{*}$ & .0010516 & .000 \\
\hline Stable/Left & Recovery/Right & $-.1350729^{*}$ & .0008407 & .000 \\
& Recovery/Left & $-.0028355^{*}$ & .0008407 & .004 \\
& Stable/Right & $-.1362730^{*}$ & .0010516 & .000 \\
\hline
\end{tabular}

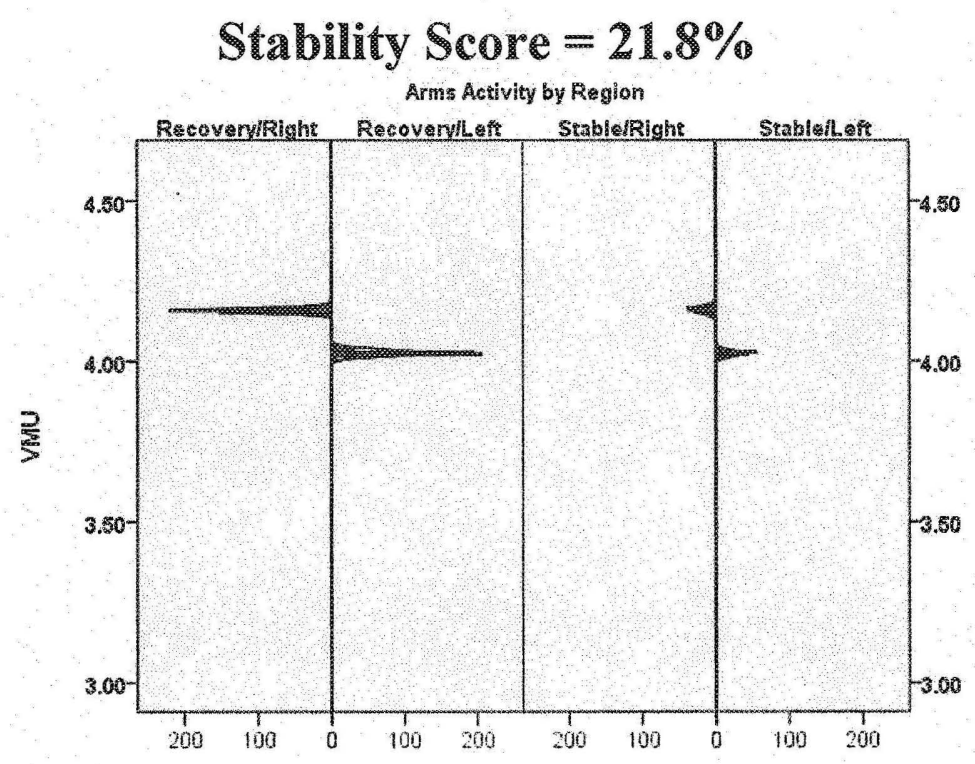

Figure 3.3.10: Arm Dynamics Histogram by Balance Regions for Subject B4 - AP Test. 


\section{Arm Activity during Lateral Balance (LAT) Board Test}

A one-way ANOVA (Table 3.3.24) shows that differences among the mean magnitudes of arm acceleration are statistically significant $(\mathrm{F}=104.674, \mathrm{P}<0.001)$. Likewise, the two-way ANOVA presented in the same table shows that interaction differences among all means are statistically significant $(\mathrm{F}=14.784, \mathrm{P}<0.001)$, while a comparison of aggregated means for arms and phases of balance during balancing tasks is not statistically significant.

Table 3.3.24 Analysis Variance for Arms Acceleration (VMU) during Periods of Stable and Periods of Balance Recovery during the LAT Test

\begin{tabular}{|l|c|c|}
\hline Analysis & S & Sig. \\
\hline One-Way ANOVA & 104.674 & .001 \\
\hline Two-Way ANOVA & F & Sig. \\
\hline Regions & 2.677 & $.349-$ n.s \\
\hline Arms & 13.875 & $.167-$ n.s \\
\hline Interaction Regions x Arms & 14.784 & .001 \\
\hline
\end{tabular}

Analysis of the data of arm movements during the LAT test (Table 3.3.25) shows that the dominant arm produces greater acceleration during periods of balance recovery (VMU=3.98) than during stable periods (VMU=3.93). During balance recovery, the non-dominant arm manifests similar accelerations $(V M U=4.02$ ) as it does during stable periods (VMU $=4.03$ ).

Table 3.3.25 Magnitude of Movements of Dominant and Non-dominant Arm Acceleration during the LAT Test

\begin{tabular}{|l|l|c|}
\hline Region & Arm & Mean VMU \\
\hline \multirow{2}{*}{ Stable } & Right (dominant) & 3.93 \\
\cline { 2 - 3 } & Left & 4.02 \\
\hline Recovery & Right (dominant) & 3.98 \\
\cline { 2 - 3 } & Left & 4.03 \\
\hline
\end{tabular}

Like all other analyses, the results show a greater magnitude of non-dominant arm acceleration during stable periods than during balance recovery (Figure 3.3.11).

In addition, the analysis shows an evident variability of acceleration for both dominant and non-dominant arms during the lateral balance board test (Table 3.3.26). Levene's Test for Equality of Variances shows that: 
- Variance of dominant arm movements during both stable (.2572 vs. .0872 , Levene's Test $\mathrm{F}=$ $\left.2106.618^{* * *}\right)$ and recovery $\left(.1965\right.$ vs. .0787, Levene's Test $\left.\mathrm{F}=750.862^{* * *}\right)$ periods is significantly greater than the variance of movements for the non-dominant arm.

- Variance of dominant arm movements during the stable (.2572) period is greater than that during the recovery period $\left(0.1965\right.$ Levene's Test $\left.F=118.055^{* * *}\right)$.

- By contrast, variance of non-dominant arm movements is very similar during both recovery $(.0787)$ and stable $\left(.0872\right.$, Levene's Test $\left.\mathrm{F}=4.734^{*}\right)$ periods during balancing tasks.

Table 3.3.26 Variability of Acceleration of Dominant and Non-dominant Arms for the LAT Test

\begin{tabular}{|l|l|c|}
\hline Region & Arm & S.D. VMU \\
\hline Stable & Right (dominant) & .2572 \\
\cline { 2 - 3 } & Left & .0872 \\
\hline \multirow{2}{*}{ Recovery } & Right (dominant) & .1965 \\
\cline { 2 - 3 } & Left & .0787 \\
\hline
\end{tabular}

Supplemental to the statistical tests, graphical representation of variations during balancing tasks on the lateral balance board test (Figure 3.3.11) vividly demonstrates the greater variability in the acceleration of the dominant than the non-dominant arm.

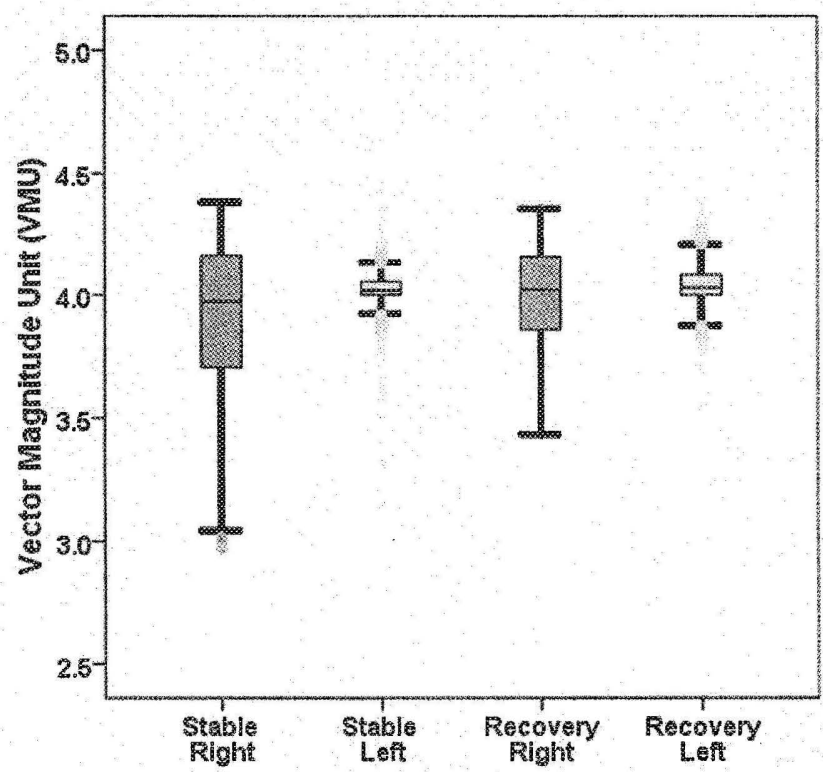

Figure 3.3.11: Variability of Dominant and Non-dominant Arms for the LAT Test. 


\section{Individual Arm Movements Strategies during the LAT Test}

Superior results on the Lateral Balance Board (LAT) Test were achieved by the participants who exerted similar intensities of arm movements with both dominant and nondominant arms (Subjects $\mathrm{C} 2$ and $\mathrm{C} 1$ ). Also, better results were accomplished by the participants who used arms to a similar extent during the recovery and stable phases of balance (Subjects $\mathrm{C} 2$ and $\mathrm{C} 1$ ).

The participants with a greater discrepancy between the recovery and stable phases of balance maintenance (Subjects $\mathrm{C} 3$ and $\mathrm{C} 4$ ) achieved lower scores on the LAT test. In addition, there was a noticeable difference between dominant and non-dominant arms (Subjects C3 and B4) during the recovery phase.

Results on the lateral balance test also show that better coordination, or similar extent of movements between the dominant and non-dominant arms, plays a significant role in balance maintenance. These tendencies are similar to those discussed for the complex and anteriorposterior tests.

The subsequent results are for the LAT test and arm movement dynamics for each of the participants (Subject $\mathrm{C} 1-\mathrm{C} 4$ ) that were discussed in the preceding interpretation. 


\section{Subject C1}

One-way Analysis of Variance (ANOVA) and Tukey's Test for Mean Differences

Table 3.3.27: Descriptive Statistics

\begin{tabular}{|l|l|l|l|l|}
\hline & $\mathrm{N}$ & Mean & S.D. & Std. Error \\
\hline Recovery/Right & 341 & 4.143272 & .0335308 & .0018158 \\
\hline Recovery/Left & 339 & 4.008113 & .0325167 & .0017661 \\
\hline Stable/Right & 266 & 4.052745 & .1322577 & .0081092 \\
\hline Stable/Left & 266 & 4.042230 & .0754473 & .0046260 \\
\hline Total & 1212 & 4.063424 & .0919761 & .0026419 \\
\hline \multicolumn{5}{|c|}{ ANOVA F $=196.614$, P $<0.001$} \\
\end{tabular}

Table 3.3.28: Post Hoc Tests (Tukey HSD)

\begin{tabular}{|l|l|l|l|l|}
\hline (I) Arm/Region & (J) Arm/Region & Mean (I-J) & Std. Error & Sig. \\
\hline Recovery/Right & Recovery/Left & $.1351597^{*}$ & .0057896 & .000 \\
& Stable/Right & $.0905273^{*}$ & .0061752 & .000 \\
& Stable/Left & $.1010424^{*}$ & .0061752 & .000 \\
\hline Recovery/Left & Recovery/Right & $-.1351597^{*}$ & .0057896 & .000 \\
& Stable/Right & $-.0446324^{*}$ & .0061831 & .000 \\
& Stable/Left & $-.0341174^{*}$ & .0061831 & .000 \\
\hline Stable/Right & Recovery/Right & $-.0905273^{*}$ & .0061752 & .000 \\
& Recovery/Left & $.0446324^{*}$ & .0061831 & .000 \\
& Stable/Left & .0105150 & .0065455 & .375 \\
\hline Stable/Left & Recovery/Right & $-.1010424^{*}$ & .0061752 & .000 \\
& Recovery/Left & $.0341174^{*}$ & .0061831 & .000 \\
& Stable/Right & -.0105150 & .0065455 & .375 \\
\hline
\end{tabular}

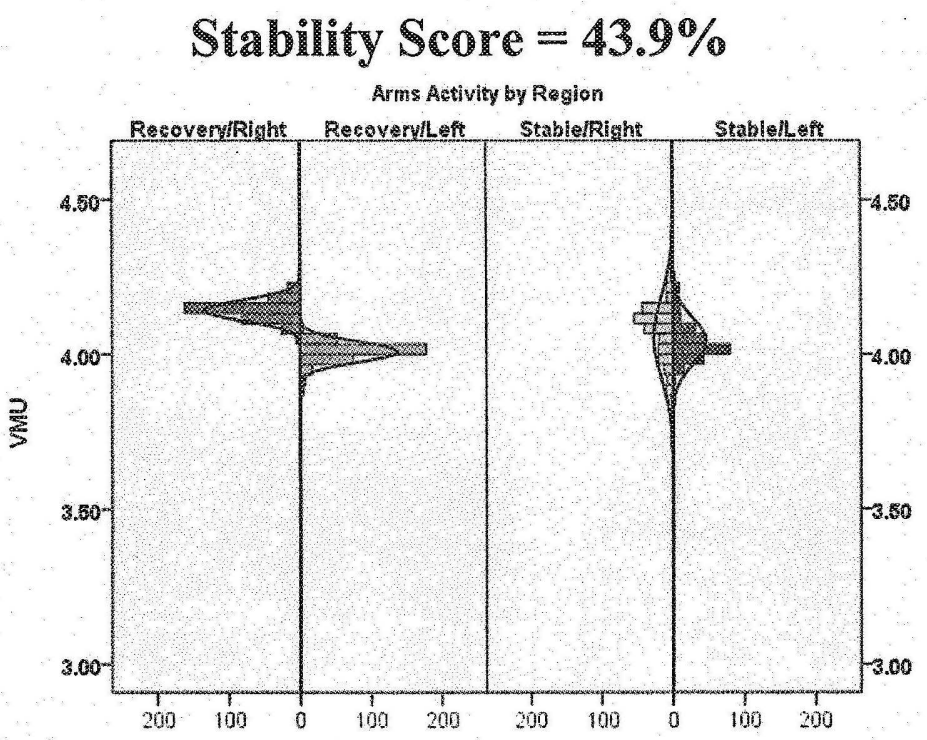

Figure 3.3.12: Arm Dynamics Histogram by Balance Regions for Subject C1 - LAT Test. 


\section{Subject C2}

One-way Analysis of Variance (ANOVA) and Tukey's Test for Mean Differences

Table 3.3.29: Descriptive Statistics

\begin{tabular}{|l|l|l|l|l|}
\hline & $\mathrm{N}$ & Mean & S.D. & Std. Error \\
\hline Recovery/Right & 366 & 3.882501 & .0809105 & .0042293 \\
\hline Recovery/Left & 366 & 4.105206 & .0775673 & .0040545 \\
\hline Stable/Right & 251 & 3.907808 & .0949957 & .0059961 \\
\hline Stable/Left & 251 & 4.086587 & .0764880 & .0048279 \\
\hline Total & 1234 & 3.995214 & .1317273 & .0037499 \\
\hline
\end{tabular}

ANOVA 646.331

Table 3.3.30: Post Hoc Tests (Tukey HSD)

\begin{tabular}{|l|l|l|l|l|}
\hline (I) Arm/Region & (J) Arm/Region & Mean (I-J) & Std. Error & Sig. \\
\hline Recovery/Right & Recovery/Left & $-.2227052^{*}$ & .0060740 & .000 \\
& Stable/Right & $-.0253074^{*}$ & .0067338 & .001 \\
& Stable/Left & $-.2040863^{*}$ & .0067338 & .000 \\
\hline Recovery/Left & Recovery/Right & $.2227052^{*}$ & .0060740 & .000 \\
& Stable/Right & $.1973978^{*}$ & .0067338 & .000 \\
& Stable/Left & $.0186189^{*}$ & .0067338 & .029 \\
\hline Stable/Right & Recovery/Right & $.0253074^{*}$ & .0067338 & .001 \\
& Recovery/Left & $-.1973978^{*}$ & .0067338 & .000 \\
& Stable/Left & $-.1787789^{*}$ & .0073346 & .000 \\
\hline Stable/Left & Recovery/Right & $.2040863^{*}$ & .0067338 & .000 \\
& Recovery/Left & $-.0186189^{*}$ & .0067338 & .029 \\
& Stable/Right & $.1787789^{*}$ & .0073346 & .000 \\
\hline
\end{tabular}

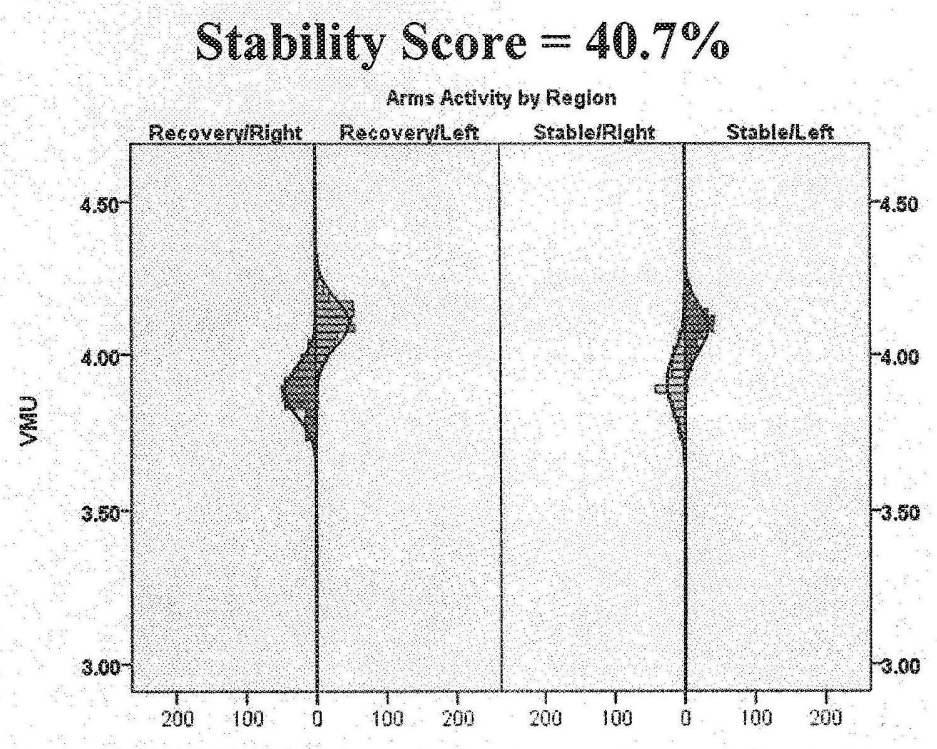

Figure 3.3.13: Arm Dynamics Histogram by Balance Regions for Subject C2 - LAT Test. 


\section{Subject C3}

One-way Analysis of Variance (ANOVA) and Tukey's Test for Mean Differences

Table 3.3.31: Descriptive Statistics

\begin{tabular}{|l|l|l|l|l|}
\hline & $\mathrm{N}$ & Mean & S.D. & Std. Error \\
\hline Recovery/Right & 396 & 4.175634 & .0301233 & .0015138 \\
\hline Recovery/Left & 396 & 4.015930 & .0182284 & .0009160 \\
\hline Stable/Right & 223 & 4.181968 & .0296488 & .0019854 \\
\hline Stable/Left & 223 & 4.015591 & .0337782 & .0022620 \\
\hline Total & 1238 & 4.096862 & .0856627 & .0024346 \\
\hline
\end{tabular}

ANOVA 3568.708

Table 3.3.32: Post Hoc Tests (Tukey HSD)

\begin{tabular}{|l|l|l|l|l|}
\hline (I) Arm/Region & (J) Arm/Region & Mean (I-J) & Std. Error & Sig \\
\hline Recovery/Right & Recovery/Left & $.1597043^{*}$ & .0019595 & .000 \\
& Stable/Right & $-.0063334^{*}$ & .0023084 & .031 \\
& Stable/Left & $.1600433^{*}$ & .0023084 & .000 \\
\hline Recovery/Left & Recovery/Right &. $.1597043^{*}$ & .0019595 & .000 \\
& Stable/Right & $-.1660377^{*}$ & .0023084 & .000 \\
& Stable/Left & .0003390 & .0023084 & .999 \\
\hline Stable/Right & Recovery/Right & $.0063334^{*}$ & .0023084 & .031 \\
& Recovery/Left & $.1660377^{*}$ & .0023084 & .000 \\
& Stable/Left & $.1663767^{*}$ & .0026112 & .000 \\
\hline Stable/Left & Recovery/Right & $-.1600433^{*}$ & .0023084 & .000 \\
& Recovery/Left & -.0003390 & .0023084 & .999 \\
& Stable/Right & $-.1663767^{*}$ & .0026112 & .000 \\
\hline
\end{tabular}

Stability Score $=36.0 \%$

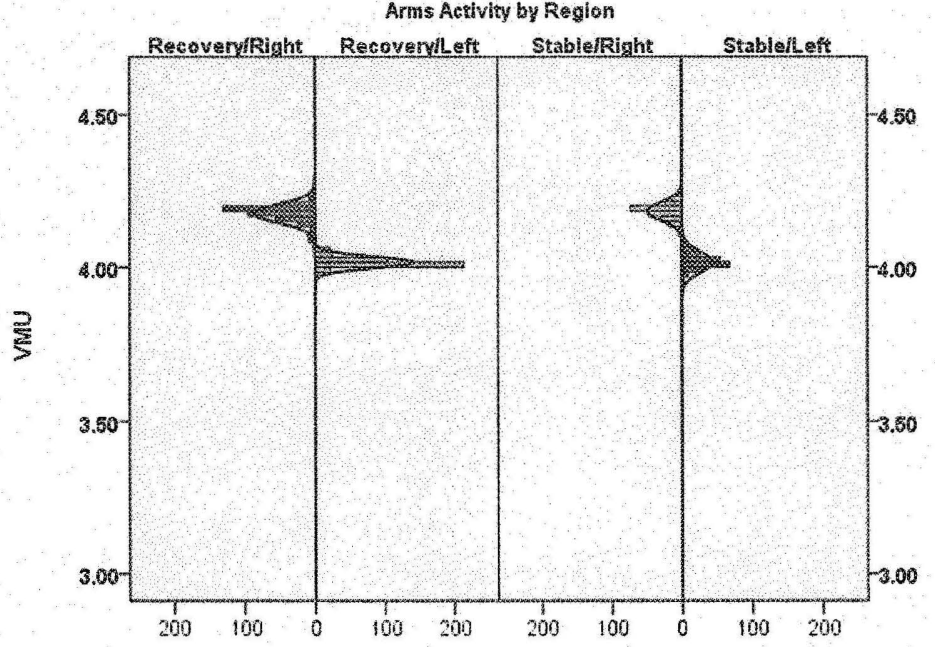

Figure 3.3.14 Arm Dynamics Histogram by Balance Regions for Subject C3 - LAT Test. 


\section{Subject C4}

One-way Analysis of Variance (ANOVA) and Tukey's Test for Mean Differences

Table 3.3.33: Descriptive Statistics

\begin{tabular}{|l|l|l|l|l|}
\hline & $\mathrm{N}$ & Mean & S.D. & Std. Error \\
\hline Recovery/Right & 477 & 3.610086 & .1606026 & .0073535 \\
\hline Recovery/Left & 477 & 3.988141 & .1140953 & .0052241 \\
\hline Stable/Right & 133 & 3.657365 & .0844066 & .0073190 \\
\hline Stable/Left & 133 & 3.985272 & .0918173 & .0079616 \\
\hline Total & 1220 & 3.803955 & .2252840 & .0064499 \\
\hline \multicolumn{5}{c}{ ANOVA 816.315} \\
\end{tabular}

Table 3.3.34: Post Hoc Tests (Tukey HSD)

\begin{tabular}{|l|l|l|l|l|}
\hline (I) Arm/Region & (J) Arm/Region & Mean (I-J) & Std. Error & Sig. \\
\hline Recovery/Right & Recovery/Left & $-.3780547^{*}$ & .0084131 & .000 \\
& Stable/Right & $-.0472790^{*}$ & .0127403 & .001 \\
& Stable/Left & $-.3751858^{*}$ & .0127403 & .000 \\
\hline Recovery/Left & Recovery/Right & $.3780547^{*}$ & .0084131 & .000 \\
& Stable/Right & $.3307757^{*}$ & .0127403 & .000 \\
& Stable/Left & .0028689 & .0127403 & .996 \\
\hline Stable/Right & Recovery/Right & $.0472790^{*}$ & .0127403 & .001 \\
& Recovery/Left & $-.3307757^{*}$ & .0127403 & .000 \\
& Stable/Left & $-.3279068^{*}$ & .0159326 & .000 \\
\hline Stable/Left & Recovery/Right & $.3751858^{*}$ & .0127403 & .000 \\
& Recovery/Left & -.0028689 & .0127403 & .996 \\
& Stable/Right & $.3279068^{*}$ & .0159326 & .000 \\
\hline
\end{tabular}

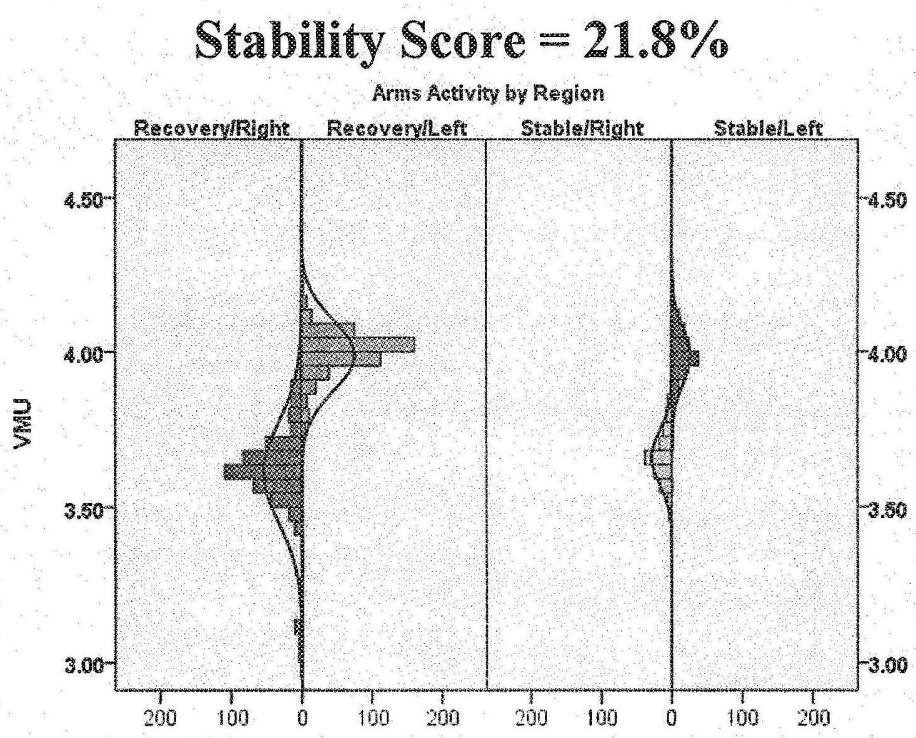

Figure 3.3.15: Arm Dynamics Histogram by Balance Regions for Subject C4 - LAT Test. 


\section{Concluding Remarks: Arm Movement Strategies during Dynamic Postural Balance}

In the majority of cases where subjects achieve lower results on the balance board test, they demonstrate a lower intensity of arm movements during stable periods of the balancing tasks. This type of arm movement can be defined as a "passive strategy" of arm use, and it is characterized by a lower intensity of movements or passive maintenance of postural stability. From this passive position, it is probably more difficult to respond to any kind of balance perturbations and to regain postural balance during recovery periods, when participants have to adjust their center of mass (CoM) to the base of support.

Results from the accelerometer-based balance tests also show that a lower magnitude of non-dominant arm movements is frequently accompanied with lower achievement on a balance board test. In addition, results indicate that better coordinated arm movements are a precondition for better maintenance of dynamic postural balance.

In summary, this chapter presented the results of the analysis of arm movements during maintenance of postural balance on instrumented balance board tests. Arm movements were analyzed during stable regions and regions of balance recovery. This chapter also examines the role of dominant handedness for balance maintenance and recovery.

Analysis of the impacts of the dominant and non-dominant arms during balance found that they have different patterns and functions. There are evident, and statistically significant differences concerning the magnitude of arm movements, and a particularly strong difference of variability of these movements. 
The study provides strong indications that both dominant and non-dominant arms and their coordinated activity play an important role for balance maintenance. It is particularly important to use both arms in a coordinated manner during both recovery and stable balance. This indicates that both arms have important and distinctive, most likely counterbalancing, function. These results are consistent with the general theory of dynamic dominance (Sainburg, 2002; Wang \& Sainburg, 2007), which supports the idea that coordinated arm movements of both arms have significant but distinctive roles for postural balance. My results provide support for dynamic dominance theory, as it applies to dynamic balance maintenance and arm movements. 


\section{Discussion}

\section{Arm Movements and Balance}

The presented study contributes to the knowledge related to arm movements and their role in dynamic postural balance. Specifically, the findings from classic balance tests suggest that the arms play an important role in the improvement of balance. The results also provide evidence that arm use during the performance of balance tests significantly alters the trunk dynamics (measure of CoM).

Based on the performance on the classic balance tests, the results indicate improved maintenance and recovery of postural balance with free arm movements. Classic balance tests have provided indications of improvements in mobility, balance, and prevention of falls (Cho, Scarpace \& Alexander, 2004) when the arms were actively used during the MSL test. Also it can be suggested that participants improved their lateral balance and overall balance comfort level when they used arm freely.

The RS and TUG tests suggest that arms help in shifting the CoM more quickly. This is evident because of the increase in the number of steps on the RS test and the faster performance on the TUG test. These findings suggest an improvement of the ability to perform sequential locomotor tasks (Morris, Morris \& lansek, 2001) and a CoM sifting speed increase during the sit-to-stand transfer. The RS test improvements suggest the existence of a better falls prevention mechanism because of the improvement in the stepping and change of support reaction abilities (e.g. Maki et al., 1996).

The results of the correlations between the trunk (CoM) movements and the ranked classic test performance suggest the positive impact of arm movements on CoM dynamics. The results suggest that free arm movements contribute to the increased magnitude of trunk 
movements that are required for adjusting the centre of mass to the base of support, most likely through an counterbalancing mechanism. The greater control of trunk, speed and rigidity of trunk movements were also shown to be significant determinants of postural balance (Maki \& Mcllroy, 1994, 2006; Allum et al., 2002; Yamazaki et al., 2005).

Overall, there is strong indication that arms provide an improved counterbalancing mechanism during dynamic balance maintenance. These results suggest that diagnostic and training of arm movements in postural balance can improve its maintenance during activities of daily living and decrease the risk of falls.

\section{Arm Dynamics during Balance}

In addition to the results from the classic balance tests, those from the novel, accelerometer-based application of the balance board tests (CBB, AP and LAT) indicate that arm movements have an important function in maintaining postural dynamic balance. The analysis of the arm movements and balance board data examines the dynamics during balancing, segmented into the regions of stable balance and balance recovery, as well as the specific function of the dominant and non-dominant arms.

The existing literature documents significant associations between arm movements, reaching reactions and balance recovery (Maki \&. Mcllroy, 1997; Yamazaki, Suzuki, Ohkuwa \& Itoh, 2005; Maki \& Mcllroy, 2006). However, there is an evident knowledge gap concerning specific arm movement strategies and reactions during dynamic balance and balance without any support. The literature does not provide data on the effect of handedness and specific arm movement strategies, and my study attempts to address these issues. 
Dynamic Arm Dominance in Balance

The analysis of overall performance tendencies for all participants indicates certain trends and specific strategies of arm movements that are used during dynamic balance.

The observations from the results of all three variants of the balance board tests (CBB, $\mathrm{AP}$ and LAT) indicate that the non-dominant arm has a greater average acceleration than the dominant arm for both recovery and stable balance periods. On the other hand, the variance of the dominant arm movements during both stable and recovery periods is significantly greater than the variance of movements for the non-dominant arm. These observations suggest that the dominant arm is more variable or that it has a dynamic function during balance, whereas the nondominant arm seems to have a more static role.

Examination of individual performance and dynamics indicate that there are distinct strategies being applied during balance. However, the prevalent trend for the majority of participants and balance board tests is that coordinated and similar movement dynamics of both arms generally lead to better balance.

These findings are very relevant, since they provide support for a new model of dynamic arm dominance that can be specifically applied to the task of dynamic balance maintenance. They support the recent studies that contradict the previously proposed motor lateralization model, which emphasizes the global advantage of one dominant hemisphere or limb system (Schaefer et al., 2007). The findings uphold the dynamic dominance model (Zhang et al., 2006; Wang and Sainburg, 2007), which emphasizes the idea that each hemisphere/limb system is specialized to control diverse features of performance. Specifically, it shows that the left and right hemispheres are specialized for controlling different features of movement (Schaefer et al., 2007). 
My results provide support for dynamic dominance as it applies to balance maintenance and arm movements. They show that the dominant arm controls the more dynamic parameters by being more involved in balance, and that the non-dominant arm has a more steady function during dynamic balancing tasks. Furthermore, my findings indicate the achievement of better balance when both arms are used in a complementary way.

These findings are in direct support of the dynamic dominance model of handedness, which argues that the dominant arm performs better in coordinating intersegmental dynamics, speed, direction, and curvature, whereas the non-dominant arm tends to perform better in steady state positions (Sainburg, 2007).

\section{Arm Movement Strategies in Balance}

Analysis of the overall trends of performance for all participants indicate that during balance recovery, the dominant and non-dominant arms both made greater average movements than during periods of stable balance. The analysis also shows that the variance of dominant arm movements during the stable period is greater than that during the recovery period.

Further examinations of individual performance and dynamics on individual levels indicate that lower results on the balance board tests are usually consistent with a lower intensity of arm movements during stable periods of balance. This type of arm movements during balancing tasks can be defined as a passive strategy of balance. Contrary to the passive strategy is the active strategy, which generally produces better balancing with a more involved use of arms. It seems that the active strategy of arms used during both stable and recovery balance regions is more efficient for maintenance of dynamic postural balance. 
Needless to say, these results indicate the importance of arm movements in balance. It can be argued that these movements have distinctive roles during both stable and balance recovery periods. The active use, counterbalancing strategy seems to be the principal one during dynamic balancing tasks.

Overall, the results suggest that arm movements have a significant impact on postural dynamic balance and indicate that efficient strategies of arm movement can improve balance maintenance and recovery, likely through counterbalancing with arms. Several previous studies evaluating balance (Allum et al., 2002) also support the counterbalancing view. Allum et al. (2002) found that trunk stiffness, which is typical among the elderly, might be corrected through the compensatory mechanism of arm movements. The results are also consistent with the active strategy proving the importance of arm movements during balance.

\section{Arm Movements and Lateral Balance}

Maki and Mcllroy (2006) report the crucial role of lateral balance for falls diagnostics and prevention. Similar indications were also suggested by the classical balance tests and by the balance board tests. The overview of balance board test performance implies that arm movements have the most important function during the LAT test. This leads to the idea that arm

movements are specifically important for lateral balance and for falls prevention (Maki and Mcllroy, 2006).

Analysis shows the greatest changes in outcome performance during the LAT test. Moreover, the worst trends and individual arm movement strategies can be seen during the AP test, suggesting a lower interaction between anterior-posterior balance and arm movements. The 
$\mathrm{CBB}$ test is a combination of lateral and anterior-posterior balance, and the arm movement dynamics seem to have an intermediate effect.

\section{Standardization of Testing with an Instrumented Balance Board Sheet}

In order to simplify interpretations of the test results, based on the experience gathered through the analysis of individual results, proposed is an Instrumented Balance Board Sheet. The form (Figure 5.1) is a procedure and a data collection sheet that can assist and standardize the data collection on the balance board tests. and interpretation of arm movements during balance.

The main purpose of this form is to aid and simplify interpretation of the arm movement strategies and results from balance board and to provide the guidelines for development and evaluation of balance training.

The histograms facilitate comparison of the intensity of dominant and non-dominant arm movements, evaluation of arm coordination, and analysis of correspondence of arm activity during stable and recovery phases of balance maintenance. In addition to visualization of test results, this sheet can also help in conversion of the accelerometer measures (VMU) into a standardized scale, more suitable for analysis of balance and arm movements in clinical practice. The standard scales include the range of intensity ( 1 to 5), coordination (Low, Moderate or High) and correspondence (Small, Partial or Optimal) of arm movements during different periods of balancing tasks. 


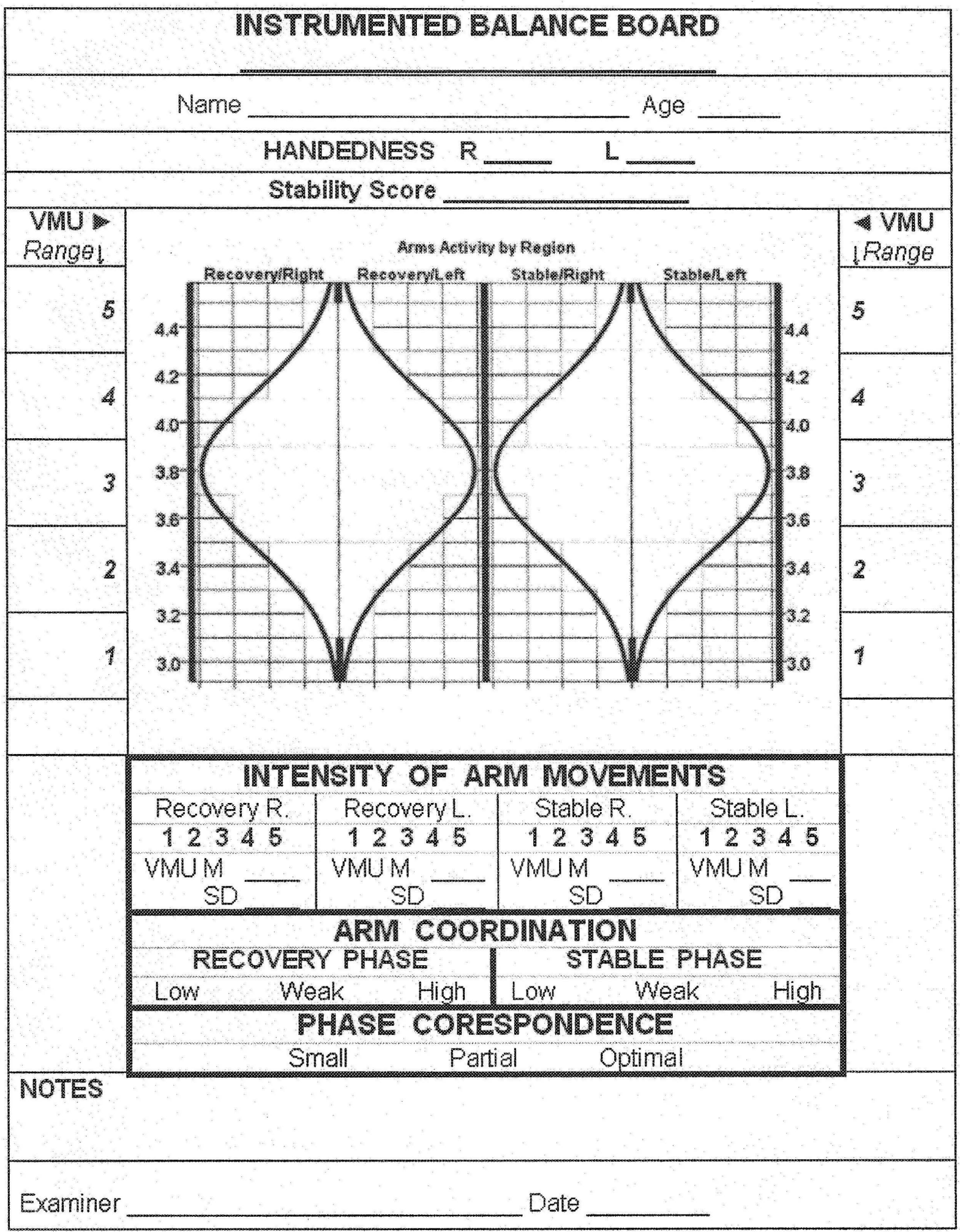

Figure 5.1: Instrumented Balance Board Sheet 
The proposed procedure and the data sheet can assist in interpretation of individual quantitative results and provide the base for balance and arm movement diagnostics. In addition, this data sheet could be used for development of individualized programs for balance training/rehabilitation and evaluation of training effects.

The Instrumented Balance Board Sheet is suitable for interpretation of all (CBB, AP and LAT) balance board tests. Future studies should include automatic processing and preparation order to additionally simplify diagnostics and provide a more clinically applicable tool.

\section{Concluding Remarks: Arm Movements in Balance}

Overall, my study provides fruitful evidence of the impacts of arm movements and their effects on dynamic balance. It seems that arm movements have an essential and potentially beneficial role in evaluating balance assessment, as well as in the future of balance training strategies.

The study provides new insights into the association between arm movements and postural balance and has immediate implications for balance training and rehabilitation by introducing a clinically relevant testing protocol for evaluation of arm movements during balance. These results could be incorporated into future balance training programs, which would specifically train arm movements within the scope of general balance training protocols.

Future studies should analyze the mechanics of arm dynamics and age-dependant changes to attempt to bridge this gap and to provide better assistance to the elderly and people

prone to falls. Studies should also evaluate whether loss of balance is associated with the directional loss and handedness and whether falls direction is associated with handedness. 


\section{Conclusions}

Dynamic postural balance is a skill significant for all human activities, and, according to Voermans et al. (2007), balance impairments manifested through postural instability are the main non-environmental, age-related cause of falls. This study presents a novel device and clinical evaluation tool for the diagnostics of dynamic postural balance and arm movements as means to assess risk of falls and to provide a cost-effective portable system for dynamic balance assessment.

Based on the results and experience it can be argued that arm movements are an important strategy in dynamic balance maintenance. Despite the fact that this study examines the balance and arm movements of able-bodied subjects, its results are also applicable for people with impaired balance. This type of study, according to clinical research studies (Popovic et al., 2000; Masani, Vette \& Popovic, 2006), provides results that can be applied for rehabilitation and development of assistive devices.

The presented accelerometer-based device and assessment protocol for cost-effective, quantitative, and portable balance and arm movements diagnostics in clinical settings provides a valid set of measures relevant to risk assessment, evaluation of dynamic postural balance and training.

Since balance control is a complex skill (Horak, 2006), based on different processes and the integration of different visual, vestibular and proprioceptive sensory systems, further study should be directed toward exploring the interactions between these systems, and developing diagnostic devices that simultaneously examine these factors and their relationship to arm movements and balance. In addition, future studies should address the evaluation of lateral 
balance which, according to the literature (Maki \& Mcllroy, 1994, Allum et al., 2002; Yamazaki et al., 2005; Maki \& Mcllroy, 2006), is highly important for the prevention of falls that often cause serious hip fractures.

In conclusion, my study shows that arm movements have an important role in balance maintenance. The development of training programs based on these findings and provided clinical tools can contribute to falls prevention among people prone to falls. Based on the suggestions from the literature related to balance and falls prevention, and on the results and experience gathered in this study, further research should be directed towards specific aspects of arm movements related to their direction, with particular emphasis on lateral balance. Also, it would be particularly important to develop a standard set of test norms for balance and arms movement strategies among different population groups. 


\section{References}

Allum, J. H., Carpenter, M. G., Honegger, F., Adkin, A. L., \& Bloem, B. R. (2002). Agedependent variations in the directional sensitivity of balance corrections and compensatory arm movements in man. J Physiol, 542(Pt 2), 643-663.

Aruin, A. S., Ota, T., \& Latash, M. L. (2001). Anticipatory postural adjustments associated with lateral and rotational perturbations during standing. $J$ Electromyogr Kinesiol, $11(1), 39$ 51.

Bagesteiro, L. B., \& Sainburg, R. L. (2002). Handedness: dominant arm advantages in control of limb dynamics. $J$ Neurophysiol, $88(5), 2408-2421$.

Bagesteiro, L. B., \& Sainburg, R. L. (2003). Nondominant arm advantages in load compensation during rapid elbow joint movements. $J$ Neurophysiol, 90(3), 1503-1513.

Bateni, H., Zecevic, A., Mcllroy, W. E., \& Maki, B. E. (2004). Resolving conflicts in task demands during balance recovery: does holding an object inhibit compensatory grasping? Exp Brain Res, 157(1), 49-58.

Borello-France, D. F., Gallagher, J. D., Furman, J. M., Redfern, M. S., \& Carvell, G. E. (2002). Voluntary upper-extremity movements in patients with unilateral peripheral vestibular hypofunction. Phys Ther, 82(3), 216-227.

Boulgarides, L. K., McGinty, S. M., Willett, J. A., \& Barnes, C. W. (2003). Use of clinical and impairment-based tests to predict falls by community-dwelling older adults. Phys Ther, $83(4), 328-339$.

Brauer, S. G., Burns, Y. R., \& Galley, P. (2000). A prospective study of laboratory and clinical measures of postural stability to predict community-dwelling fallers. J Gerontol A Biol Sci Med Sci, 55(8), M469-476.

Buatois, S., Gueguen, R., Gauchard, G. C., Benetos, A., \& Perrin, P. P. (2006). Posturography and risk of recurrent falls in healthy non-institutionalized persons aged over 65 . Gerontology, 52(6), 345-352.

Bugnariu, N., \& Fung, J. (2007). Aging and selective sensorimotor strategies in the regulation of upright balance. J Neuroeng Rehabil, 4, 19.

Campbell, A. J., Borrie, M. J., Spears, G. F., Jackson, S. L., Brown, J. S., \& Fitzgerald, J. L. (1990). Circumstances and consequences of falls experienced by a community population 70 years and over during a prospective study. Age Ageing, 19(2), 136-141.

Carver, R. H., \& Nash, J. G. (2009). Doing data analysis with SPSS version 16. Belmont, CA: Brooks/Cole Cengage Learning. 
Centers for Disease Control and Prevention (CDC). (2003). Rates of hospitalization related to traumatic brain injury--nine states. MMWR Morbidity and Mortality Weekly Report, 56(8), $167-170$.

Cho, B. L., Scarpace, D., \& Alexander, N. B. (2004). Tests of stepping as indicators of mobility, balance, and fall risk in balance-impaired older adults. $J$ Am Geriatr Soc, 52(7), 11681173 .

Cho, C. Y., \& Kamen, G. (1998). Detecting balance deficits in frequent fallers using clinical and quantitative evaluation tools. $J$ Am Geriatr Soc, 46(4), 426-430.

Choi, B. C. (1997). Causal modeling to estimate sensitivity and specificity of a test when prevalence changes. Epidemiology, 8(1), 80-86.

Cobb, S. V. G., Nichols, S., Ramsey, A., \& Wilson, J. R. (1999). Virtual reality-induced symptoms and effects (VRISE). Presence: Teleoperators and virtual environments, 8(2), $169-186$.

Cordo, P. J., \& Nashner, L. M. (1982). Properties of postural adjustments associated with rapid arm movements. $J$ Neurophysiol, 47(2), 287-302.

Culhane, K. M., O'Connor, M., Lyons, D., \& Lyons, G. M. (2005). Accelerometers in rehabilitation medicine for older adults. Age Ageing, 34(6), 556-560.

Delbaere, K., Crombez, G., Van Den Noortgate, N., Willems, T., \& Cambier, D. (2006). The risk of being fearful or fearless of falls in older people: an empirical validation. Disabil Rehabil, 28(12), 751-756.

Diracoglu, D., Aydin, R., Baskent, A., \& Celik, A. (2005). Effects of kinesthesia and balance exercises in knee osteoarthritis. J Clin Rheumatol, 11(6), 303-310.

Dite, W., \& Temple, V.A. (2002). A clinical test of stepping and change of direction to identify multiple falling older adults. Arch Phys Med Rehabil, 83(11), 1566-1571.

Dobkin, B. H. (2004). Strategies for stroke rehabilitation. Lancet Neurol, 3(9), 528-536.

Dodge, C., \& Jerse, T. A. (1997). Computer Music: Synthesis, Composition, and Performance (2nd ed.). New York: Schirmer Books.

Duarte, M., \& Zatsiorsky, V. M. (2001). Long-range correlations in human standing. Physics Letters, A 283, 124-128.

English, C. K., Hillier, S. L., Stiller, K. R., \& Warden-Flood, A. (2007). Circuit class therapy versus individual physiotherapy sessions during inpatient stroke rehabilitation: a controlled trial. Arch Phys Med Rehabil, 88(8), 955-963. 
Ferrell, W. R., Tennant, N., Sturrock, R. D., Ashton, L., Creed, G., Brydson, G., et al. (2004). Amelioration of symptoms by enhancement of proprioception in patients with joint hypermobility syndrome. Arthritis and Rheumatism, 50(10), 3323-3328.

Ford, M. P., Wagenaar, R. C., \& Newell, K. M. (2007). Arm constraint and walking in healthy adults. Gait Posture, 26(1), 135-141.

Fujiwara, K., Toyama, H., Kunita, K., Asai, H., \& Miyaguchi, A. (2001). Modality of postural movement in men and women with both arms flexed during standing. Percept Mot Skills, 93(3), 611-625.

Gage, W. H., Zabjek, K. F., Hill, S. W., \& Mcllroy, W. E. (2007). Parallels in control of voluntary and perturbation-evoked reach-to-grasp movements: EMG and kinematics. Exp Brain Res, 181(4), 627-637.

Ghafouri, M., Mcllroy, W. E., \& Maki, B. E. (2004). Initiation of rapid reach-and-grasp balance reactions: is a pre-formed visuospatial map used in controlling the initial arm trajectory? Exp Brain Res, 155(4), 532-536.

Gruneberg, C., Duysens, J., Honegger, F., \& Allum, J. H. (2005). Spatio-temporal separation of roll and pitch balance-correcting commands in humans. $J$ Neurophysiol, 94(5), 31433158 .

Hayes, W. C., Myers, E. R., Robinovitch, S. N., Van Den Kroonenberg, A., Courtney, A. C., \& McMahon, T. A. (1996). Etiology and prevention of age-related hip fractures. Bone, $18(1$ Suppl), 77S-86S.

Hill, K., Bernhardt, J., \& McGann. D. et al. (1996). A new test of dynamic standing balance for stroke patients: Reliability, validity and comparison with healthy elderly. Physiother Can, $48,257-262$.

Holroyd-Leduc, J. M., Liu, B. A., Maki, B. E., Zecevic, A., Herrmann, N., \& Black, S. E. (2005). The role of buspirone for the treatment of cerebellar ataxia in an older individual. Can $J$ Clin Pharmacol, 12(3), e218-221.

Hoogvliet, P., van Duyl, W. A., de Bakker, J. V., Mulder, P. G., \& Stam, H. J. (1997). Variations in foot breadth: effect on aspects of postural control during one-leg stance. Arch Phys Med Rehabil, 78(3), 284-289.

Horak, F. B. (2006). Postural orientation and equilibrium: what do we need to know about neural control of balance to prevent falls? Age Ageing, 35 Suppl 2, ii7-iil1.

Horak, F. B., \& Macpherson, J. M. (1996). Postural orientation and equilibrium. In L. B. Rowell \& J. T. Shepherd (Eds.), Handbook of Physiology. Exercise: Regulation and Integration of Multiple Systems (pp. 255-292), New York, NY: Oxford University Press. 
Howe, J. A., Inness, E. L., Venturini, A., Williams, J. I., \& Verrier, M. C. (2006). The Community Balance and Mobility Scale--a balance measure for individuals with traumatic brain injury. Clin Rehabil, 20(10), 885-895.

Hulley et al. (2001). Designing clinical research: An epidemiologic approach (2nd ed.). Philadelphia: Lippincott Williams \& Wilkins.

Isles, R. C., Choy, N. L., Steer, M., \& Nitz, J. C. (2004). Normal values of balance tests in women aged 20-80. J Am Geriatr Soc, 52(8), 1367-1372.

Jackson, D. M., Reilly, J. J., Kelly, L. A., Montgomery, C., Grant, S., \& Paton, J. Y. (2003). Objectively measured physical activity in a representative sample of 3- to 4-year-old children. Obes Res, 11(3), 420-425.

Jacob, R. G., Woody, S. R., Clark, D. B., \& Lilienfeld, S. O. (1993). Discomfort with space and motion. A possible marker of vestibular dysfunction assessed by the situational characteristic questionnaire. Journal of Psychopathology \& Behavioral Assessment, 15, 299-324.

Jeka, J., Kiemel, T., Creath, R., Horak, F., \& Peterka, R. (2004). Controlling human upright posture: velocity information is more accurate than position or acceleration. $J$ Neurophysiol, 92(4), 2368-2379.

Kennedy, R. S., Lane, N. E., Berbaum, K. S., \& Lilienthal, M. L. (1993). Simulator sickness questionnaire: An enhanced method for quantifying simulator sickness. International Journal of Aviation Psychology, 3, 203-220.

Kennedy, R. S., Stanney, K. M., \& Dunlap, W. P. (2000). Duration and exposure to virtual environments: simulator sickness curves during and across sessions. Presence: Teleoperators and virtual environments, 9(5), 463-472.

Kim, K. J., \& Ashton-Miller, J. A. (2003). Biomechanics of fall arrest using the upper extremity: age differences. Clin Biomech (Bristol, Avon), 18(4), 311-318.

Kim, K.-J., \& Ashton-Miller, J. A. (2009). Segmental dynamics of forward fall arrests: A system identification approach. Clinical Biomechanics, 24(4), 348-354.

Kionix Inc. (2004). Serial Development Board. User's Manual. Ithaca, NY: Kionix Inc.

Kristensen, M. T., Foss, N. B., \& Kehlet, H. (2007). Timed "up \& go" test as a predictor of falls within 6 months after hip fracture surgery. Phys Ther, 87(1), 24-30.

Kristensen, M. T., Foss, N. B., \& Kehlet, H. (2009). Factors with independent influence on the 'timed up and go' test in patients with hip fracture. Physiother Res Int, 14(1), 30-41.

Lindemann, U., Lundin-Olsson, L., Hauer, K., Wengert, M., Becker, C., \& Pfeiffer, K. (2008). Maximum step length as a potential screening tool for falls in non-disabled older adults living in the community. Aging Clin Exp Res, 20(5), 394-399. 
Lindemann, U., Rupp, K., Muche, R., Nikolaus, T., \& Becker, C. (2004). Improving balance by improving motor skills. Z Gerontol Geriatr, 37(1), 20-26.

Lord, S. R., Sambrook, P. N., Gilbert, C., Kelly, P. J., Nguyen, T., Webster, I. W., et al. (1994). Postural stability, falls and fractures in the elderly: results from the Dubbo Osteoporosis Epidemiology Study. Med J Aust, 160(11), 684-685, 688-691.

Mak, M. K., \& Pang, M. Y. (2009). Balance confidence and functional mobility are independently associated with falls in people with Parkinson's disease. J Neurol.

Maki, B. E., Cheng, K. C., Mansfield, A., Scovil, C. Y., Perry, S. D., Peters, A. L., et al. (2007). Preventing falls in older adults: New interventions to promote more effective change-insupport balance reactions. J Electromyogr Kinesiol.

Maki, B. E., Holliday, P. J., \& Topper, A. K. (1994). A prospective study of postural balance and risk of falling in an ambulatory and independent elderly population. $J$ Gerontol, 49(2), M72-84.

Maki, B. E., \& Mcllroy, W. E. (1997). The role of limb movements in maintaining upright stance: the "change-in-support" strategy. Phys Ther, 77(5), 488-507.

Maki, B. E., \& Mcllroy, W. E. (2006). Control of rapid limb movements for balance recovery: age-related changes and implications for fall prevention. Age Ageing, 35 Suppl 2, ii12ii18.

Maki, B. E., Mcllroy, W. E., \& Fernie, G. R. (2003). Change-in-support reactions for balance recovery. IEEE Eng Med Biol Mag, 22(2), 20-26.

Mansfield, A., Peters, A. L., Liu, B. A., \& Maki, B. E. (2007). A perturbation-based balance training program for older adults: study protocol for a randomised controlled trial. $B M C$ Geriatr, 7, 12.

Masani, K., Vette, A. H., \& Popovic, M. R. (2006). Controlling balance during quiet standing: proportional and derivative controller generates preceding motor command to body sway position observed in experiments. Gait Posture, 23(2), 164-172.

McConville, K. M. V., \& Virk, S. (2007). Motor Learning in a Virtual Environment for Vestibular Rehabilitation. 3rd International IEEE/EMBS Conference on Neural Engineering(2-5), 600-603.

McConville, K. M. V., Virk, S., \& Milosevic, M. (2007). Head Movement Effects in a CostEffective Virtual Reality Training Environment for Balance Rehabilitation. Proceedings of International Workshop on Virtual Rehabilitation 2007, 27-29 Sept. 2007 Page 87.

Mechling, R. W. (1986). Objective assessment of postural balance through use of the variable resistance balance board. Physical Therapy, 66(5), 685-688. 
Medell, J. L., \& Alexander, N. B. (2000). A clinical measure of maximal and rapid stepping in older women. J Gerontol A Biol Sci Med Sci, 55(8), M429-433.

Mille, M. L., Johnson, M. E., Martinez, K. M., \& Rogers, M. W. (2005). Age-dependent differences in lateral balance recovery through protective stepping. Clin Biomech (Bristol, Avon), 20(6), 607-616.

Milosevic, M., \& McConville, K. M. V. (2007). Falls Prevention for the Elderly Through Monitoring of Hand Movements and Quantitative Balance Assessment. Paper Presented at ICTA - 2nd International Conference on Technology and Aging, 18 June, 2007, Toronto. Avialble on-line: http://stargate.uwaterloo.ca/ jzelek/teaching/syde361/ficcdat2007/Full\%20Papers/ICTA/ T0243.pdf.

Milosevic, M., \& McConville, K. M. V. (2007b). Arm Movements in Balance Maintenance and Recovery Based on Quantitative Balance Assessment. Motor Control, 11, S167-S168.

Morris, R. (2007). Predicting falls in older women. Menopause Int, 13(4), 170-177.

Morris, R., Harwood, R. H., Baker, R., Sahota, O., Armstrong, S., \& Masud, T. (2007). A comparison of different balance tests in the prediction of falls in older women with vertebral fractures: a cohort study. Age Ageing, 36(1), 78-83.

Morris, S., Morris, M. E., \& Iansek, R. (2001). Reliability of measurements obtained with the Timed "Up \& Go" test in people with Parkinson disease. Phys Ther, 81(2), 810-818.

Nadeau, S. E. (2002). A paradigm shift in neurorehabilitation. Lancet Neurol, 1(2), 126-130.

Nnodim, J. O., Strasburg, D., Nabozny, M., Nyquist, L., Galecki, A., Chen, S., et al. (2006). Dynamic balance and stepping versus tai chi training to improve balance and stepping in at-risk older adults. $J$ Am Geriatr Soc, 54(12), 1825-1831.

Nnodim, J. O., Strasburg, D., Nabozny, M., Nyquist, L., Galecki, A., Chen, S., et al. (2006). Dynamic balance and stepping versus tai chi training to improve balance and stepping in at-risk older adults. $J$ Am Geriatr Soc, 54(12), 1825-1831.

Nordt, W. E., 3rd, Sachatello, S. A., Plotkin, E. S., \& Dintino, K. (1999). The effects of singleaxis balance board intervention on balance parameters in the elderly. The American journal of orthopedics, $28(8), 447-450$.

Norusis, M. J. (2008). SPSS 16.0 advanced statistical procedures companion. Upper Saddle River, NJ: Prentice Hall.

O'Sullivan, M., Blake, C., Cunningham, C., Boyle, G., \& Finucane, C. (2009). Correlation of accelerometry with clinical balance tests in older fallers and non-fallers. Age Ageing.

Pan, J., \& Tompkins, W. J. (1985), A real-time QRS detection algorithm. IEEE Trans Biomed Eng, 32(3), 230-236. 
Peterka, R. J., \& Loughlin, P. J. (2004). Dynamic regulation of sensorimotor integration in human postural control. J Neurophysiol, 91(1), 410-423.

Peters, R. (2006). Ageing and the brain. Postgraduate Medical Journal, 82, 84-88.

Popovic, M., Pappas, I. P., Nakazawa, K., Keller, T., Morari, M., \& Dietz, V. (2000). Stability criterion for controlling standing in able-bodied subjects. J Biomech, 33(11), 1359-1368.

Proudlock, F. A., Shekhar, H., \& Gottlob, I. (2004). Age-related changes in head and eye coordination. Neurobiol Aging, 25(10), 1377-1385.

Rangayyan, R. M. (2002). Biomedical signal analysis: A case-study approach. New York, NY: IEEE PressB / Wiley。

Rietdyk, S., Patla, A. E., Winter, D. A., Ishac, M. G., \& Little, C. E. (1999). Balance recovery from medio-lateral perturbations of the upper body during standing. $J$ Biomech, 32(11), $1149-1158$.

Rogers, M. W., \& Mille, M. L. (2003). Lateral stability and falls in older people. Exerc Sport Sci Rev, 31(4), 182-187.

Rubenstein, L. Z. (2006). Falls in older people: Epidemiology, risk factors and strategies for prevention. Age Ageing, 35, ii37-ii41.

Rubenstein, L. Z., \& Josephson, K. R. (2006). Falls and their prevention in elderly people: what does the evidence show? Med Clin North Am, 90(5), 807-824.

Sainburg, R. L. (2002). Evidence for a dynamic-dominance hypothesis of handedness. Exp Brain Res, 142(2), 241-258.

Sainburg, R. L. (2007). Hemispheric specialization for control of movement trajectory and steady state position. Paper presented at the Presentation on the Santos Brazil, August, 10, 2007.

Sainburg, R. L., \& Schaefer, S. Y. (2004). Interlimb differences in control of movement extent. $J$ Neurophysiol, 92, 1374-1383.

Salbach, N. M., Mayo, N. E., Higgins, J., Ahmed, S., Finch, L. E., \& Richards, C. L. (2001). Responsiveness and predictability of gait speed and other disability measures in acute stroke. Arch Phys Med Rehabil, 82(9), 1204-1212.

Schaefer, S. Y, Haaland, K. Y., \& Sainburg, R. L. (2007). Ipsilesional motor deficits following stroke reflect hemispheric specializations for movement control. Brain, 130(Pt 8), 21462158.

Schultheis, M. T., \& Rizzo, A. A. (2001). The application of virtual reality technology in balance rehabilitation. Rehabilitation Psychology, 46, 296-311. 
Schulz, B. W., Ashton-Miller, J. A., \& Alexander, N. B. (2007). Maximum step length: relationships to age and knee and hip extensor capacities. Clin Biomech (Bristol, Avon), $22(6), 689-696$.

Shiratori, T., \& Aruin, A. S. (2004). Anticipatory postural adjustments associated with rotational perturbations while standing on fixed and free-rotating supports. Clin Neurophysiol, $115(4), 797-806$.

Snijders, A. H., van de Warrenburg, B. P., Giladi, N., \& Bloem, B. R. (2007). Neurological gait disorders in elderly people: clinical approach and classification. Lancet Neurol, 6(1), 6374.

Sparto, P. J., Whitney, S. L., Hodges, L. F., Furman, J. M., \& Redfern, M. S. (2004). Simulator sickness when performing gaze shifts within a wide field of view optic flow environment: preliminary evidence for using virtual reality in vestibular rehabilitation. $J$ Neuroeng Rehabil, 1(1), 14.

Stalenhoef, P. A., Diederiks, J. P., de Witte, L. P., Schiricke, K. H., \& Crebolder, H. F. (1999). Impact of gait problems and falls on functioning in independent living persons of 55 years and over: a community survey. Patient Educ Couns, 36(1), 23-31.

Steele, B. G., Holt, L., Belza, B., Ferris, S., Lakshminaryan, S., \& Buchner, D. M. (2000). Quantitating physical activity in COPD using a triaxial accelerometer. Chest, 117(5), 1359-1367.

Stevens, J. A., \& Olson, S. (2000). Reducing falls and resulting hip fractures among older women. In: CDC Recommendations Regarding Selected Conditions Affecting Women's Health. MMWR Morbidity and Mortality Weekly Report, 49(RR-2), 3-12.

Stolze, H., Klebe, S., Zechlin, C., Baecker, C., Friege, L., \& Deuschl, G. (2004). Falls in frequent neurological diseases--prevalence, risk factors and aetiology. $J$ Neurol, $251(1), 79-84$.

Suzuki, K., Imada, G., Iwaya, T., Handa, T., \& Kurogo, H. (1999). Determinants and predictors of the maximum walking speed during computer-assisted gait training in hemiparetic stroke patients. Arch Phys Med Rehabil, 80(2), 179-182.

Talbot, L. A., Musiol, R. J., Witham, E. K., \& Metter, E. J. (2005). Falls in young, middle-aged and older community dwelling adults: perceived cause, environmental factors and injury. BMC Public Health, 5, 86.

Tang, P. F., \& Woollacott, M. H. (1998). Inefficient postural responses to unexpected slips during walking in older adults. J Gerontol A Biol Sci Med Sci, 53(6), M471-480.

Tinetti, M. E., \& Williams, C. S. (1997). Falls, injuries due to falls, and the risk of admission to a nursing home. $N$ Engl $J$ Med, 337(18), 1279-1284.

Tompkins, W. J. (1995). Biomedical Digital Signal Processing. Upper Saddle River, NJ: Prentice-Hall. 
Toronto Rehabilitation Institute. (1998). The Community Balance and Mobility Scale (2002 ed.). Toronto: Toronto Rehabilitation Institute.

Virk, S., Kant, C.-C. L., Milosevic, M., Mravyan, D. M., Grabovac, B., Khodaei, M., et al. (2007, June 16-19). Improvement in balance with a cost-effective virtual reality environment. Paper presented at the the 2007 FICCDAT - Festival of International Conferences on Caregiving, Disability, Aging and Technology, Toronto.

Virk, S., \& McConville, K. M. (2006). Virtual reality applications in improving postural control and minimizing falls. Conf Proc 28th Annual IEEE/EMBS Eng Med Biol Soc, 1, 26942697.

Voermans, N. C., Snijders, A. H., Schoon, Y., \& Bloem, B. R. (2007). Why old people fall (and how to stop them). Pract Neurol, 7(3), 158-171.

Wade, D. T., Wood, V. A., Heller, A., Maggs, J., \& Langton Hewer, R. (1987). Walking after stroke. Measurement and recovery over the first 3 months. Scand J Rehabil Med, 19(1), 25-30.

Wang, J., \& Sainburg, R. L. (2007). The dominant and nondominant arms are specialized for stabilizing different features of task performance. Exp Brain Res, 178(4), 565-570.

Wang, J., \& Stelmach, G. E. (1998). Coordination among the body segments during reach-tograsp action involving the trunk. Exp Brain Res, 123(3), 346-350.

Weiss, P., Rand, D., Katz, N., \& Kizony, R. (2004). Video Capture Virtual reality as a flexible and effective rehabilitation tool. Journal of NeuroEngineering and Rehabilitation, 1, 12.

Woollacott, M., Inglin, B., \& Manchester, D. (1988). Response preparation and posture control. Neuromuscular changes in the older adult. Ann N Y Acad Sci, 515, $42-53$.

Yamazaki, Y., Suzuki, M., Ohkuwa, T., \& Itoh, H. (2005). Maintenance of upright standing posture during trunk rotation elicited by rapid and asymmetrical movements of the arms. Brain Res Bull, 67(1-2), 30-39.

Zhang, W., Sainburg, R. L., Zatsiorsky, V. M., \& Latash, M. L. (2006). Hand dominance and multi-finger synergies. Neurosci Lett, 409(3), 200-204. 


\section{Appendix A:}

Canadian Community Health Survey; Incidences and Causes of Falls

Note: The results are based on the analysis form the Canadian Community Health Survey (CCHS) $2005(n=132,221)$.

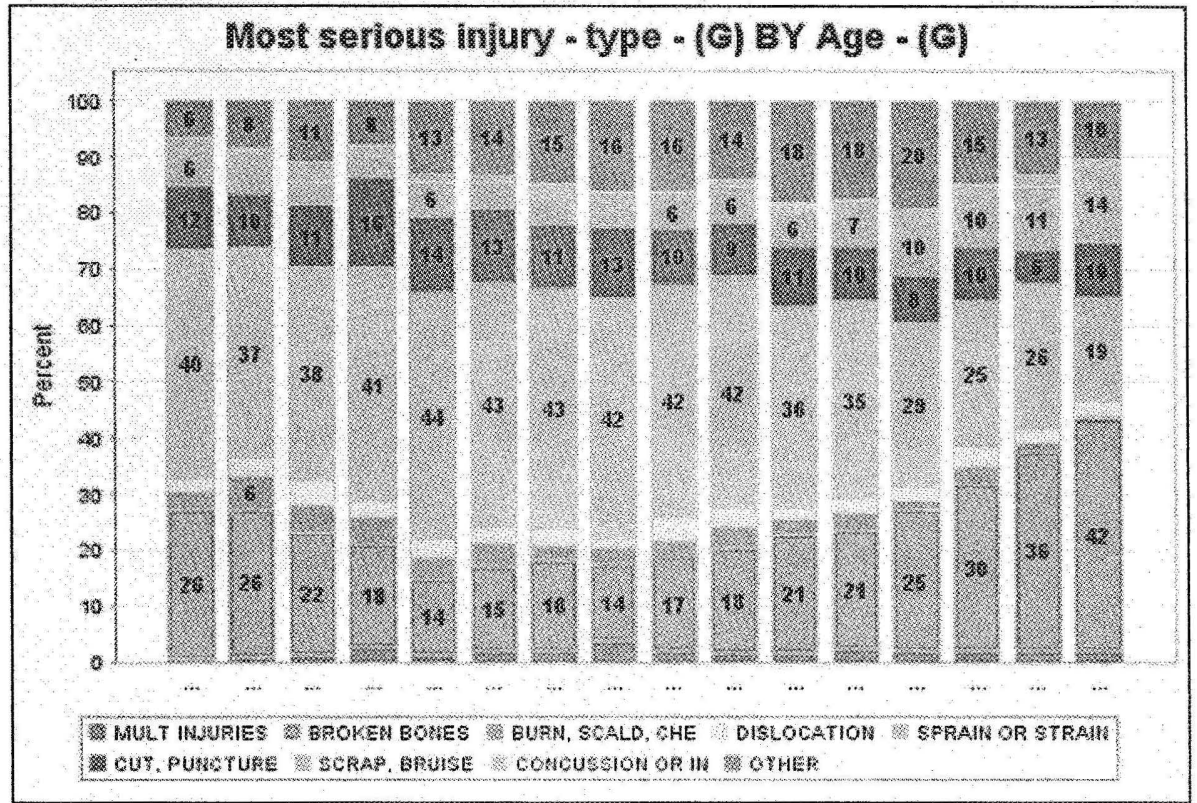

Figure 1: Most Serious Injury by Age (Source: Canadian Community Health Survey 2005. Custom Tabulation)

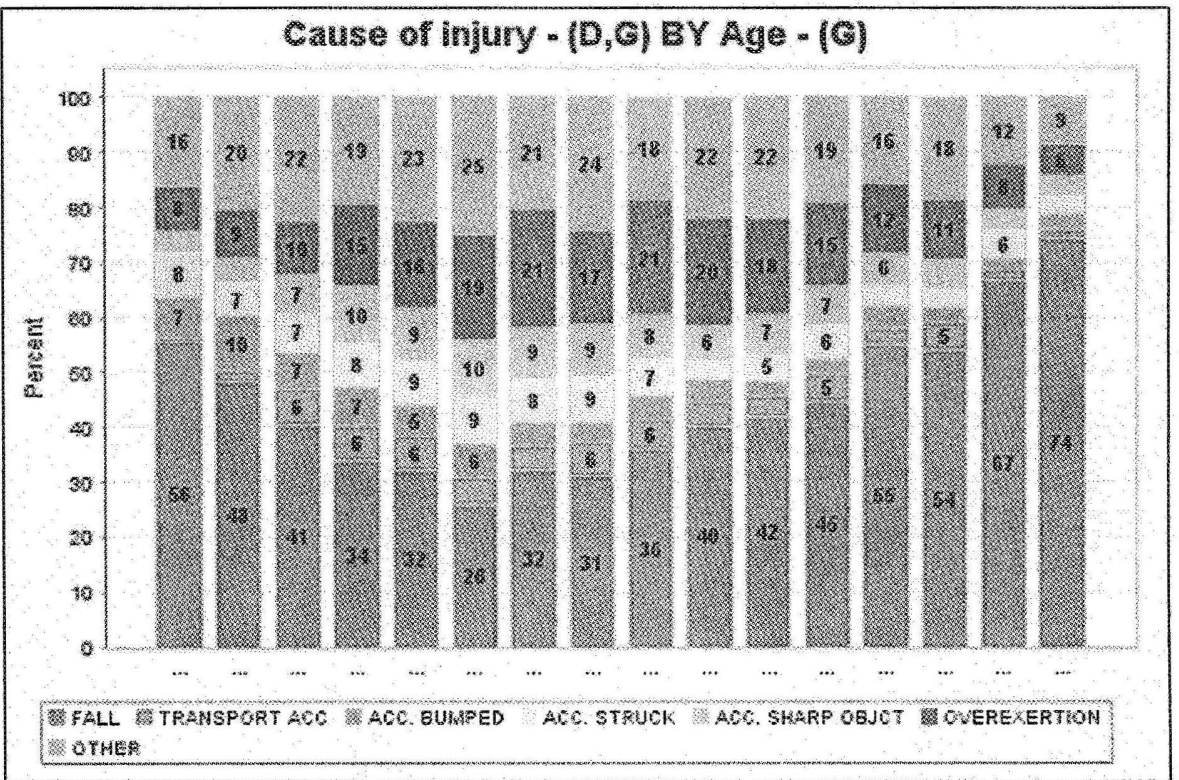

Figure 2: Cause of Injury by Age (Source: Canadian Community Health Survey 2005. Custom Tabulation) 


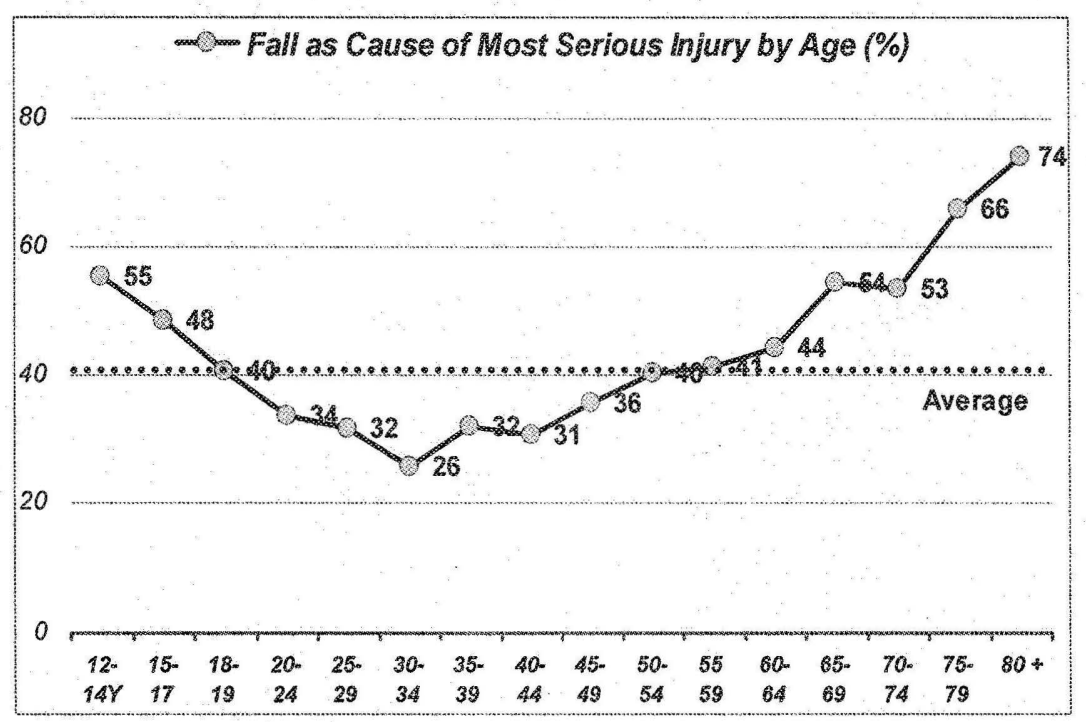

Figure 3: Falls as a Cause of Most Serious Injury by Age

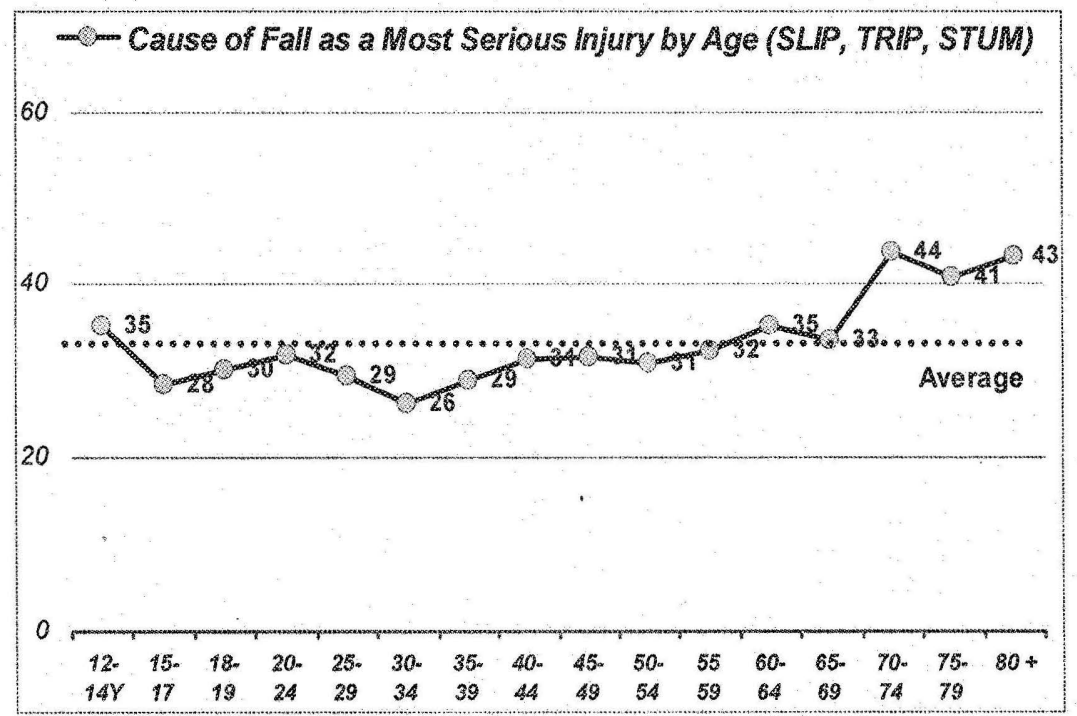

Figure 4: Falls as a Cause of Most Serious Injury from Slip, Trip and Stumble by Age 


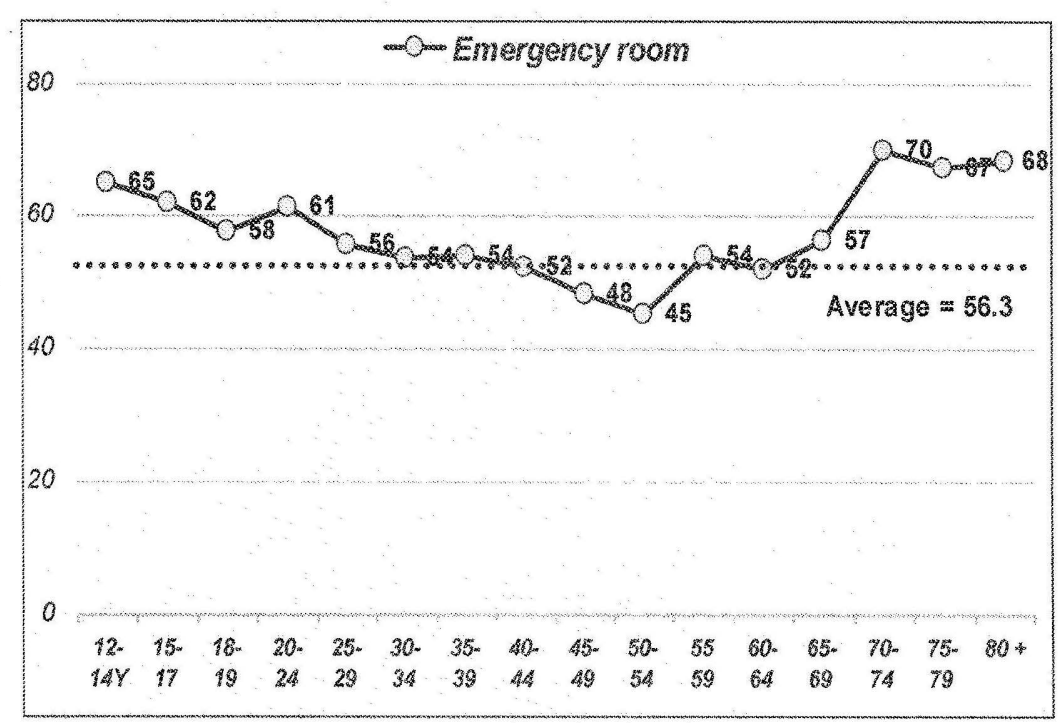

Figure 5: Emergency room Visits by Age

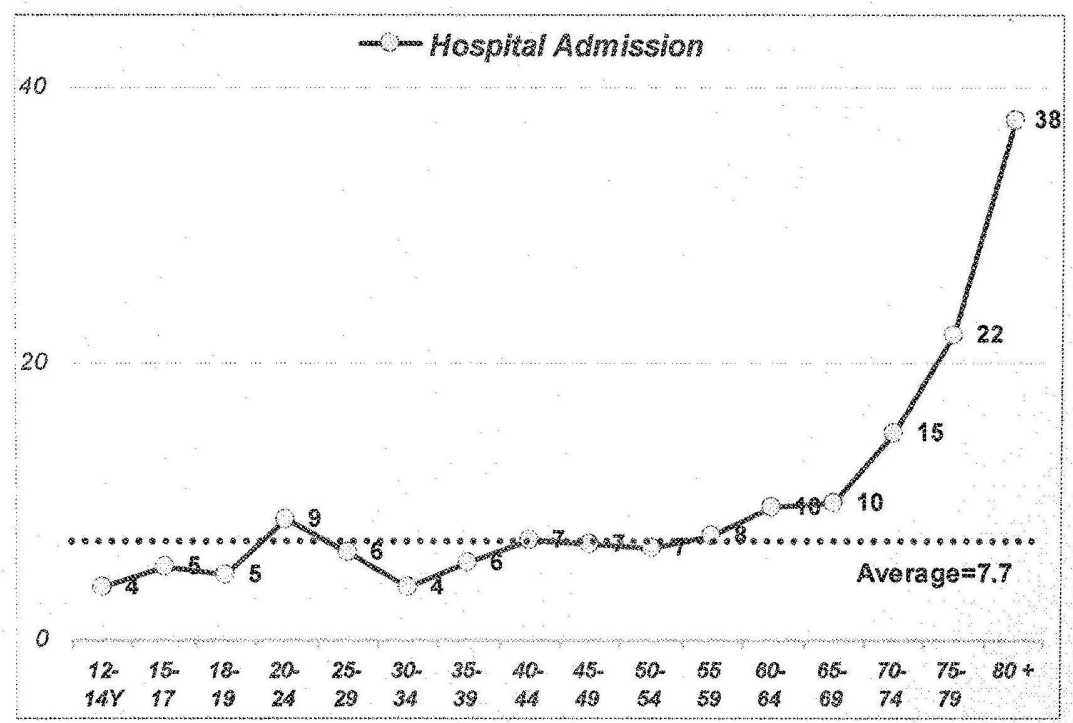

Figure 6: Hospital admissions by Age 